\title{
ELECTROMagNetic NOISE IN ITMANN MINE
}

W. D. Bensema

M. Kanda

J. W. Adams

Electromagnetics Division

Institute for Basic Standards

National Bureau of Standards

Boulder, Colorado 80302

June 1974

Prepared for

U. S. Bureau of Mines

United States Department of the Interior

Pittsburgh, Pennsylvania 15222

Working Fund Agreement HO 133005 


\section{NBSIR $74-390$}

\section{ELECTROMAGNETIC NOISE IN ITMANN MINE}

W. D. Bensema

M. Kanda

J. W. Adams

Electromagnetics Division

Institute for Basic Standards

National Bureau of Standards

Boulder, Colorado 80302

The views and conclusions contained in this document should not be interpreted as necessarily representing the official policies or recommendations of the Interior Department's Bureau of Mines of the U.S. Government

June 1974

Prepared for

U. S. Bureau of Mines

United States Department of the Interior

Pittsburgh, Pennsylvania 15222

Working Fund Agreement HO 133005

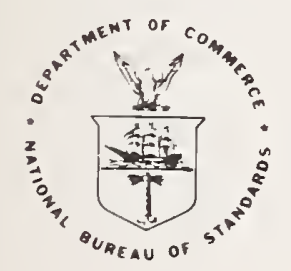

U.S. DEPARTMENT OF COMMERCE. Frederick B. Dent. Secretary 
This report was prepared by the National Bureau of Standards, Boulder, Colorado, under USBM Contract No. HO 133005. The contract was initiated under the Coal Mine Health and Safety Research Program. It was administered under the technical direction of the Pittsburgh Mining and Safety Research Center with Mr. Howard Parkinson and Mr. Harry Dobroski acting as the technical project officers.

This report is a summary of the work completed as part of this contract during the period January 1973 to June 1974. This report was submitted by the authors in October 1974 . 


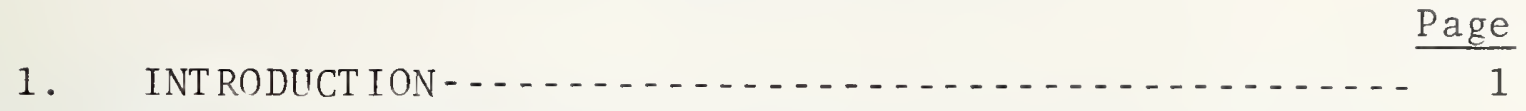

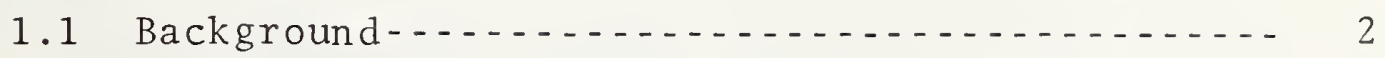

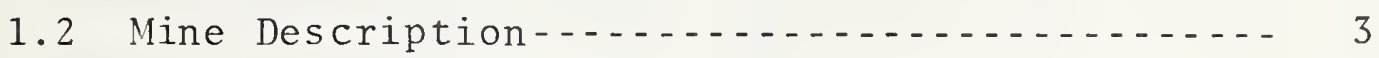

2. MEASUREMENT INISTRUMENTATION - ............... 5

3. SPECTRUM MEASUREMENT RESULTS ................... 10

3.1 Introduction and Uncertainties........... 10

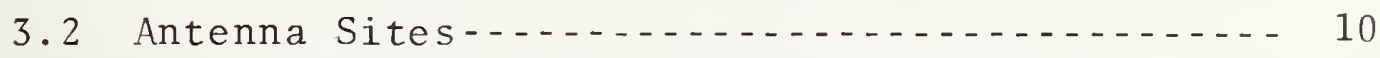

3.3 Electromagnetic (EM) Noise Spectrum Results-.. 11

3.3.1 Interpretation -................... 11

3.3.2 Cabin Creek Pane1.................... 11

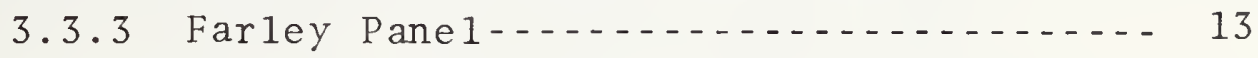

3.4 Miscellaneous Measurements -............ 14

3.4.1 Electric Field_................. 14

3.4.2 Measurements of Voltage Between Roof:

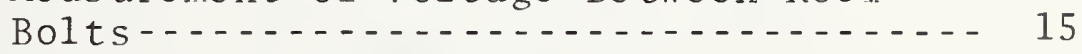

3.5 Intercomparison of Different Mines-........ 16

3.5.1 Roof Bolt Voltage Intercomparison-...- 16

3.5.2 Summary of $1 \mathrm{kHz}$ to $3 \mathrm{kHz}$ Data...... 17

3.5.3 Intercomparison of $3 \mathrm{kHz}$ to $200 \mathrm{kHz}$ Data $\ldots \ldots \ldots$

4. AMPLITUdE PROBABILITY DISTRIBUTION MEASUREMENTS- - - 47

4.1 Introduction and Uncertainties........... 47

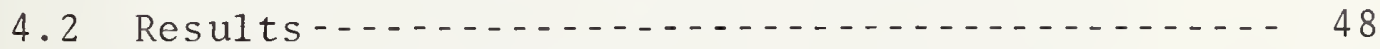

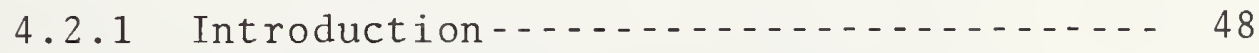

4.2.2 Measurement Results_............. 49

4.2.3 RMS and Average Values............ 51

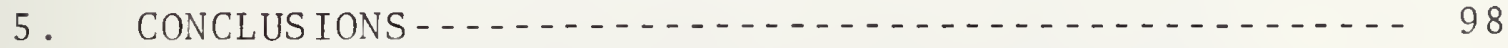

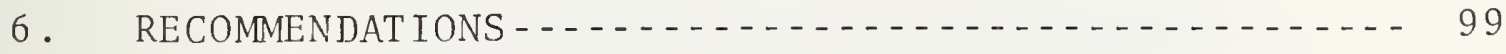

7. ACKNOWLEDGMENTS - _... $\ldots \ldots 100$

8. REFERENCES - $\ldots \ldots-\ldots 101$

9. APPENDIX $\ldots \ldots \ldots 2$ 
Figure 2-1.

Figure 2-2.

Figure 2-3.

Figure 3-1.

Figure 3-2.

Figure 3-3.

Figure 3-4.

Figure 3-5.

Figure 3-6.

Figure 3-7.

Figure 3-8.
Block diagram of portable instrumentation-

7

System for field recording data to obtain amplitude probability distributions.......

Block diagram of laboratory recording system modified for field use-.........

Map of Itmann Mine where measurements wére made, Cabin Creek pane1..............

Spectrum with mine in operation, measurements made 10 meters from end of longwall face, Cabin Creek panel. Spectral resolution of $78.1 \mathrm{~Hz} \ldots \ldots \ldots$

Spectrum with mine in operation, measurements made 10 meters from end of longwall face, Cabin Creek panel. Spectral resolution of $3.91 \mathrm{~Hz} \ldots \ldots$

Spectrum with mine in operation, measurements made 5 meters from end of longwall face, Cabin Creek panel. Spectral resolution of $78.1 \mathrm{~Hz} \ldots \ldots$

Spectrum with mine in operation, measurements made 5 meters from end of longwall face, Cabin Creek pane1. Spectral resolution of $3.91 \mathrm{~Hz} \ldots \ldots$

Spectrum with second shift in full operation, measurements made 5 meters from end of longwal1 face, Cabin Creek panel.

Spectral resolution of $3.91 \mathrm{~Hz}-\ldots-\ldots$

Spectrum of quiet time between shifts, measurements made 5 meters from end of longwall face, Cabin Creek panel.

Spectral resolution of $78.1 \mathrm{~Hz} \ldots \ldots$

Spectrum of quiet time between shifts, measurements made 5 meters from end of longwall face, Cabin Creek panel.

Spectral resolution of $3.91 \mathrm{~Hz} \ldots \ldots . . .$. 
Figure 3-9.

Spectrum with mine in operation, measurements made 10 meters from end of 1ongwa11 face, Farley panel. Spectral resolution of $78.1 \mathrm{~Hz} \ldots \ldots \ldots \ldots$

Figure 3-10. Spectrum with mine in operation, measurements made 10 meters from end of longwall face, Farley panel. Spectral resolution of $3.91 \mathrm{~Hz} \ldots \ldots \ldots$

Figure 3-11. Spectrum with hydraulic pump operating, measurements made 10 meters from end of longwall face, Farley panel. Spectral resolution of $78.1 \mathrm{~Hz} \ldots \ldots$

Figure 3-12. Spectrum with hydraulic pump operating, measurements made 10 meters from end of longwall face, Farley panel. Spectral resolution of $3.91 \mathrm{~Hz} \ldots \ldots$

Figure 3-13. Spectrum with conveyor belt starting up, measurements made 10 meters from end of longwall face, Farley panel. Spectral resolution of $78.1 \mathrm{~Hz} \ldots \ldots$

Figure 3-14. Spectrum with conveyor belt starting up, measurements made 10 meters from end of longwall face, Farley pane1. Spectral resolution of $3.91 \mathrm{~Hz} \ldots \ldots$

Figure 3-15. Vertical component of magnetic field spectrum about 3 meters from longwall machine - . . . . . . . . . . . . . . . . . .

Figure 3-16. Vertical component of magnetic field spectrum at end of haulageway in Farley pane1..........................

Figure 3-17. Vertical component of magnetic field spectrum at end of haulageway in Farley

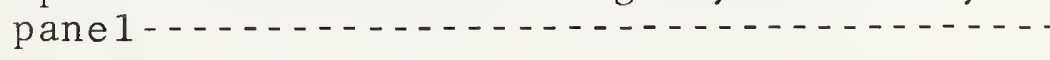

Figure 3-18. Horizontal component of magnetic field spectrum at end of haulageway in Farley pane 1-.......................... 
Figure 3-19. Vertical component of magnetic field spectrum at end of haulageway in Farley panel..........................

Figure 3-20. Vertical component of magnetic field spectrum at end of haulageway in Farley panel $1 .-2$,

Figure 3-21. Horizontal component of magnetic field spectrum at end of haulageway in Farley pane 1

Figure 3-22. Spectrum obtained with an active dipole, 0.75 meters from phone line. Spectral resolution of $78.1 \mathrm{~Hz} \ldots \ldots . \ldots 40$

Figure 3-23. Voltage spectrum obtained between roof bolts located 15.2 meters apart, Farley pane1. Spectral resolution of $78.1 \mathrm{~Hz}$

Figure 3-24. Voltage spectrum obtained between roof bolts located 15.2 meters apart, Farley pane1. Spectral resolution of $3.91 \mathrm{~Hz}-\cdots$

Figure 3-25. Summary of rms noise voltage measured underground between roof-support-bolts

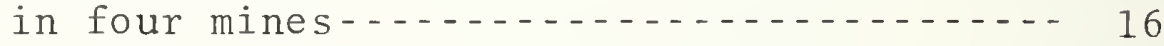

Figure 3-26. Comparison of logarithmic average of magnetic field strengths of three mines

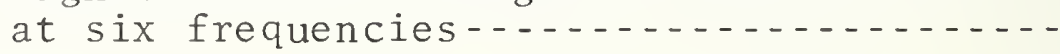

Figure 3-27. Logarithmic average magnetic field strength summary-........................

Figure 3-28. Comparison of EM noise levels near operating machinery from four mines-........-

Figure 3-29. Comparison of EM noise levels along haulageways in four mines............

Figure 4-1. APD, $10 \mathrm{kHz}$, vertical component, Cabin Creek-.............................

Figure 4-2. APD, $30 \mathrm{kHz}$, vertical component, Cabin

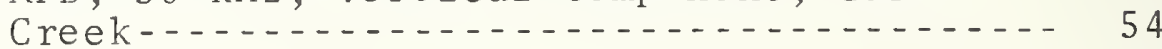


Figure 4-3. APD, $70 \mathrm{kHz}$, vertical component, Cabin $\underline{\text { Page }}$ 55

Figure 4-4.

APD, $130 \mathrm{kHz}$, vertical component, Cabin Creek-.......................... 56

Figure 4-5.

$\mathrm{APD}, 160 \mathrm{kHz}$, vertical component, Cabin Creek-

Figure 4-6.

APD, $250 \mathrm{kHz}$, vertical component, Cabin

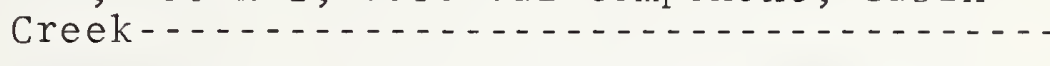

Figure 4-7. APD, $500 \mathrm{kHz}$, vertical component, Cabin Creek--

Figure 4-8. $\mathrm{APD}, 1 \mathrm{MHz}$, vertical component, Cabin Creek 60 Figure 4-9. APD, $2 \mathrm{MHz}$, vertical component, Cabin Creek 61 Figure 4-10. APD, $6 \mathrm{MHz}$, vertical component, Cabin Creek 62 Figure 4-11. APD, $14 \mathrm{MHz}$, vertical component, Cabin

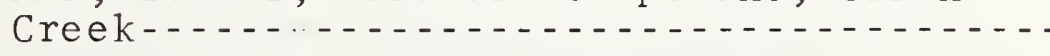

Figure 4-12. APD, $32 \mathrm{MHz}$, vertical component, Cabin

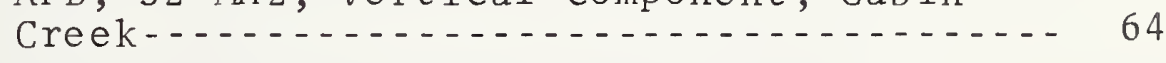

Figure 4-13. APD, $10 \mathrm{kHz}$, vertical component, quiet

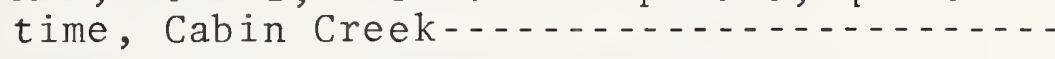

Figure 4-14. APD, $30 \mathrm{kHz}$, vertical component, quiet

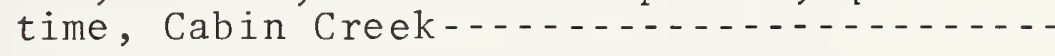
66

Figure 4-15. APD, $130 \mathrm{kHz}$, vertical component, quiet time, Cabin Creek-................

Figure 4-16. APD, $500 \mathrm{kHz}$, vertical component, quiet

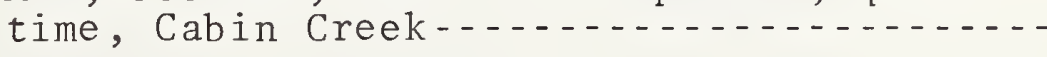
68

Figure 4-17. APD, $1 \mathrm{MHz}$, vertical component, quiet time, Cabin Creek
time, $2 \mathrm{MHz}$, vertical component, quiet

Figure 4-18.

Figure 4-19. APD, $6 \mathrm{MHz}$, vertical component, quiet time, Cabin Creek- 
Figure 4-20. APD, $10 \mathrm{kHz}$, roof bolts..........................

Figure 4-21. APD, $10 \mathrm{kHz}$, vertical component, Farley

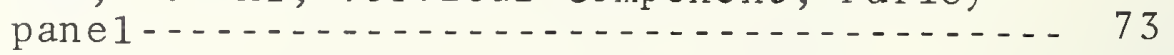

Figure 4-22. APD, $30 \mathrm{kHz}$, vertical component, Farley

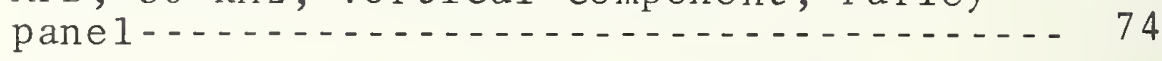

Figure 4-23. APD, $70 \mathrm{kHz}$, vertical component, Farley pane1_.............................. 75

Figure 4-24. APD, $130 \mathrm{kHz}$, vertical component, Farley

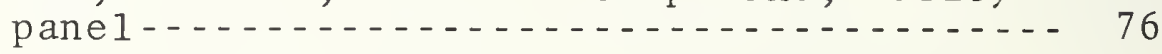

Figure 4-25. APD, $250 \mathrm{kHz}$, vertical component, Farley pane1_............................. 77

Figure 4-26. APD, $500 \mathrm{kHz}$, vertical component, Farley

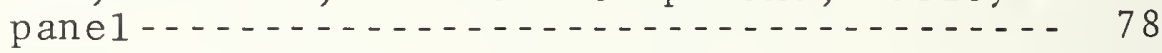

Figure 4-27. APD, 1 MHz, vertical component, Farley pane1 -...........................

Figure 4-28. APD, $2 \mathrm{MHz}$, vertical component, Farley

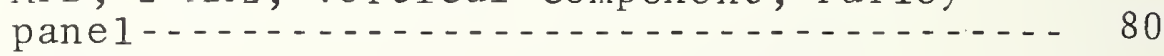

Figure 4-29. APD, $10 \mathrm{kHz}$, vertical component, Farley headpiece at the end of main belt haulage- 81

Figure 4-30. APD, $30 \mathrm{kHz}$, vertical component, Farley headpiece ........................... 82

Figure 4-31. APD, $70 \mathrm{kHz}$, vertical component, Farley

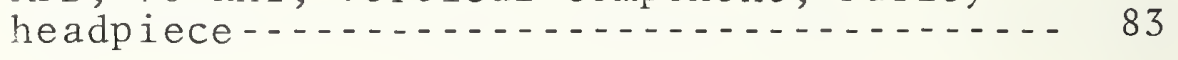

Figure 4-32. APD, $130 \mathrm{kHz}$, vertical component, Farley headpiece ........................ 84

Figure 4-33. APD, $160 \mathrm{kHz}$, vertical component, Farley headpiece .......................... 85

Figure 4-34. APD, $250 \mathrm{kHz}$, vertical component, Farley headpiece-......................... 86

Figure 4-35. APD, $500 \mathrm{kHz}$, vertical component, Farley

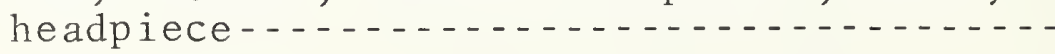


Figure 4-36. APD, $1 \mathrm{MHz}$, vertical component, Farley headpiece ............................ 88

Figure 4-37. APD, $2 \mathrm{MHz}$, vertical component, Farley

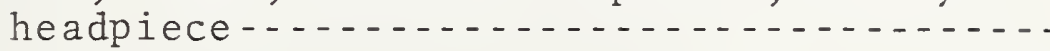

Figure 4-38. APD, $6 \mathrm{MHz}$, vertical component, Farley

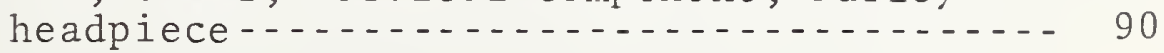

Figure 4-39. APD, $14 \mathrm{MHz}$, vertical component, Farley

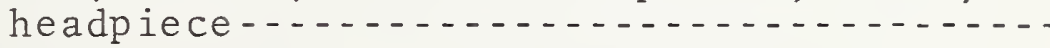

Figure 4-40. APD, $32 \mathrm{MHz}$, vertical component, Farley he adpiece .......................... 92

Figure 4-41. APD, $10 \mathrm{kHz}$, roof bolts -

Figure 4-42. Field strength excursions between $0.001 \%$ and $99 \%$ of the time as a function of frequency, vertical component, Cabin Creek 94

Figure 4-43. Field strength excursions between $0.001 \%$ and $99 \%$ of the time as a function of frequency, vertical component, quiet time,

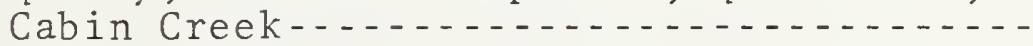

Figure 4-44. Field strength excursions between $0.001 \%$ and $99 \%$ of the time as a function of frequency, vertical component, Farley panel,

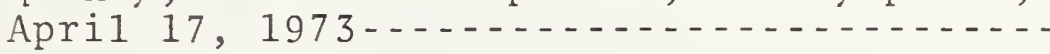

Figure 4-45. Field strength excursions between $0.001 \%$ and $99 \%$ of the time as a function of frequency, vertical component, Farley headpiece, April 19, 1973-............ 

Two different techniques were used to make measurements of the absolute value of electromagnetic noise in an operating coal mine, Itmann No. 3 Mine, located near Mullens, West Virginia. The electromagnetic environment created by 250-volt-dc and 550- and 950-volt-ac machinery in two longwall panels was measured and is reported. One technique measures noise over the entire electromagnetic spectrum of interest for brief time periods. It is recorded using broadband analog magnetic tape, and the noise data is later transformed to give spectral plots. The other technique records noise amplitudes at several discrete frequencies for a sufficient amount of time to provide amplitude probability distributions .

The specific, measured results are given in a number of spectral plots and amplitude probability distribution plots.

Key words: Amplitude probability distribution; coal mine noise; digital data; electromagnetic communications; electromagnetic interference; electromagnetic noise; Fast Fourier Transform; Gaussian distribution; impulsive noise; magnetic field strength; measurement instrumentation; spectral density; time-dependent spectral density.

\section{INTRODUCTION}

This report gives data concerning electromagnetic noise in a coal mine that uses dc rail haulage power and ac-powered conveyor belt and longwall equipment. In this section, background information and a brief mine description are covered. In Section 2, measurement instrumentation is discussed. In Section 3, spectral plots of data are presented. In Section 4 , amplitude probability distributions (APD) of magnetic-field noise are given. 
Only representative samples of the total data measured are given in this report. Only a limited set of datapresentation formats have been used. If additional data, or data presentation in other formats, are required, please contact any of the authors. With specific permission of the Bureau of Mines, we will supply the additional data. A more complete description of the measurement systems used is given in the Robena Mine report [1] and the Grace Mine report [2].

\subsection{Background}

The need for reliable communication systems in mines is a long-standing problem. For emergency use, when all power in a mine is off, the residual electromagnetic noise is no problem. However, if a communication system were designed only for emergency use, it would have two serious drawbacks. First, it would not be ready for immediate use in an emergency; second, it would not be of any value during normal operations. Therefore, the Bureau of Mines decided to design a communication system that could be used for both emergency and normal operating conditions.

During operation, the machinery used in mines creates a wide range of many types of intense electromagnetic interference (EMI). This EMI is a major limiting factor in the design of a communication system. The work reported here gives the results of comprehensive measurements of this EMI in critical communication locations where miners extract coal as well as along haulageways.

There are several EMI parameters that can be measured: magnetic field strength, $\mathrm{H}$; electric field strength, E; conducted current, I; and voltage, V, between two conductors. One parameter was emphasized, magnetic field strength. There are several reasons. First, electric field sensors are very insensitive at lower frequencies, and hence probably will not 
be useful in any practical mine communication system. Second, at any air-earth interface, only the magnetic field is essentially undisturbed, while the electric field is severely reduced. Third, any currents will induce magnetic fields, and hence measurement of the magnetic field will directly sense currents. Fourth, power line voltages are propagated as transmission line phenomena, are directly related to transmission line currents, and hence to magnetic fields induced. Thus, measuring magnetic field strength gives a representative composite picture of noise from currents and voltages from most sources.

Although magnetic field strength measurements are emphasized here, even this one parameter is difficult to measure meaningfully. The IEEE definition [3] of magnetic field strength, $H$ (magnitude of the magnetic field vector), is used in this report. The resultant magnetic field strength noise vector is a function of frequency, time, orientation, and 1ocation. Small variations in these parameters can cause several orders of magnitude difference in measured field strength.

\subsection{Mine Description}

The results and data presented in this report are based on measurements made on April 17 and 19, 1973, in the Itmann No. 3 Coal Mine located near Mullens, southwest of Beckley, West Virginia. The mine belongs to Consolidation Coal Company. The coal in this mine occurs in a narrow seam, approximately one meter thick, and is called "low-coal." The measurements were made in the two sections of the mine using the longwall mining technique. These sections were called Cabin Creek panel and Farley pane 1 and were separated by about 1500 meters at the time of measurement. Overburden at Cabin Creek was 
290 meters and at Farley was 440 meters. The mine has seven conventional, room-and-pillar sections; measurements were restricted to the longwall panels.

The mine uses $250 \mathrm{~V}$ dc trolley haulage to carry coal out of the mine, and ac powered conveyor belt haulage from the section to the trolley. All of the section longwall mining equipment is ac powered, with the exception of a dc-powered cable winch which was used occasionally to advance portions of the longwall equipment. The face and associated longwall equipment were 145 meters 1ong. Each of the separate components of the longwall mining equipment was made by a different manufacturer, typically in England or Scotland. There were a total of six electric motors in the section ranging from 15 to $300 \mathrm{HP}$. The shear and face conveyor used 950 volts and the stage loader and hydraulic pumps used 550 volts. The stepdown transformer supplying these voltages is kept 45 to 230 meters back from the face, and is supplied with 13,200 volts.

Vertical clearance for personnel passage in Cabin Creek panel was limited to the 1.0 meter left by the extracted coal. In Farley pane1, clearance was increased to 1.2 meters by the removal of some shale in the personnel passageways.

Acoustical noise at the longwall face may be high enough to seriously degrade voice communication systems. 


\section{MEASUREMENT INSTRUMENTATION}

Two measurement techniques were used. In the first technique used a large portion of the spectrum is covered as a "snapshot" at one relatively short period of time. In three-dimensional form, several such "snapshots" can show how drastically a signal varies, not only with frequency, but also with time. In the second technique, variations over a 20 -minute time interval are measured at one frequency. Usually, a set of twelve different frequencies was used. Both techniques were used to measure two orthogonal components of magnetic field strength. This was done either by using two systems simultaneously or by varying the orientation of one system; both techniques were used in as many different locations as possible.

With the exception of the electric dipole spectral plots and the roof-bolt APD's, all measured noise is reported in absolute quantities (instead of relative) to allow others to make effective use of the data. For the magnetic field strength measurements, the NBS field calibration site [4] was used with each complete measurement system to assure correct calibration.

A complication to making these measurements is the mine environment, which is generally humid, dusty, poorly lighted, and potentially explosive. In Itmann Mine, the restriction caused by the one meter clearance in the passageways caused a significant reduction in the total number of locations where measurements could be made. Battery-operated, dust-protected, permissible gear was used for most of our portable measuring equipment.

There are two types of noise recorded in the spectral plots, and hence two different magnetic field strength parameters are required, $\mathrm{H}$ and $\mathrm{H}_{\mathrm{d}}$. Results are given as the rms value of one component of magnetic field strength, $H$, versus frequency for 
discrete frequencies, or as one component of magnetic-fieldstrength spectrum density level [3], $H_{d}$, versus frequency for broadband noise in the spectral plots. In the amplitude probability distributions, results are given as the rms value of one component of magnetic field strength versus percent of time this value is exceeded. The APD gives the distribution of the actual instantaneous values only as far as the measurement-system detector bandwidth will allow the detector to follow the time variations of the actual magnetic field. (In this context, noise envelope is sometimes used.) Thus, the results are applicable for a communication receiver whose bandwidth is similar to the measurement-system detector bandwidth .

Three measurement systems were used to make measurements underground. The three systems are described in the block diagrams shown in figures 2-1, 2-2, and 2-3. For a detailed description of these systems, see two previous reports [1,2]. There are some differences in the systems used in Itmann Mine from the systems used in Robena \#4. The systems used in Itmann are the same ones used in Grace.

The first system measures data for spectral plots and is fully permissible and portable. The second system measures data for statistical descriptions of time variations, most commonly amplitude probability distribution; it is also permissible. The third system is not permissible but is portable (with considerable effort); it records data for both spectral plots and statistical presentations. 


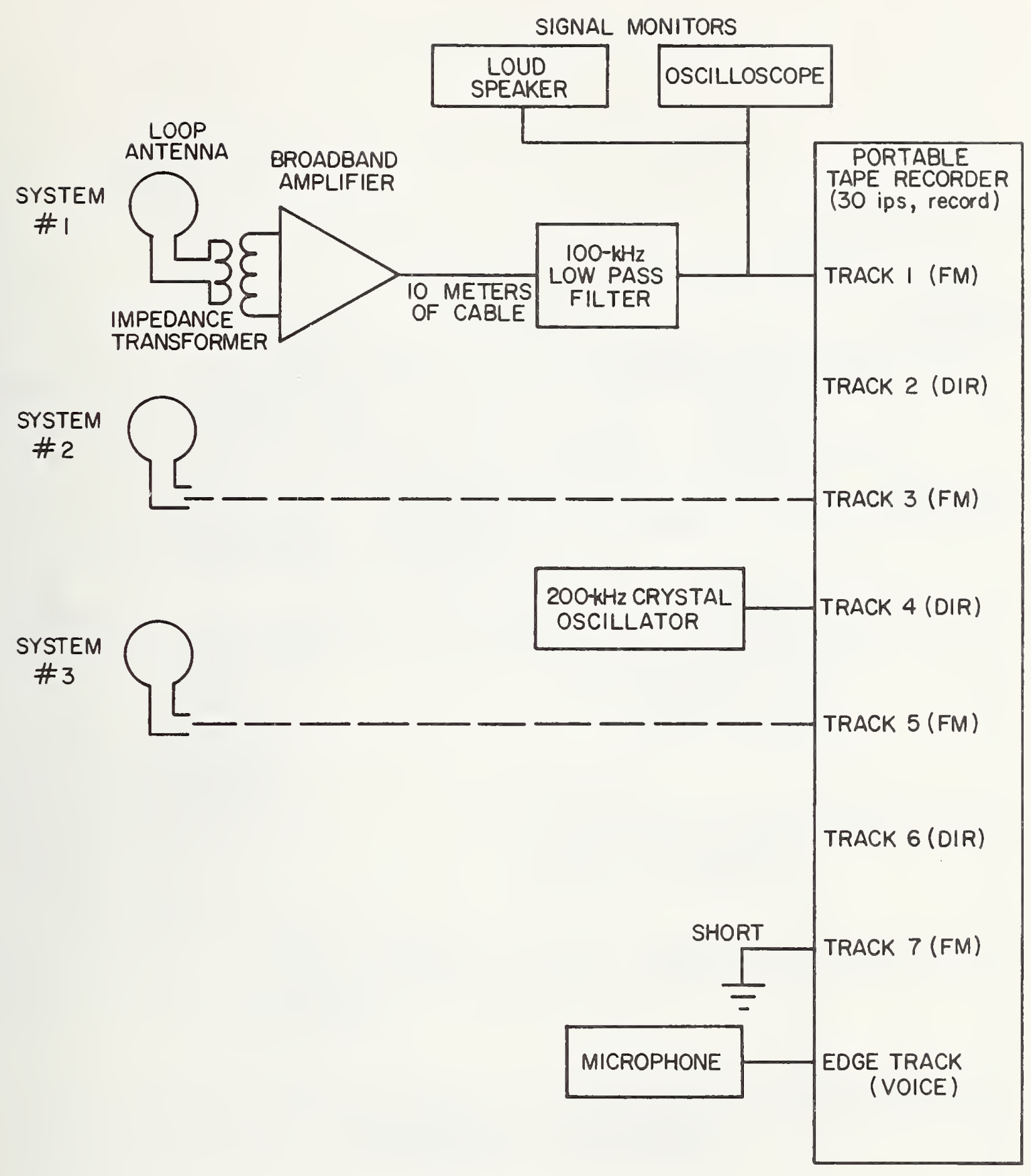

Figure 2-1 Block diagram of portable instrumentation. FM tracks are used to record from $40 \mathrm{~Hz}$ to $100 \mathrm{kHz}$; direct tracks are used from $3 \mathrm{kHz}$ to $320 \mathrm{kHz}$. Systems 2 and 3 are identical to system 1 . When the direct tracks are used, the $100-\mathrm{kHz}$ low pass filters are eliminated, and the amplifier bandwidth is increased from $100 \mathrm{kHz}$ to $300 \mathrm{kHz}$. The microphone is used for occasional vocal comments by the operator. 
COLLAPSIBLE

ANTENNA

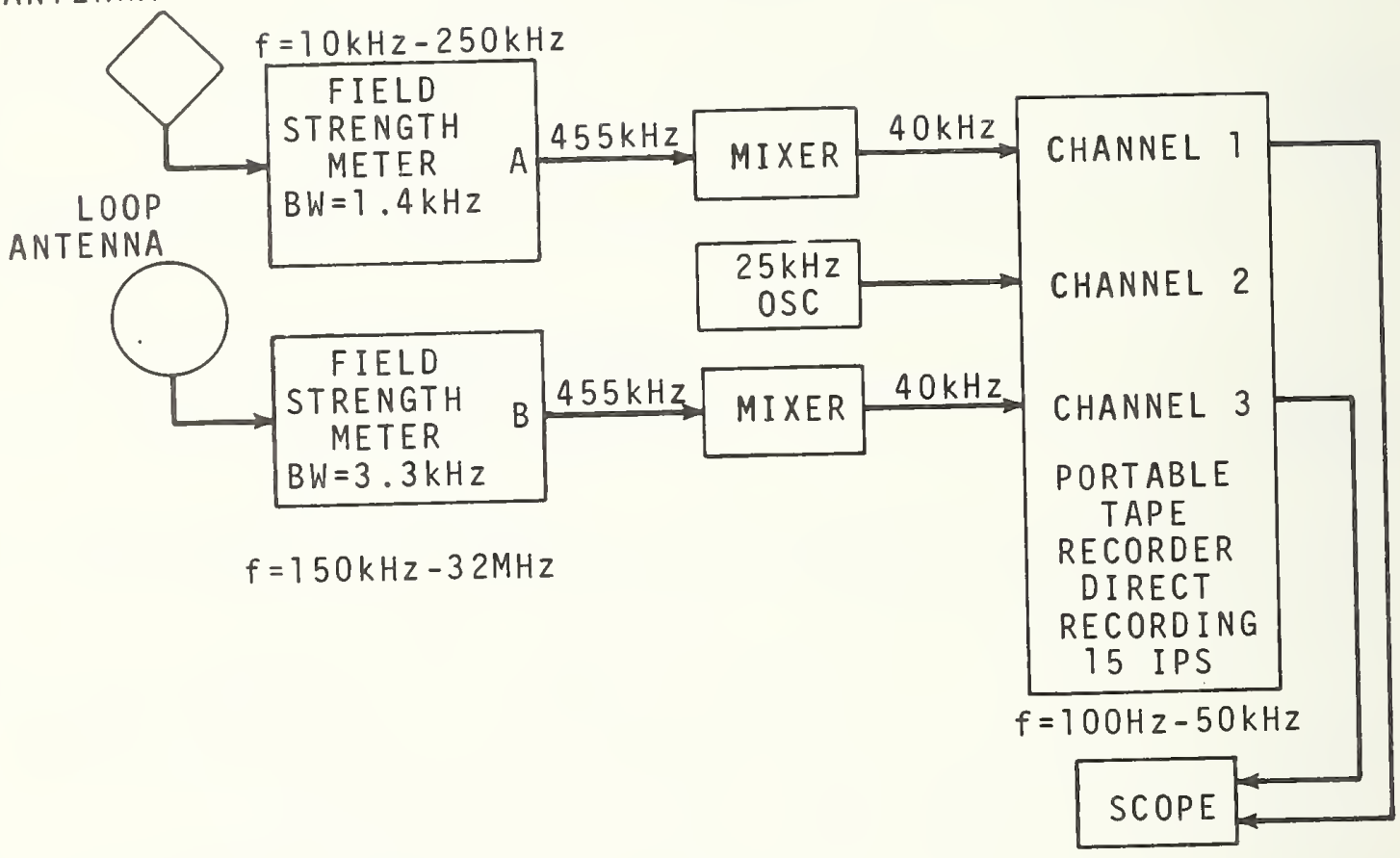

Figure 2-2 System for field recording data to obtain amplitude probability distributions. 


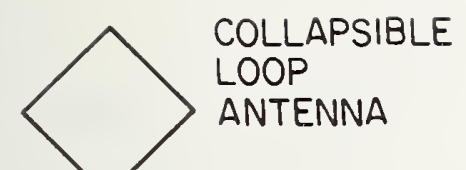

COLLAPSIBLE

ANTENNA
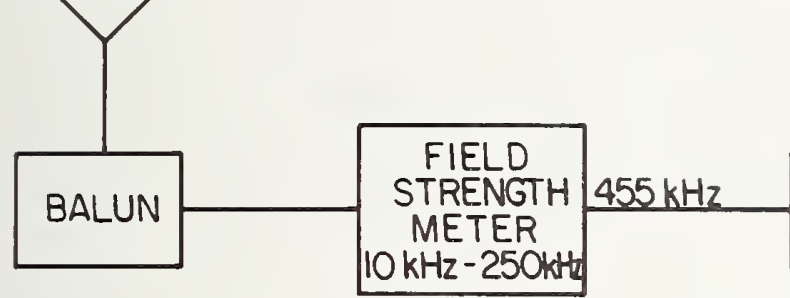

\section{MIXER}

$40 \mathrm{kHz}$

Ifo- CHANNELI (FM)
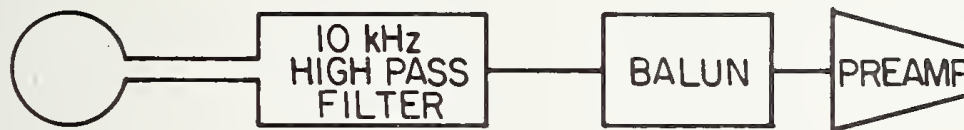

CHANNEL 3 (DIR)

\section{LOOP}

ANTENNA

(SENSITIVE AXIS VERTICAL)

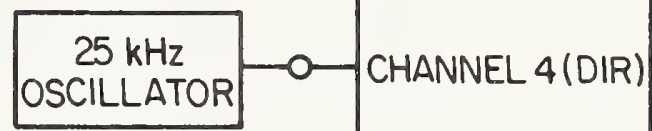

\section{COLLAPSIBLE}

LOOP

ANTENNA

EQUIPMENT

SIMILAR TO 3, O-CHANNEL 5 (DIR) BUT WITH HORIZONTAL

ANTENNA ORIENTATION

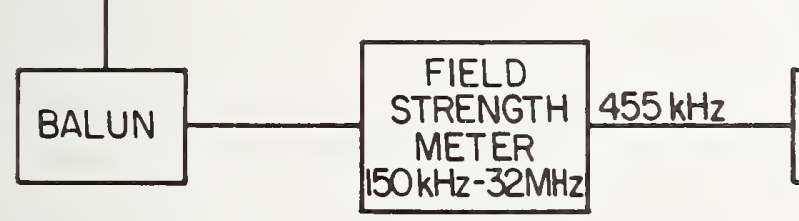

MIXER $40 \mathrm{kHz} \sim$ CHANNEL 6 (DIR)

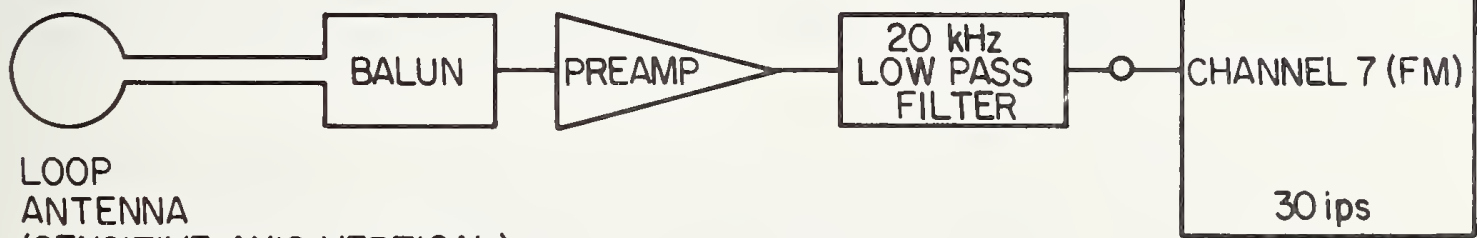

(SENSITIVE AXIS VERTICAL)

Figure 2-3 Block diagram of laboratory recording system modified for field use. 


\subsection{Introduction and Uncertainties}

In this section of the report, spectrum plots are presented and discussed. Most of these plots present magnetic field strength up to $100 \mathrm{kHz}$. Measurements were made at many different locations and results can be used to characterize electromagnetic noise levels generated by most fixed and mobile equipment used in this mine. Some plots give data to $3 \mathrm{kHz}, 20 \mathrm{kHz}$, and $230 \mathrm{kHz}$.

The spectra to $100 \mathrm{kHz}$, to $3 \mathrm{kHz}$, and to $20 \mathrm{kHz}$ have uncertainties of $\pm 1 \mathrm{~dB}$ over the following portions of the spectra. The $100 \mathrm{kHz}$ spectra are valid either from 1 to 100 $\mathrm{kHz}$ or $10 \mathrm{kHz}$ to $100 \mathrm{kHz}$ as stated or shown. The $3 \mathrm{kHz}$ spectra have the $\pm 1 \mathrm{~dB}$ uncertainty from $100 \mathrm{~Hz}$ to $3 \mathrm{kHz}$. Between $40 \mathrm{~Hz}$ and $100 \mathrm{~Hz}$ the uncertainty is $\pm 6 \mathrm{~dB}$. The $20 \mathrm{kHz}$ spectra have an uncertainty of $\pm 1 \mathrm{~dB}$ from $750 \mathrm{~Hz}$ to $20 \mathrm{kHz}$.

The spectra shown to $230 \mathrm{kHz}$ have an uncertainty of $\pm 2 \mathrm{~dB}$ from $3 \mathrm{kHz}$ to $180 \mathrm{kHz}$.

\subsection{Antenna Sites}

Figure 3-1 is a map of Cabin Creek pane1 as it was on Apri1 17, 1973, the first day measurements were made. The shear would operate back and forth across the face, as the mining operation advanced. The recording equipment was set up in the dinner man hole, and the antennas were deployed in the locations labeled $\mathrm{A}$ and $\mathrm{B}$.

On the second day measurements were made in Farley pane1, which has similar equipment but was arranged in the mirror image of Cabin Creek pane1. The layout can be determined by looking at figure 3-1 through the back side of the drawing. No separate map is given for Farley panel. 


\subsection{Electromagnetic Noise Spectrum Results}

\subsubsection{Interpretation}

When reading values from the spectra in this report, keep the following points in mind:

1. Field strength values above the upper roll-off frequency and below the lower roll-off frequency are not calibrated and are therefore not shown on the spectra. 2. The correct units for the spectral peaks are microamperes per meter $(\mu \mathrm{A} / \mathrm{m})$.

3. The broadband noise between spectral peaks is as seen by a receiver having the same bandwidth as the Fast Fourier Transform (FFT) spectral resolution bandwidth used to compute the spectrum. The correct units for the background noise between peaks are microamperes per meter per square root $x$ hertz $[(\mu \mathrm{A} / \mathrm{m}) / \sqrt{\mathrm{xHz}}]$, where $\mathrm{x}$ is the spectral resolution of the FFT ( $x$ equals $78.1 \mathrm{~Hz}$ for the 1 - to $-100-\mathrm{kHz}$ graphs).

An easy way to obtain the spectral density per (one) root hertz for broadband noise is to subtract the required number of $\mathrm{dB}$, remembering that the units have now changed to $(\mu \mathrm{A} / \mathrm{m}) / \sqrt{\mathrm{Hz}}$. For spectra with a resolution bandwidth of 78.1 $\mathrm{Hz}$, subtract $10 \log _{10}(78.1)$ or $18.93 \mathrm{~dB}$.

The Appendix gives the code key used in determining the meaning of the numbers in the header block at the top of each spectrum. The resolution bandwidth is also given on the ordinate of the plots.

\subsubsection{Cabin Creek Pane1}

Figure 3-2 upper curve, shows the magnetic field noise spectrum from $1 \mathrm{kHz}$ to $100 \mathrm{kHz}$ received at the antenna 1 ocation identified as A (in figure 3-1). The antenna sensitive 
axis was vertical. Location $A$ is near the dinner man hole, 10 meters from the end of the face, and is a busy area in the section. The lower curve in this, and in following figures, is the receiving system noise. It is included to indicate frequency ranges in which system noise may predominate. The lower curve is obtained by replacing the loop antenna with a dummy antenna. This figure shows data from $1 \mathrm{kHz}$ to $100 \mathrm{kHz}$ from one system and from $10 \mathrm{kHz}$ to $100 \mathrm{kHz}$ from another system that had lower system noise. An obvious feature in figure 3-2 is a signal at $17.8 \mathrm{kHz}$. This is from the U.S. Navy transmitter NAA located in Cutler, Maine. With the exception of one shallow location in a hardrock mine, this is the only underground mine location where reception of a distant VLF station occurred. This strong signal from NAA in a coal mine under this large overburden (290 meters) is very unusual. The minegenerated noise shown on figure $3-2$ extends to $100 \mathrm{kHz}$ at the $-20 \mathrm{~dB}$ relative to $1 \mathrm{\mu A} / \mathrm{m}$ level. Between 60 and $75 \mathrm{kHz}$, there is a dip in amplitude of $8 \mathrm{~dB}$ or more. Figure $3-3$ shows the expanded spectrum at location A, ten meters from the end of the longwall face, with the mine operating. Figure $3-3$ shows a noise spectrum dominated by powerline harmonics of $60 \mathrm{~Hz}$.

Figure 3-4 was measured at location B, five meters from the end of the longwall face, with the mine in operation. The noise spectrum at location $B$, with the antenna axis vertical, has about the same shape as the spectrum at location $A$, but is 4 to $10 \mathrm{~dB}$ higher. The spectra recorded at $\mathrm{B}$, as at location $\mathrm{A}$, shows a rise in noise level from about $80 \mathrm{kHz}$ to $100 \mathrm{kHz}$. Figure 3-5 shows the expanded spectrum at location B. The spectrum taken with the antenna sensitive axis horizontal gives 4 to $10 \mathrm{~dB}$ less noise than with the sensitive axis vertical. Figure 3-6 shows the expanded spectrum at location B later, during the second shift, with the mine in full operation. Figure 3-6 is included because of the high level (108 dB relative to $1 \mu \mathrm{A} / \mathrm{m}$ ) of $60 \mathrm{~Hz}$ noise. 
Figure 3-7 shows the noise spectrum measured at Cabin Creek panel during the quiet time between shifts at location B. This spectrum is about 10 to $20 \mathrm{~dB}$ quieter than when the mine is in full operation. Figure $3-8$ shows the expanded spectrum measured at location $B$ between shifts. The $60 \mathrm{~Hz}$ noise here is $46 \mathrm{~dB}$ lower than when the mine was in full operation during the second shift.

\subsubsection{Farley Pane1}

Figure'3-9 shows the spectrum measured ten meters from the end of the 1ongwall face in Farley panel. Farley panel was the mirror image of Cabin Creek. The measurement location for figure 3-9 corresponds to location A on figure 3-1. While the noise in Farley between $10 \mathrm{kHz}$ and $20 \mathrm{kHz}$ is sometimes as much as $10 \mathrm{~dB}$ higher than in Cabin Creek, generally, the noise in Farley may be considered lower than the noise in Cabin Creek panel. Neither the signal from NAA nor the increase in noise between 80 and $100 \mathrm{kHz}$ show up in Farley. Figure 3-10 shows the expanded spectrum at location A, Farley panel, with the mine in operation. In Farley, the $60 \mathrm{~Hz}$ noise is $24 \mathrm{~dB}$ lower, the $360 \mathrm{~Hz}$ noise is the same amplitude, and most other harmonics are lower by as much as $15 \mathrm{~dB}$, than at Cabin Creek.

Figure 3-11 shows the spectrum measured at Farley pane1, ten meters from the end of the longwall miner, during the quiet time at lunch hour. Only the hydraulic pump, associated with the 134 roof jacks, was running. This pump was left running much of the time. The spectrum is essentially the same as shown in figure 3-9 when the mine was in operation. Figure 3-12 shows the expanded spectrum at Farley during 1 unch hour. The noise at $60 \mathrm{~Hz}$ is $4 \mathrm{~dB}$ lower during lunch hour. With some minor variation, the remainder of the expanded spectrum is about the same during lunch hour as during mine operation. 
Figures $3-13$ and $3-14$ show the spectrum recorded in Farley pane1, ten meters from the end of the longwall face. The ac-powered conveyor belt was just starting up. Evident on figure $3-13$ is powerline related noise out to $100 \mathrm{kHz}$, occurring with broad peaks about every $20 \mathrm{kHz}$. This noise signature is probably associated with an ac motor starting, and is probably of correspondingly short duration. Figure 3-14 shows $7 \mathrm{~dB}$ higher $60 \mathrm{~Hz}$ noise than with the mine in operation (figure 3-10). Induction motors typically require about 2.5 times $(8 \mathrm{~dB})$ more current to start than to run. Probably the increased $60 \mathrm{~Hz}$ noise comes from the increased starting current being drawn by the starting of the conveyorbelt motor.

Data taken with the third system in Farley Panel are shown in the following figures. Figure $3-15$ shows a spectrum from 0.8 to $20 \mathrm{kHz}$ taken about three meters from an operating shear on the longwall machine. Figure 3-16 shows typical noise at the end of the rail haulage, about 200 meters from the longwall face. Figures 3-17 and 3-18 show two components of noise generated by an unidentified piece of machinery. Figure 3-19 shows an expanded (to $20 \mathrm{kHz}$ ) spectra of figure 3-17. There were strong $\mathrm{cw}$ signals at frequencies higher than our systems were normally operated; however, two illustrations are shown at frequencies higher than the system's calibration is valid. One signal shown in figures 3-20 and 3-21 is at $202.5 \mathrm{kHz}$; it may be a control signal specific to this mine. It did generate higher harmonics that were detected with other equipment.

\subsection{Miscellaneous Measurements}

\subsubsection{Electric Field}

An active dipole, 1.93 meters long, was used as a sensor on the second day while in Farley panel. This dipole has not 
been calibrated, nor have any system nonlinearities in gain vs. frequency been removed by a correction curve. Therefore, all field strength information is only qualitative. Figure 3-22 shows unprocessed data results obtained with the dipole ends pointed paralle 1 with the drift and 0.75 meters from the phone line. Measurements taken with the dipole pointed across (perpendicular to) the drift gave fields that were 10 to $20 \mathrm{~dB}$ stronger than those shown in figure 3-22. Fields were 20 to $30 \mathrm{~dB}$ weaker when the dipole was 4 meters from the phone 1 ine. This indicates the noise was coming from the phone line. The electric field data shown in figure 3-22 was taken simultaneously with the magnetic field data in two previous figures, 3-13 and 3-14. The mine conveyor belt was just starting up. There is some similarity in the general shape of the two $1 \mathrm{kHz}$ to $100 \mathrm{kHz}$ spectra shown in figures 3-13 and 3-22.

Because of the relative nature of the electric field measurements, the principal conclusions that can be drawn are restricted to: (1) an electric noise field exists in Farley pane1; (2) it is primarily powerline related, similar to the magnetic field noise; (3) the electric noise field is maximum for horizontal dipole orientation across (perpendicular to) the drift; and (4) the source of the electric field noise appears to be the phone line.

\subsubsection{Measurements of Voltage Between Roof Bolts}

A single roof-support-bolt measurement was performed at Farley panel on the second day. The separation between the two bolts was 15.2 meters, and the voltage was measured using nonshielded copper wire clipped to the bolts. Figures 3-23 and 3-24 show the resulting spectra. No receiver system noise curves are available for these spectra. It is not possible to say that the voltage measured between bolts was induced by any 
single mechanism. It may be any combination of electric field and magnetic field acting on the copper wires connected to the bolts, as well as by any potential produced by current flow between the bolts.

\subsection{Intercomparison of Different Mines}

\subsubsection{Roof Bolt Voltage Intercomparison}

Figure 3-25 shows a summary table of the rms noise voltage measured between roof bolts of various spacings, in four mines.

$\begin{array}{cccc}\text { Mine } & \begin{array}{c}\text { Frequency } \\ (\mathrm{Hz})\end{array} & \begin{array}{c}\text { Roof Bolt Voltage } \\ \text { dB Relative to 1 Vrms }\end{array} & \begin{array}{c}\text { Logarithmic } \\ \text { Average } \\ \text { Voltage }\end{array} \\ \begin{array}{c}\text { Itmann } \\ \text { (coal) }\end{array} & \begin{array}{l}1080 \\ 2160\end{array} & -46 & -53 \\ \begin{array}{c}\text { McElroy } \\ \text { (coal) }\end{array} & 1080 & -60 & \\ \text { Grace } & 160 & -62 & -64.5 \\ \text { (hardrock) } & 2160 & -67 & \\ \text { Robena } & 1080 & -68 & -68 \\ \text { (coal) } & 2160 & -68 & -81.5\end{array}$

Figure 3-25. Summary of the rms noise voltage measured underground between roof-support-bolts in four mines.

The logarithmic average is the arithmetic average of the $d B$ values. Two frequencies within the voice baseband were chosen for comparison: $1080 \mathrm{~Hz}$, the third harmonic of $360 \mathrm{~Hz}$, and $2160 \mathrm{~Hz}$, the sixth harmonic of $360 \mathrm{~Hz}$. The results show that the logarithmic averages for these two frequencies give the highest voltage ( $-53 \mathrm{~dB}$ with respect to $1 \mathrm{~V}$ rms) for Itmann, and the lowest value for Robena ( $-81.5 \mathrm{~dB}$ with respect to $1 \mathrm{~V}$ rms). Possibly a factor contributing to the low roof bolt voltage in Robena, is the fact that the bolts were on a 
line perpendicular to the haulageway. In Itmann, the bolts were on a line along the haulageway. In McElroy and Grace this distinction could not be made.

\subsubsection{Summary of $1 \mathrm{kHz}$ to $3 \mathrm{kHz}$ Data}

Figure 3-26 is a summary of magnetic field strength at powerline harmonic frequencies observed within Itmann (acpowered longwa11), Robena (a11 $600 \mathrm{v} \mathrm{dc}$ ) and the Grace (dieselpowered haulage) mines. Plotted are the $\mathrm{dB}$ averages of $\mathrm{six}$ powerline harmonics. This logarithmic average masks the highest single value. Average fields at five locations in Itmann are plotted as a function of distance from the nearest current-carrying cable or wire. The six frequencies chosen are between $1020 \mathrm{~Hz}$ and $2940 \mathrm{~Hz}$ and are either the third through eighth harmonic of $360 \mathrm{~Hz}$, or the'highest adjacent powerline harmonic.

The logarithmic average of noise from $1 \mathrm{kHz}$ to $3 \mathrm{kHz}$ in Cabin Creek pane 1 of Itmann was $40 \mathrm{~dB}$ relative to $1 \mu \mathrm{A} / \mathrm{m}$ with the mine in operation. The noise was $7 \mathrm{~dB}$ less between shifts. The noise in Farley pane 1 was $28 \mathrm{~dB}$ (as measured with the third system, first day) and $29 \mathrm{~dB}$ (as measured with the first system, second day) relative to $1 \mu \mathrm{A} / \mathrm{m}$ during operation, and was also $29 \mathrm{~dB}$ during 1 unch hour. The noise in Farley was $5 \mathrm{~dB}$ higher during the time the conveyor belt was starting up than while running, and $8 \mathrm{~dB}$ higher measured 70 meters back from the face, near the end of the dc-powered rail haulage. This last finding is consistent with the observation that, in general, dc machinery is noisier than ac machinery.

Figure 3-27 is a summary of magnetic field strength over the same frequency region as measured in the McElroy Coal Mine [7] (ac-powered continuous miner and head loader, dc-powered shuttle cars and trolley). 
A comparison of the magnetic noise from $1 \mathrm{kHz}$ to $3 \mathrm{kHz}$ in the four mines shows:

1. Robena is noisiest, McElroy is next, followed by Grace and Itmann, which are about equal.

a. The highest logarithmic average of section noise measured one meter from a cable in McElroy is $15 \mathrm{~dB}$ relative to $1 \mathrm{\mu A} / \mathrm{m}$ (at the power center). The noise is $16 \mathrm{~dB}$ higher at the "air split" on the haulageway in Robena, and $21 \mathrm{~dB}$ higher at the car pull in operation in Robena than the $15 \mathrm{~dB}$ value in McElroy. b. The highest logarithmic average of haulageway noise measured 2 meters from a cable in McElroy is $7 \mathrm{~dB}$ stronger than the noise measured 2 meters from a load-haul-dump in Grace. The Grace noise is equal to the noise measured in Cabin Creek panel in Itmann. c. For a given constant distance from the currentcarrying cable in each of the four mines measured, the maximum logarithmic average noise between $1 \mathrm{kHz}$ and $3 \mathrm{kHz}$ varies over a rather small range. For example, at the 2 meter distance from the cable (or noise source), the highest noise was $48 \mathrm{~dB}$ (in McElroy), and the lowest was $40 \mathrm{~dB}$ (in Grace and Itmann). The range of values is only $8 \mathrm{~dB}$. Part of the reason for this low spread may be due to the parameter chosen for measurement, the logarithmic average.

This average masks the peak value, which is dominant in causing interference to a broadband system.

\section{5 .3 Intercomparison of $3 \mathrm{kHz}$ to $200 \mathrm{kHz}$ Data}

Comparative spectra from $3 \mathrm{kHz}$ to $200 \mathrm{kHz}$. from four mines are shown in figures 3-28 and 3-29. The Robena curve is only calibrated to $100 \mathrm{kHz}$. 


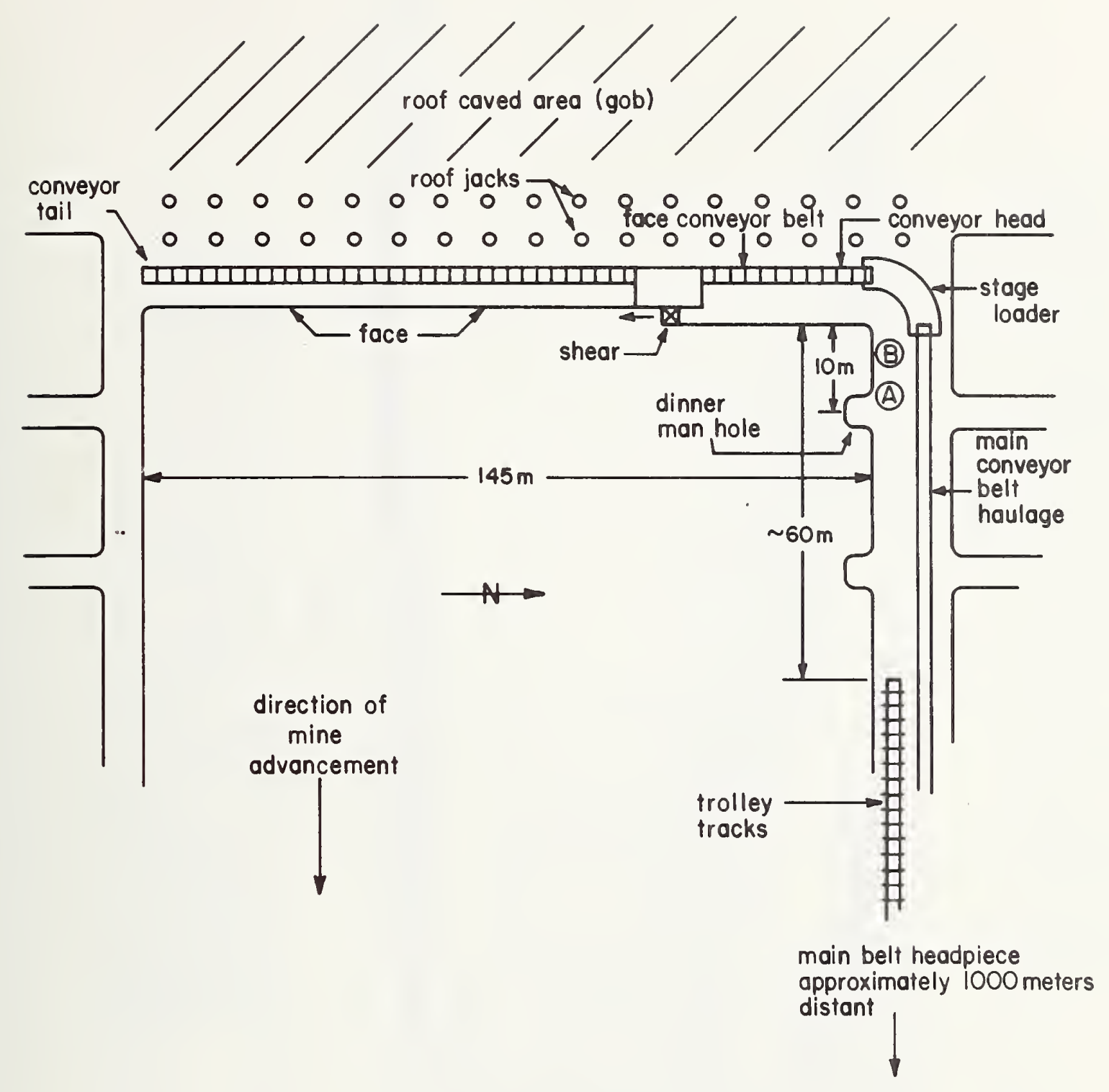

Figure 3-1 Map of Itmann Coal Mine, Cabin Creek pane1 1ong-wall mining section. Farley panel is a minor image of this section. 


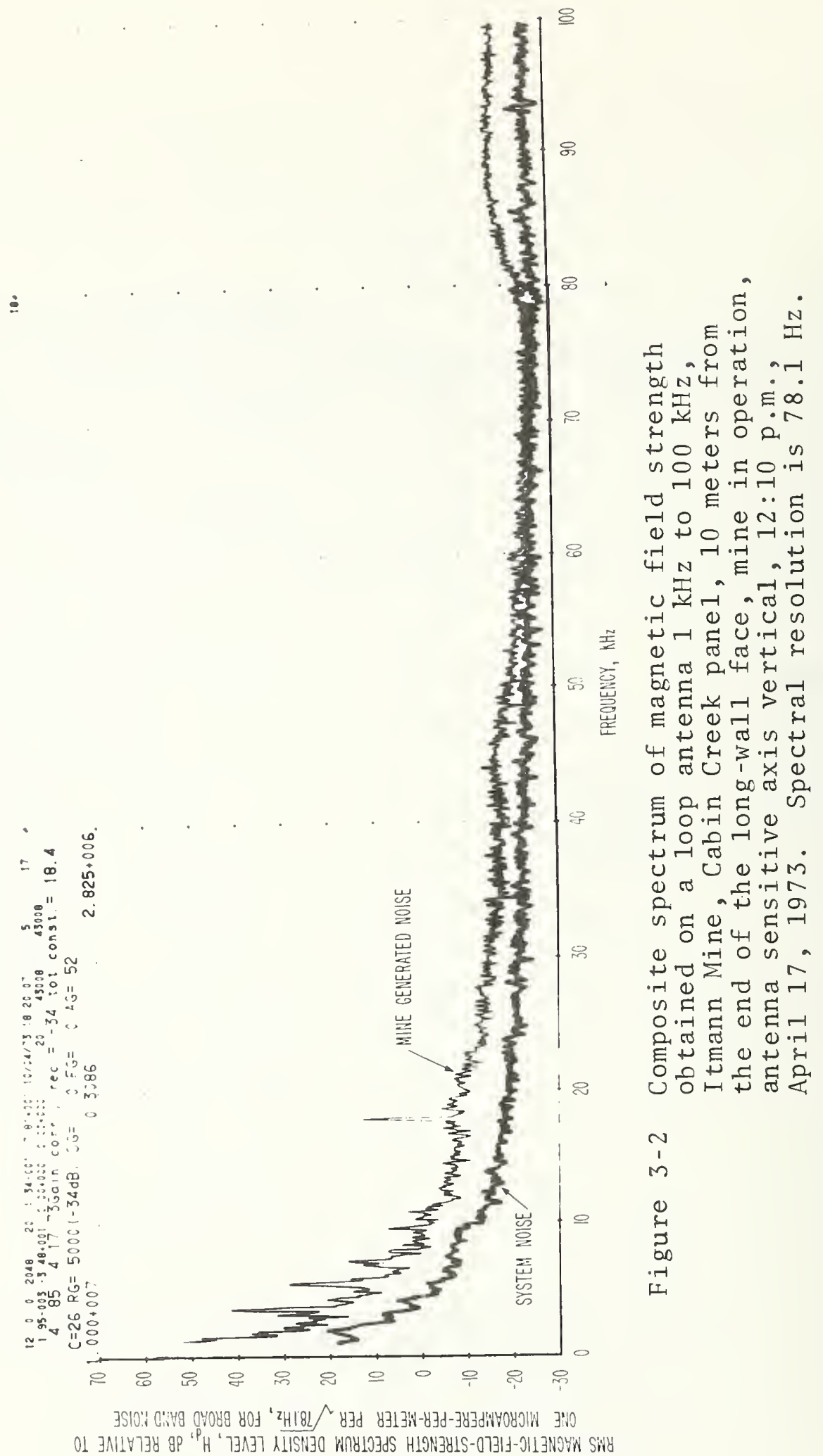

o1 3ni1

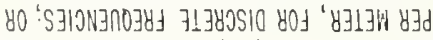

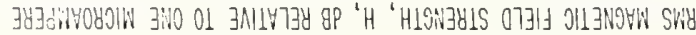




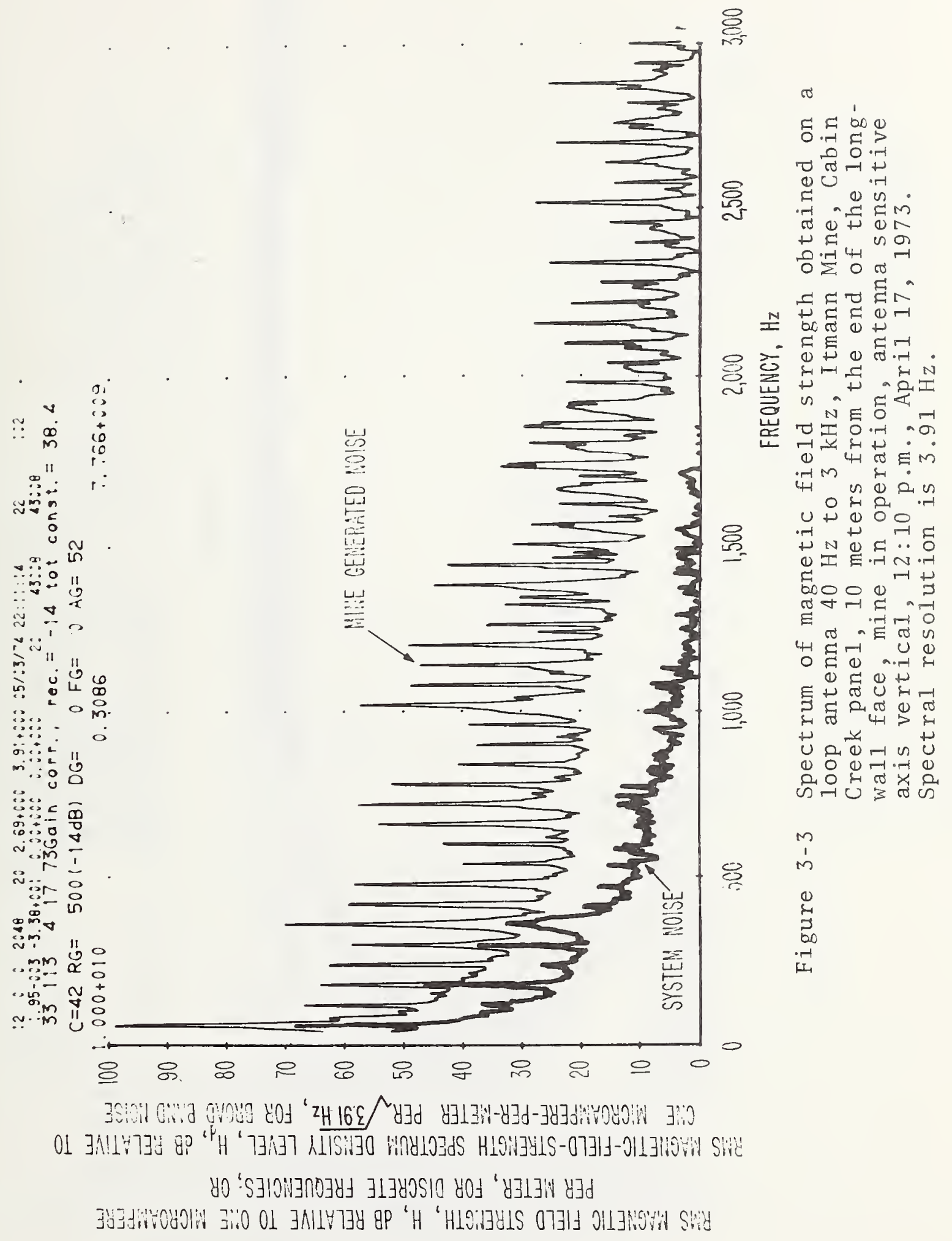




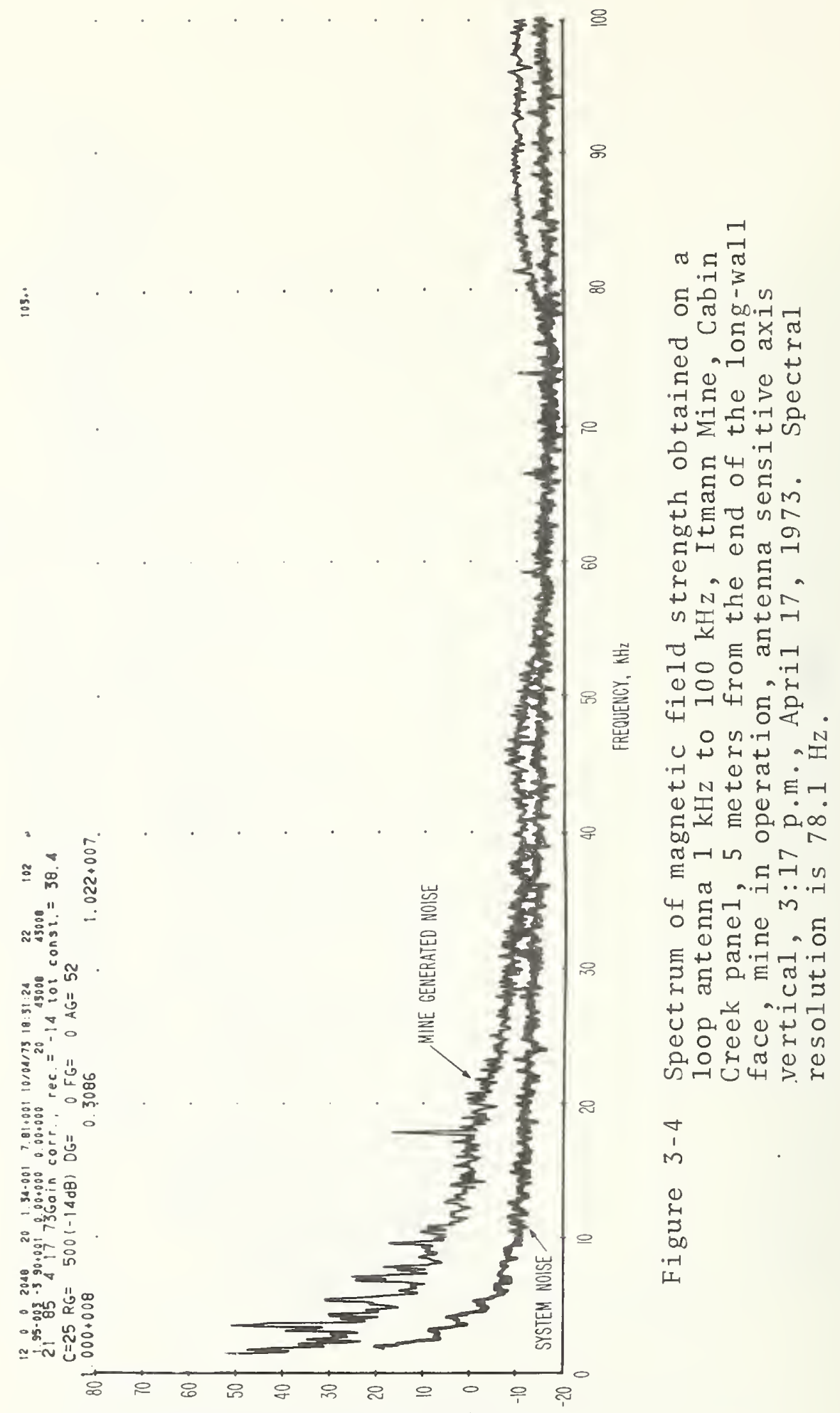

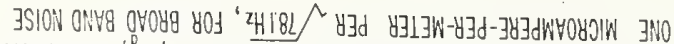

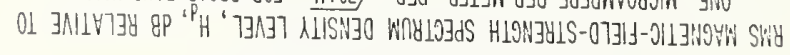

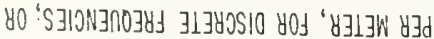

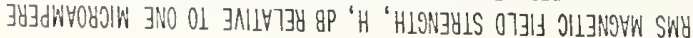




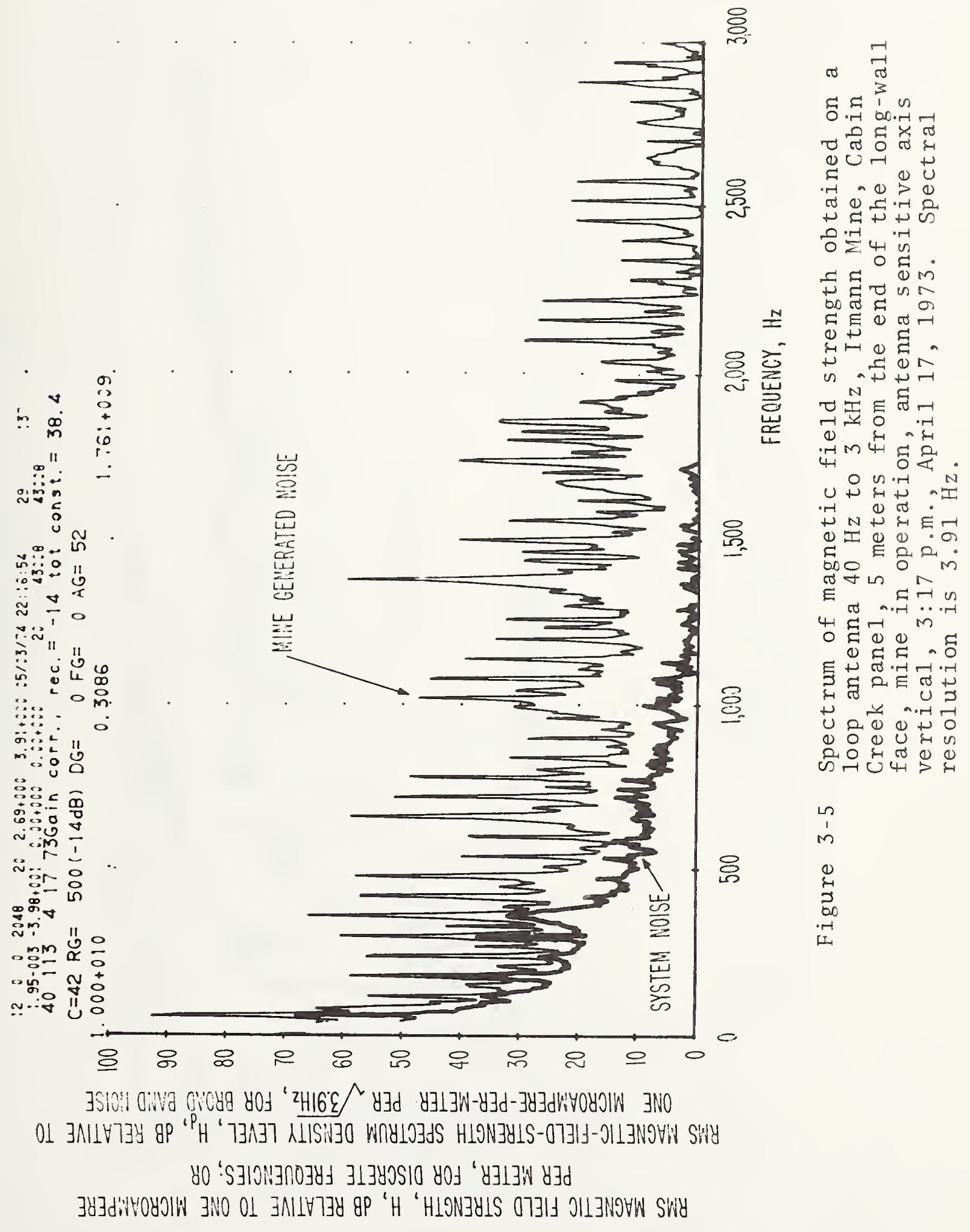




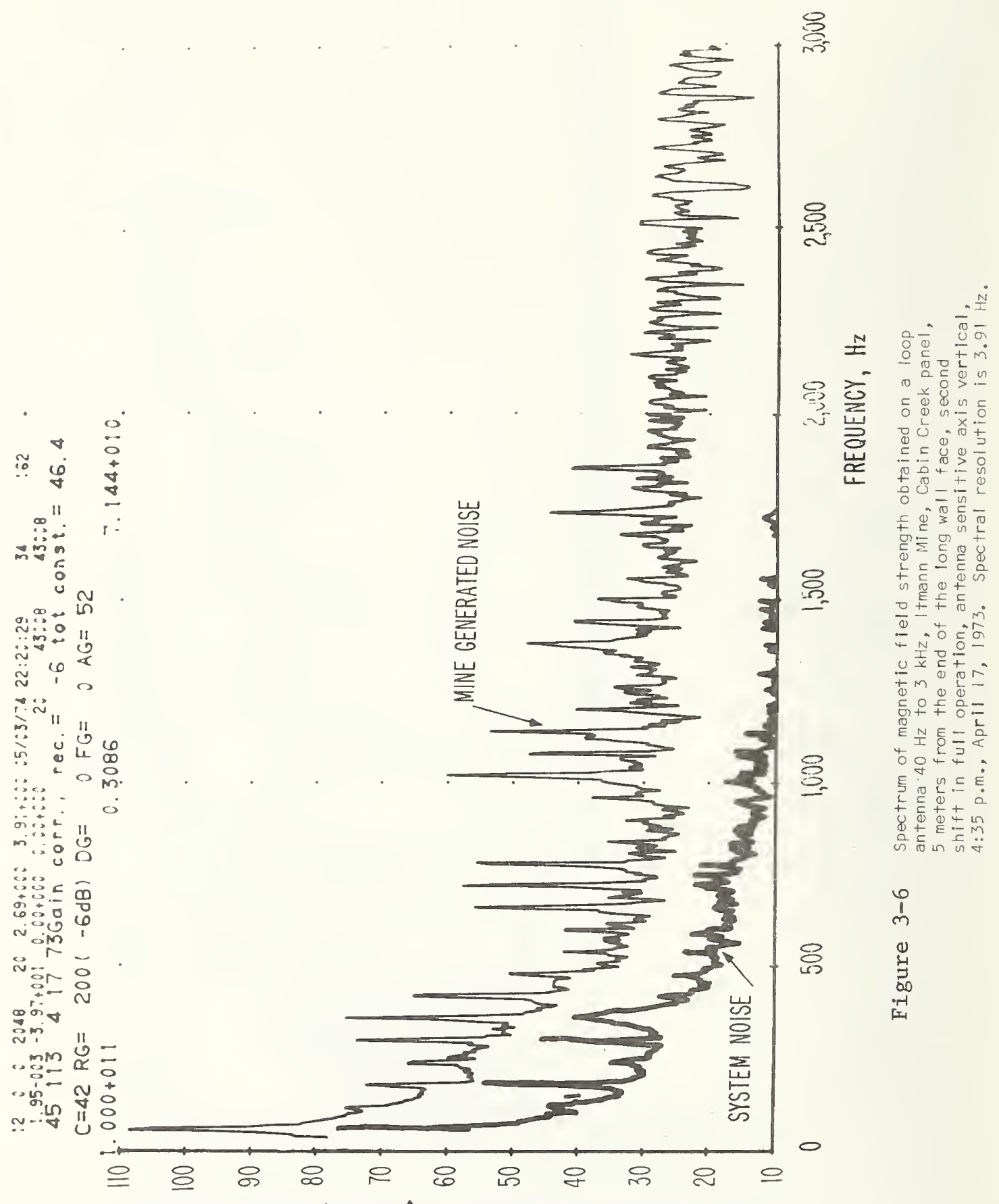

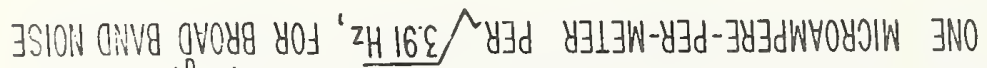

OL JN11

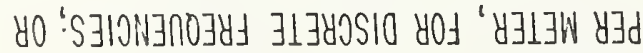

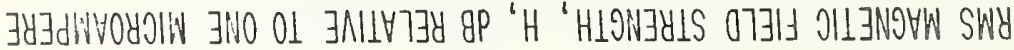




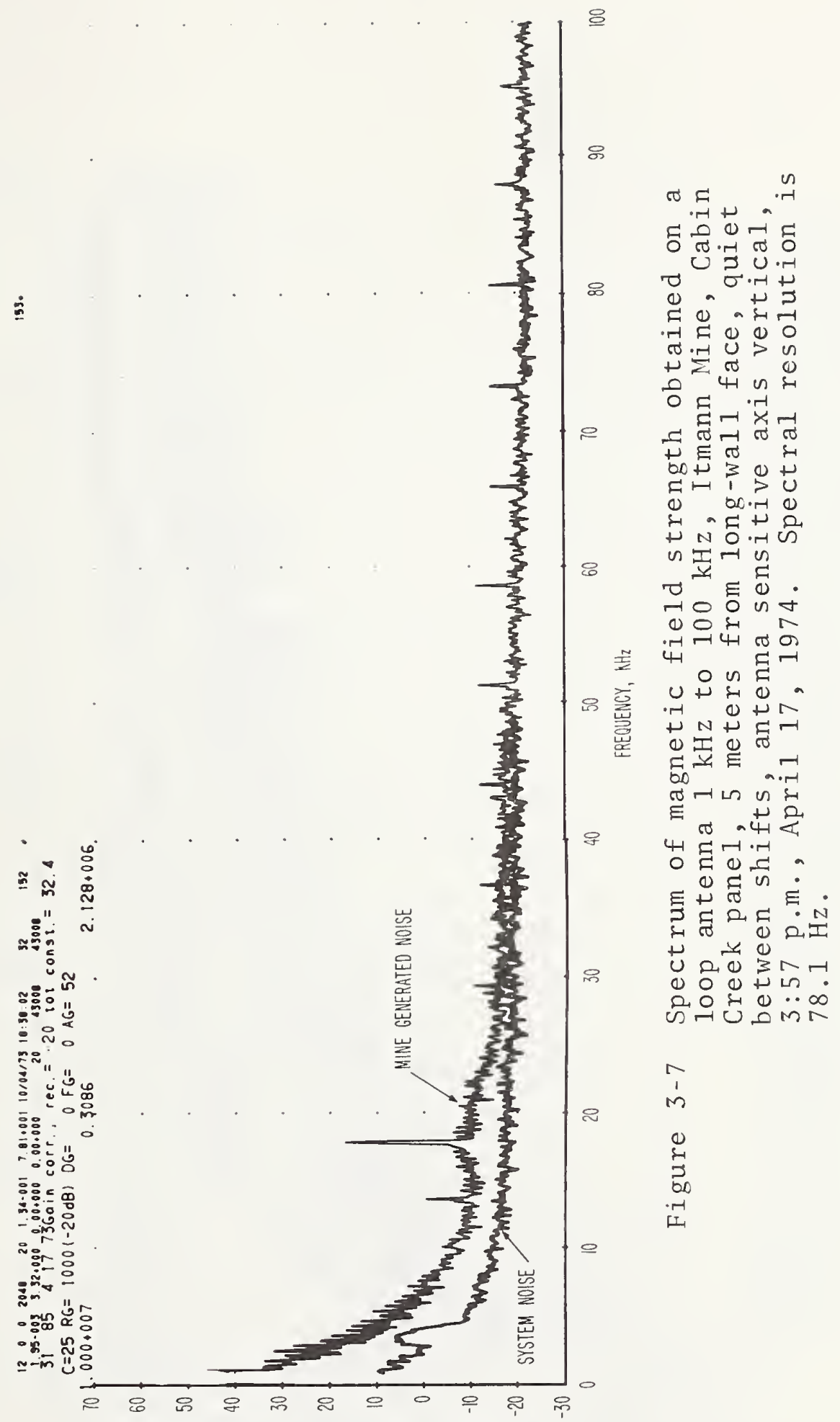

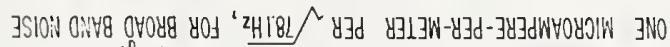

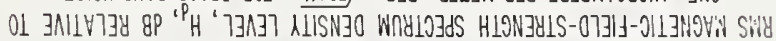

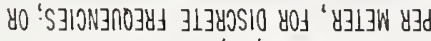

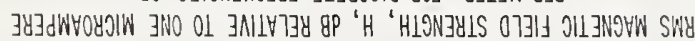




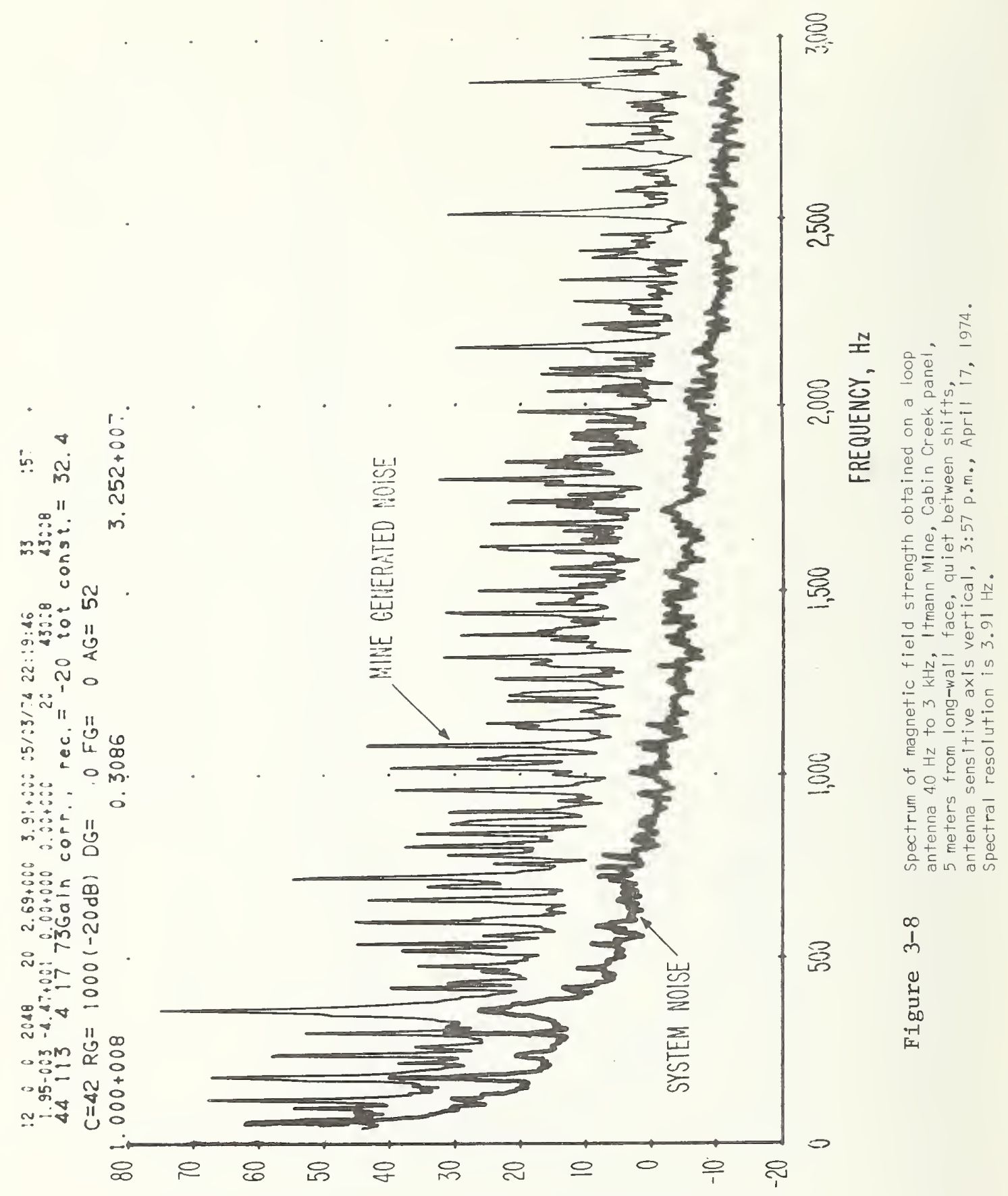

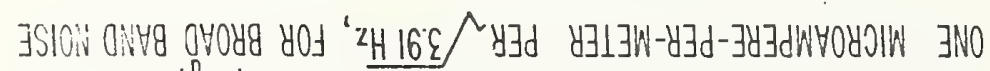

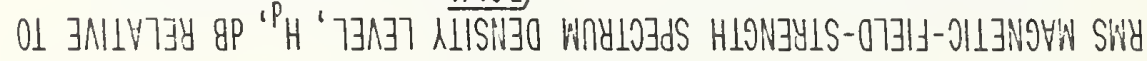

y०

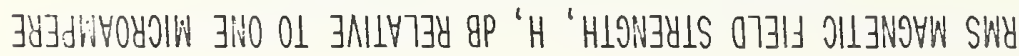




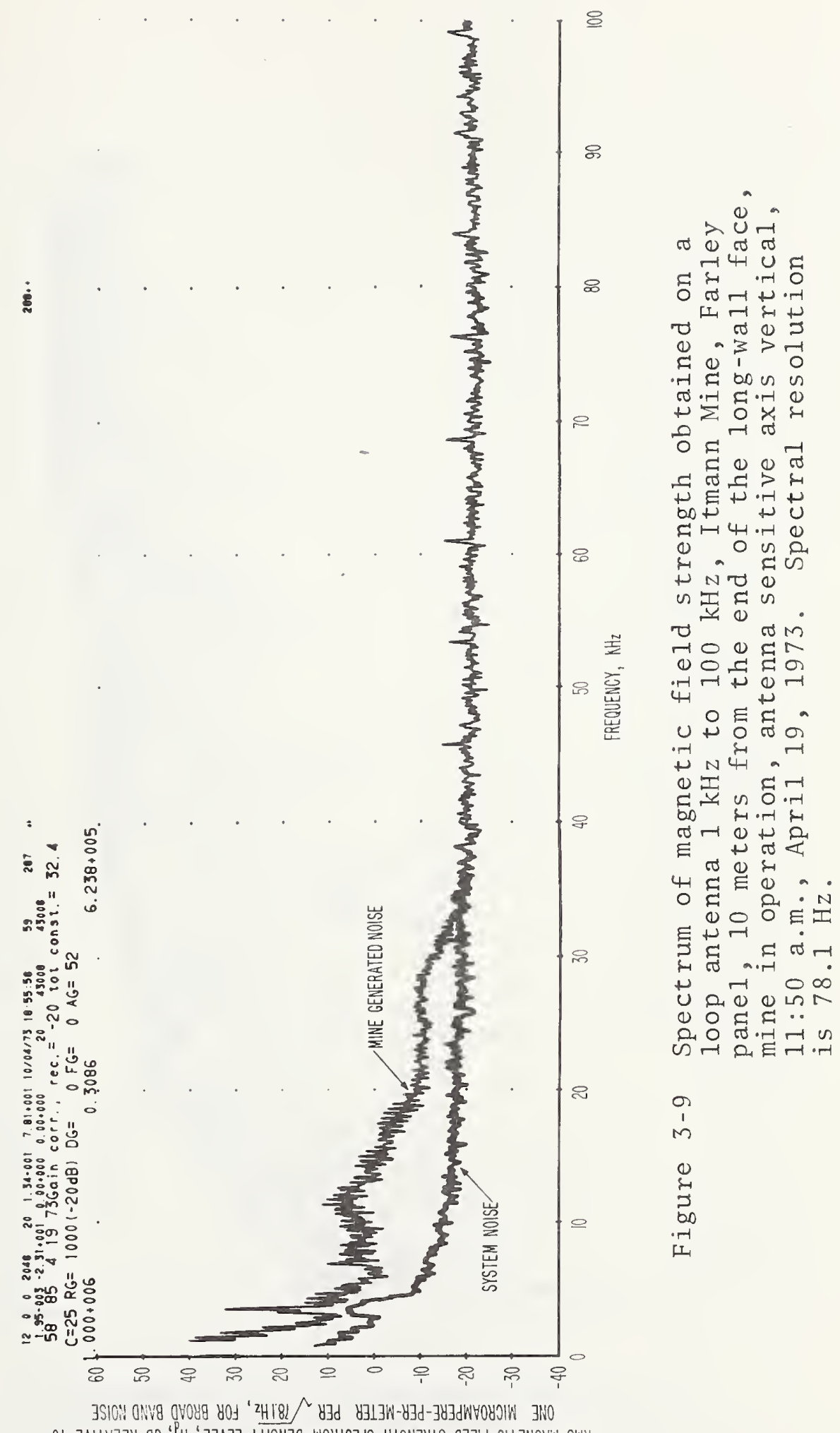

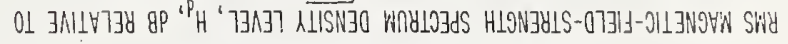

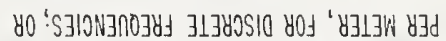

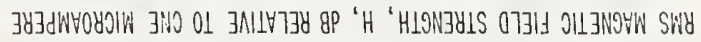




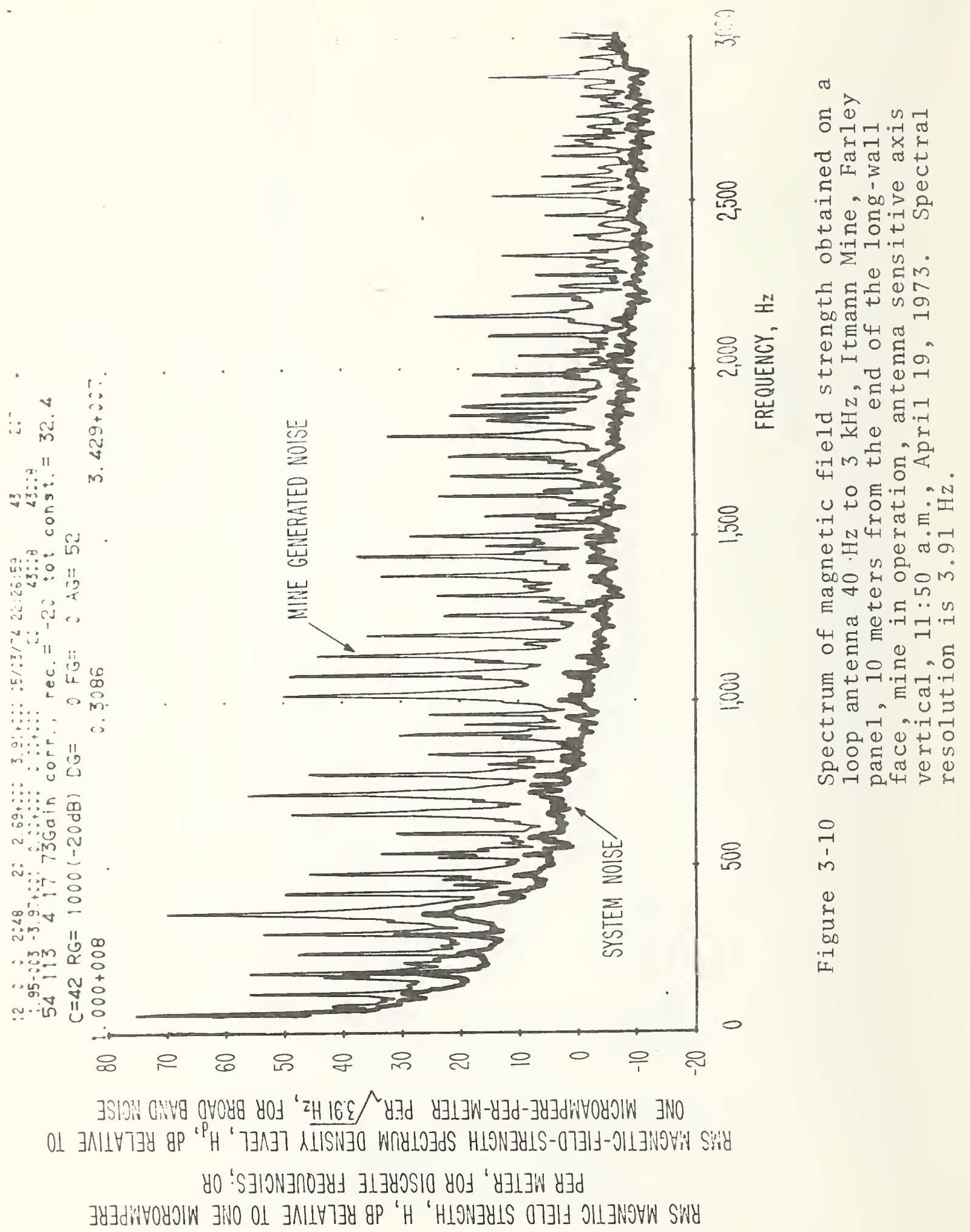




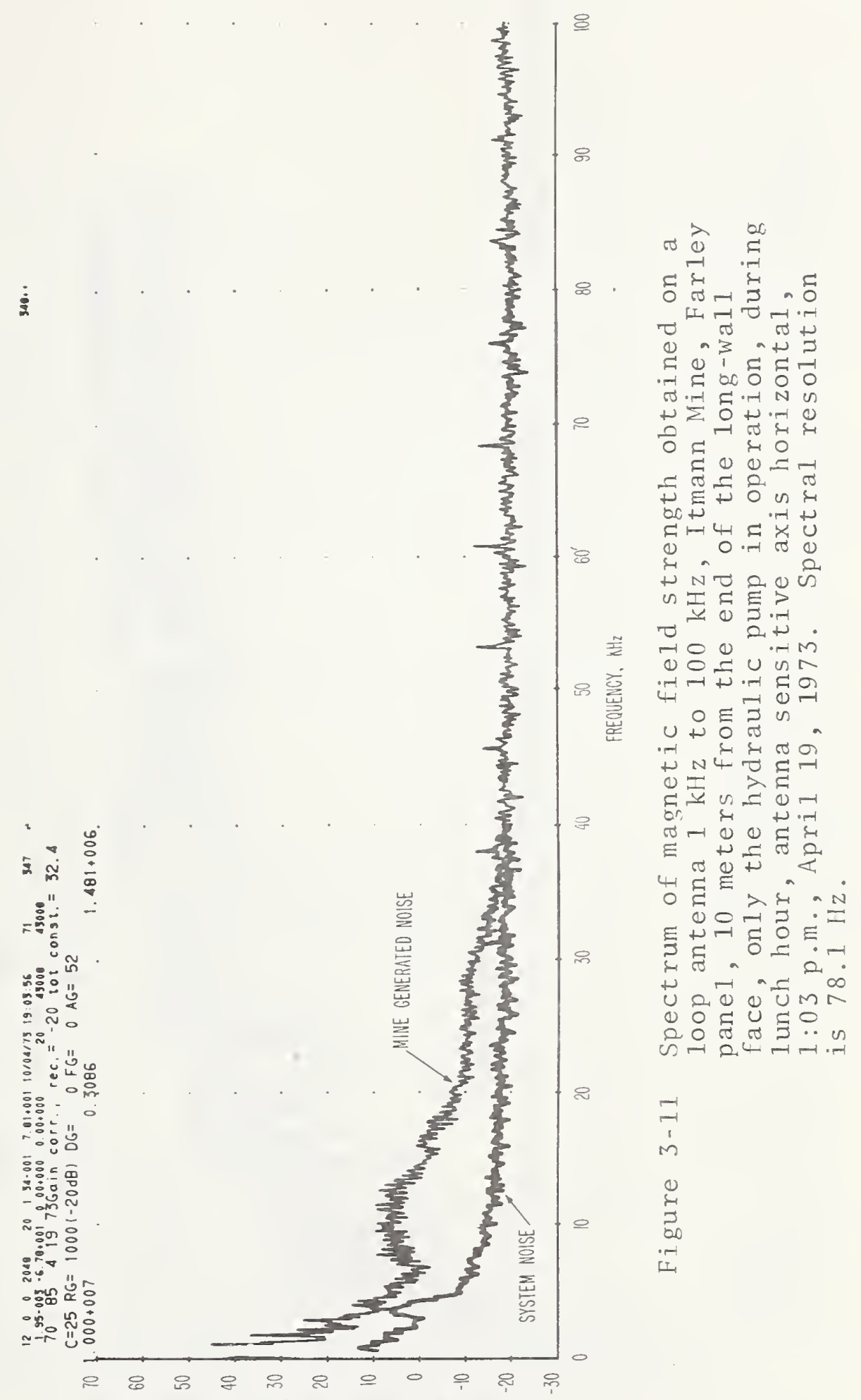

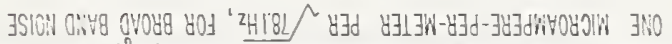

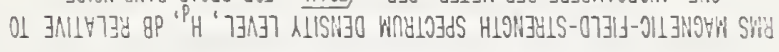

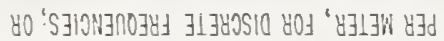

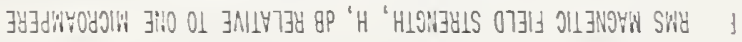




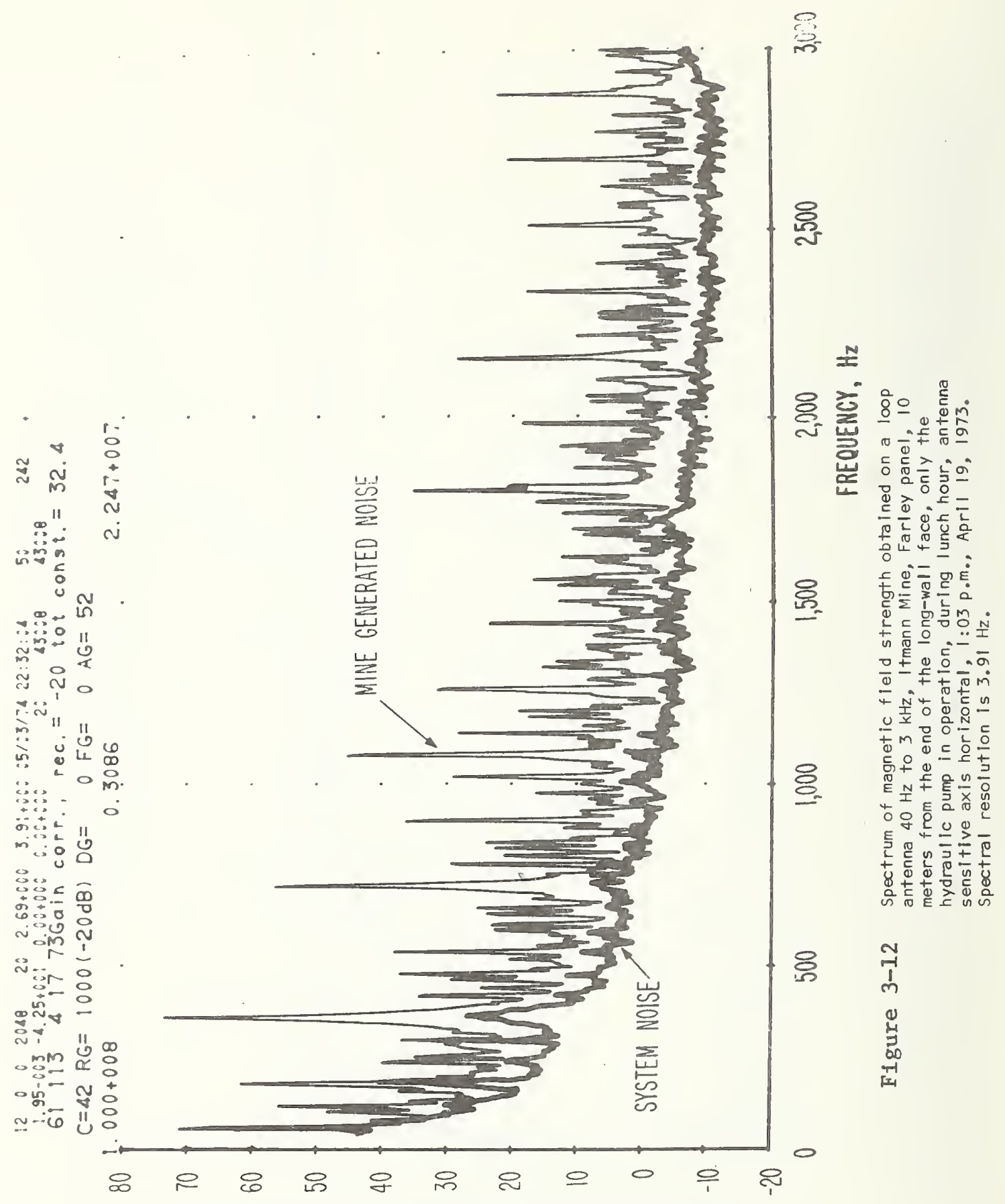

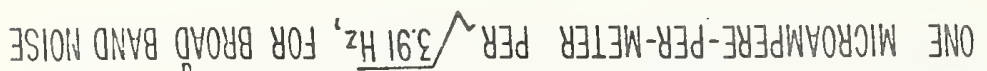

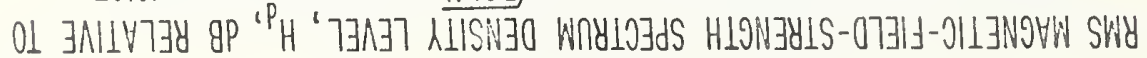

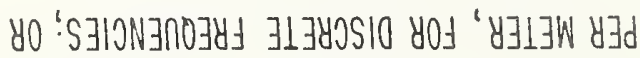

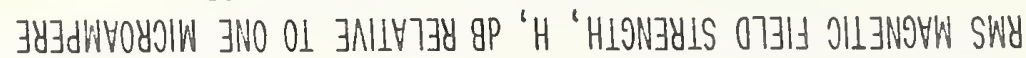




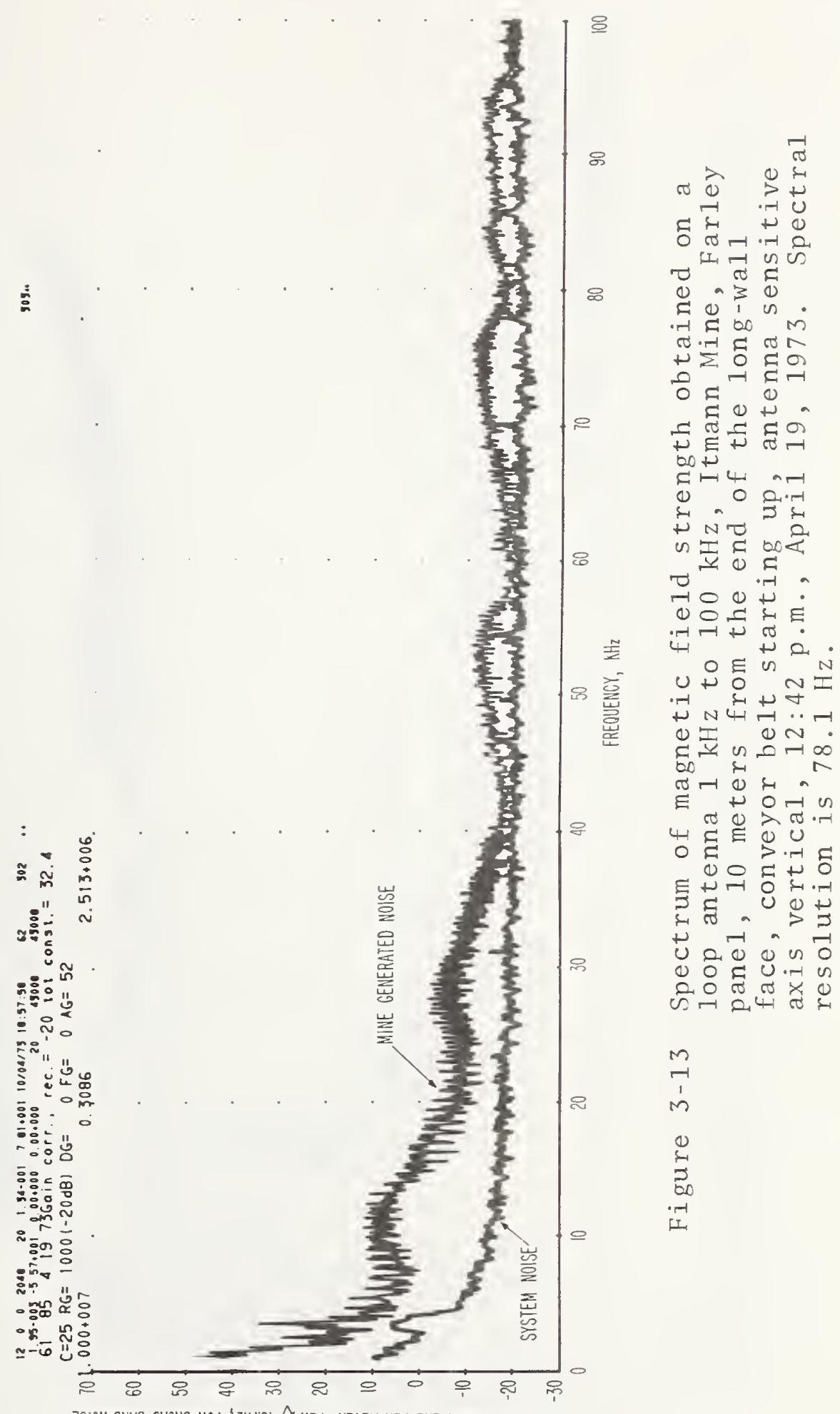

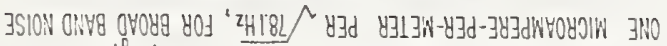

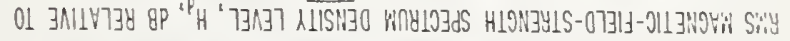

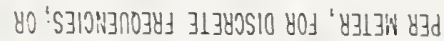

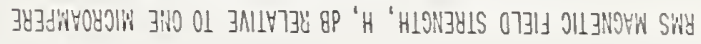




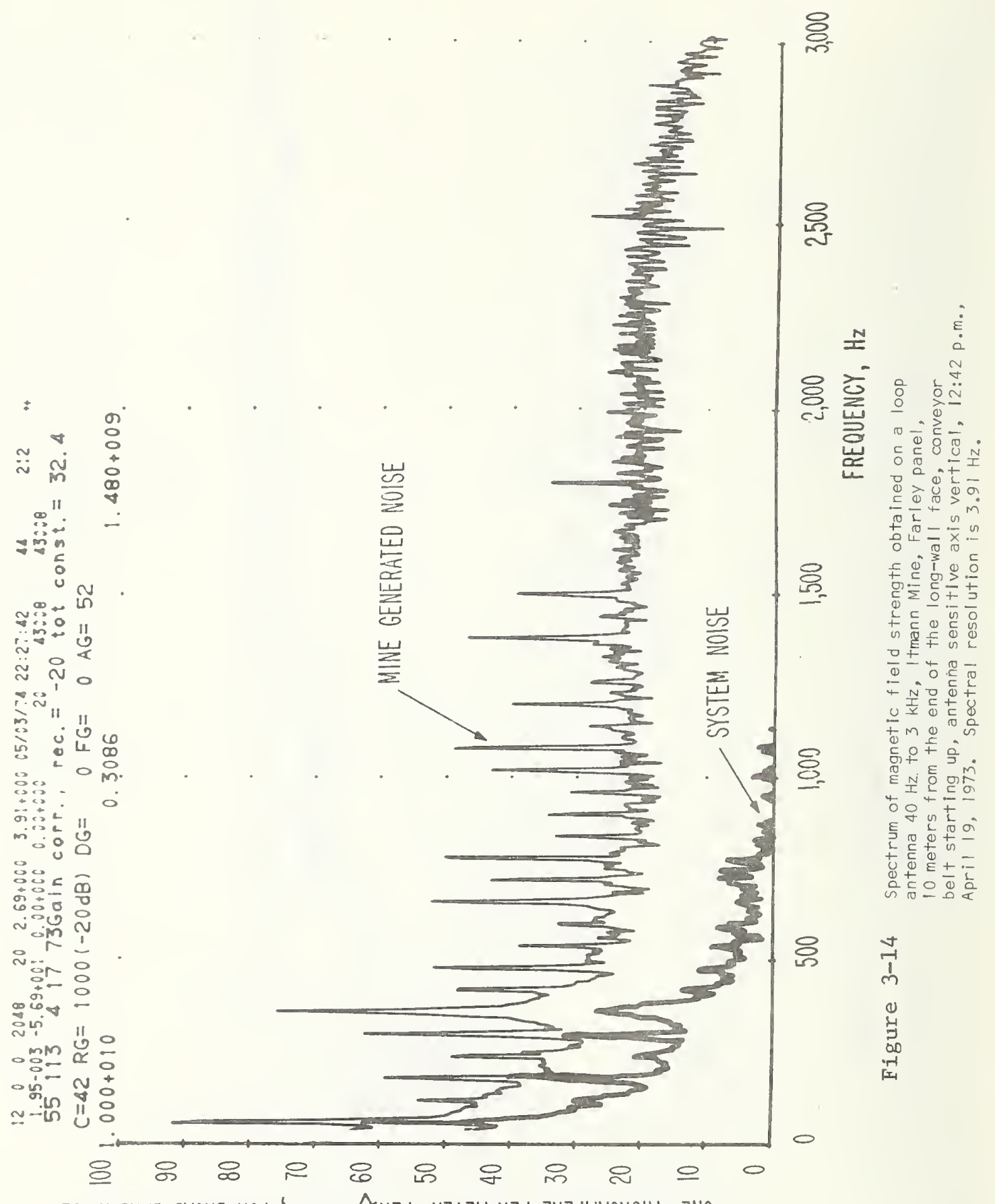

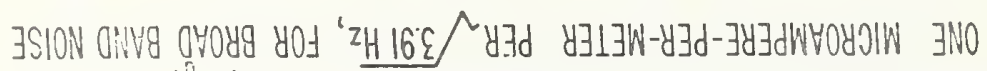

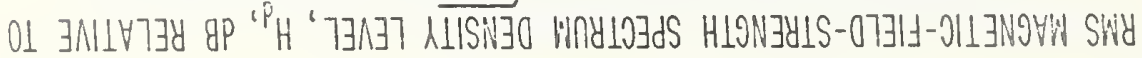

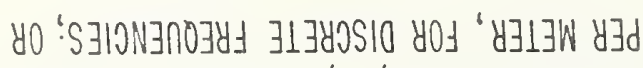

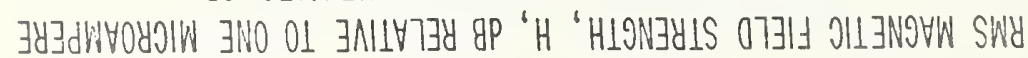




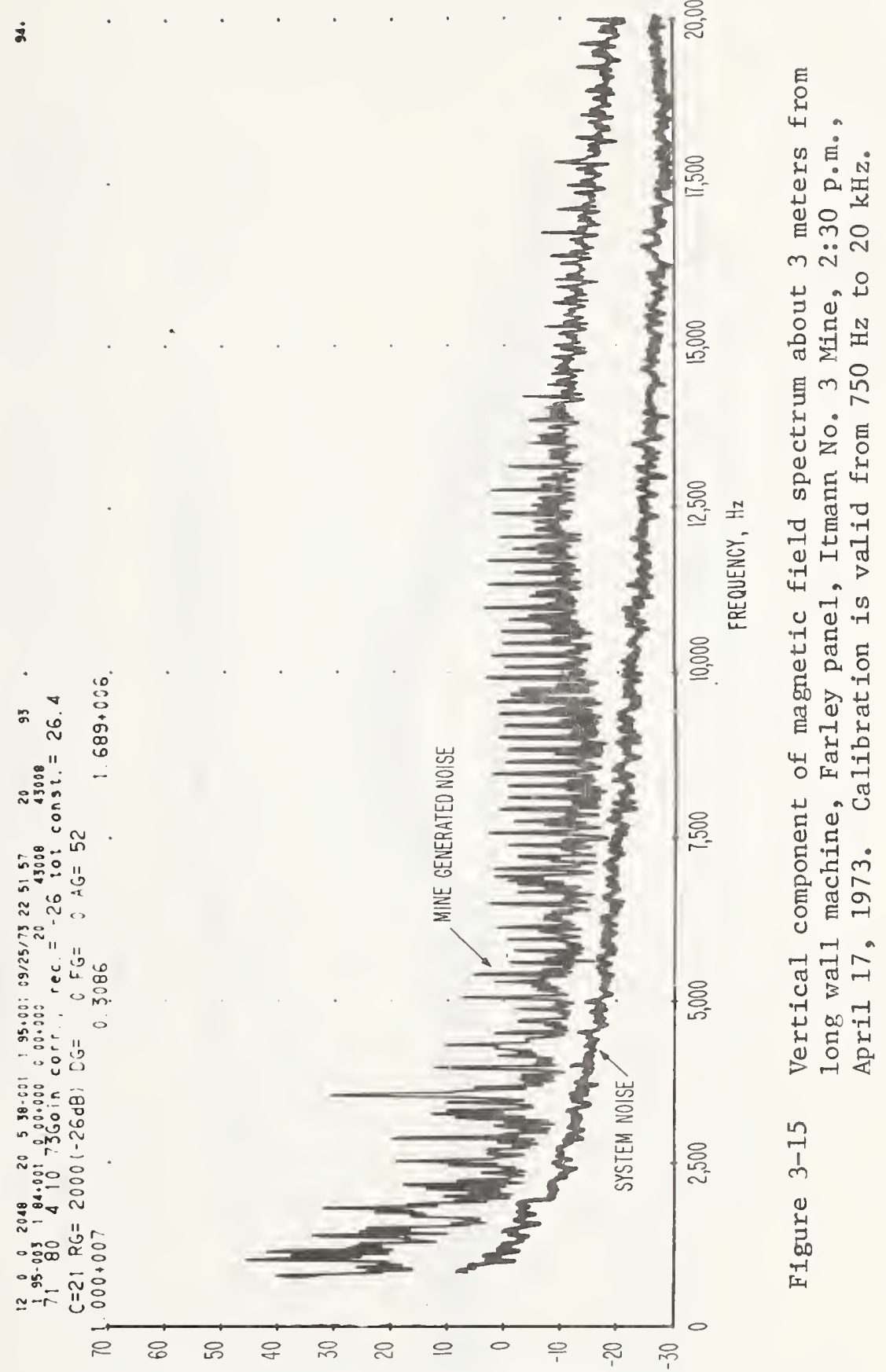

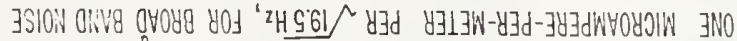

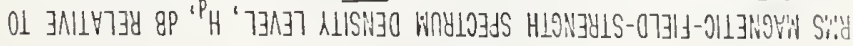

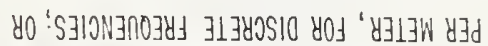

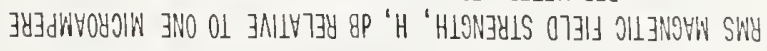




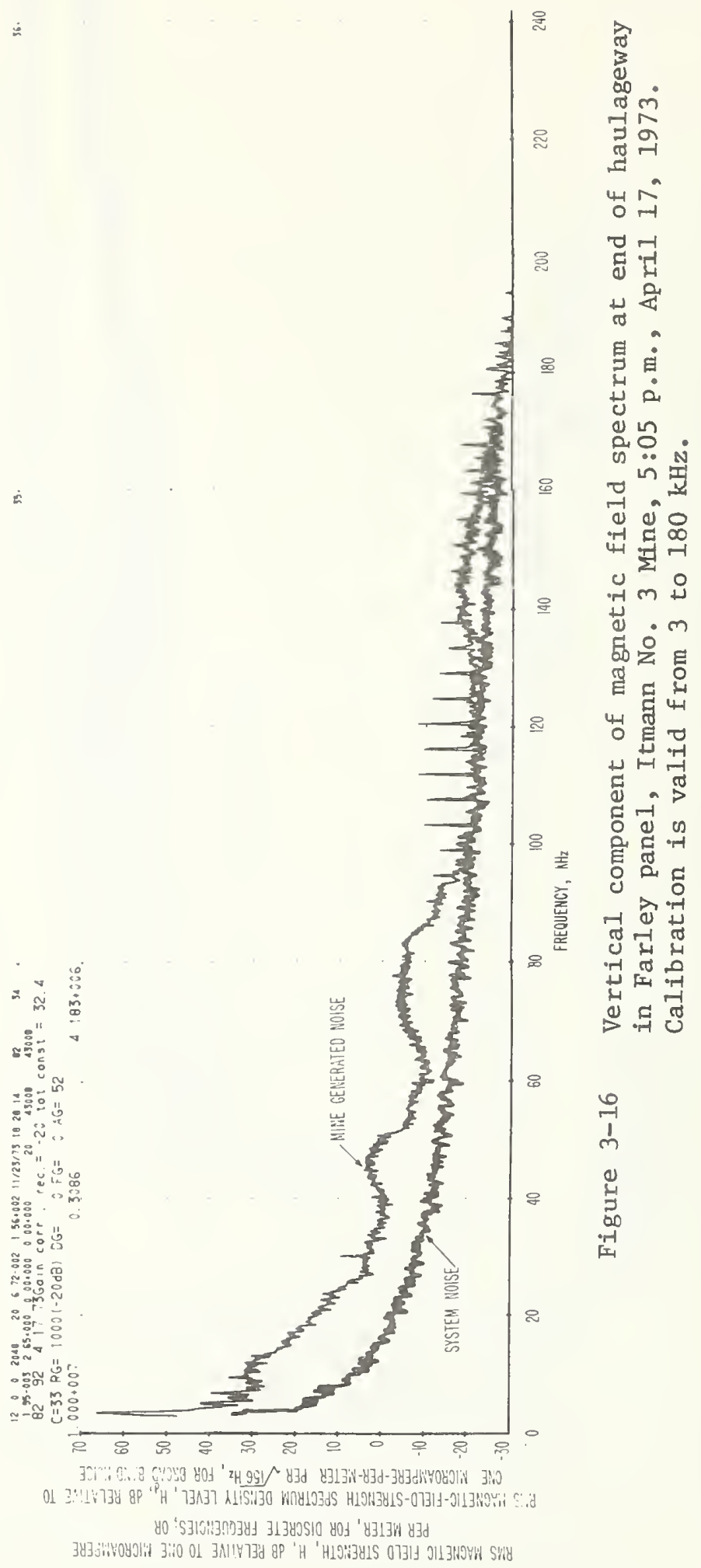




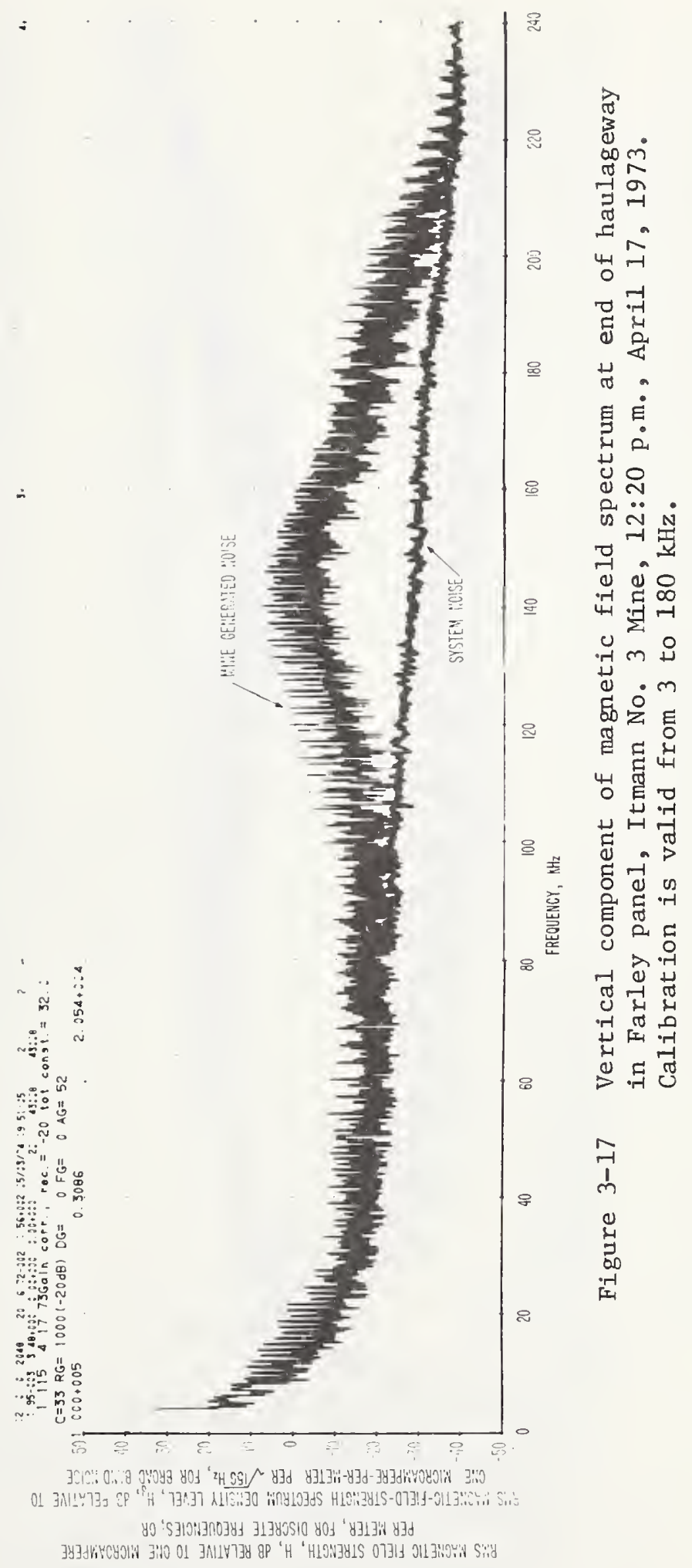




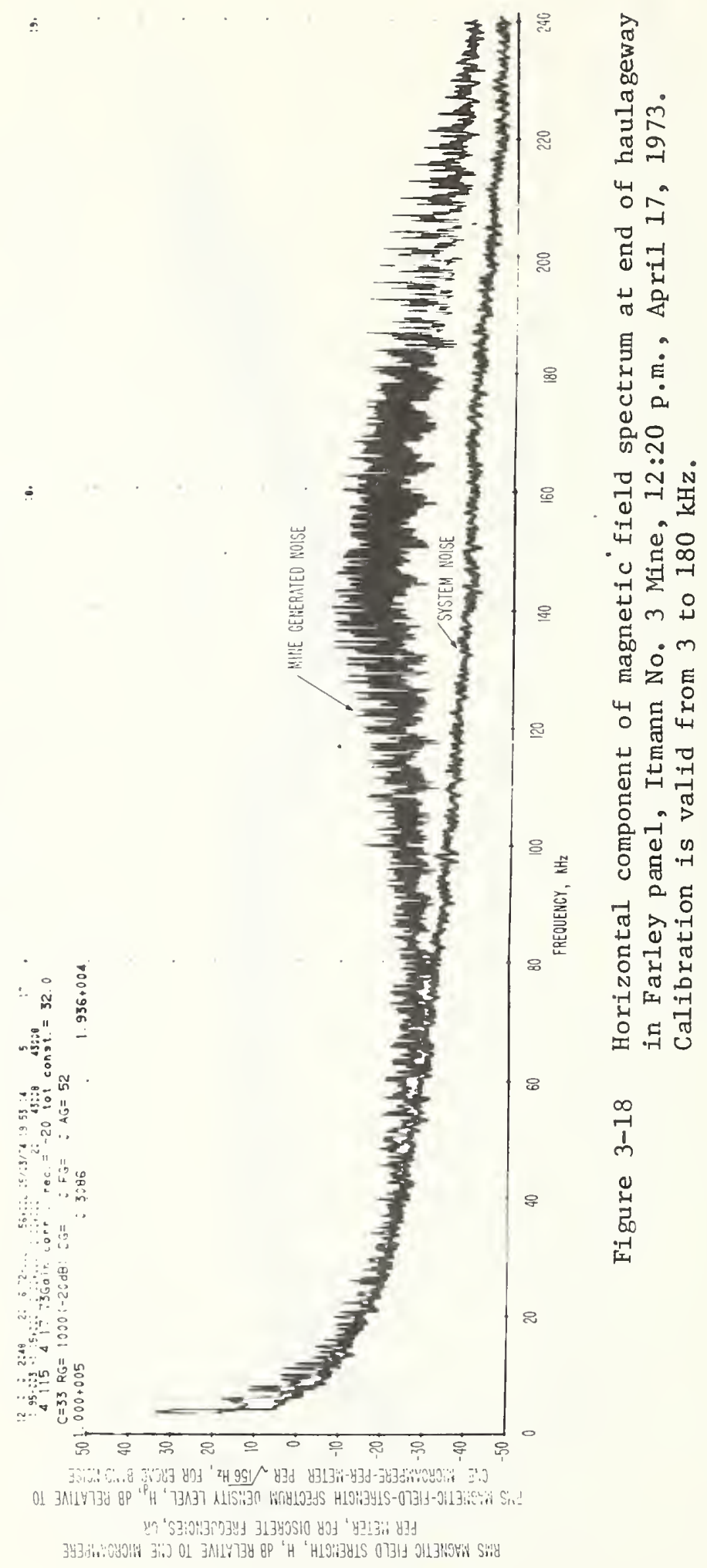




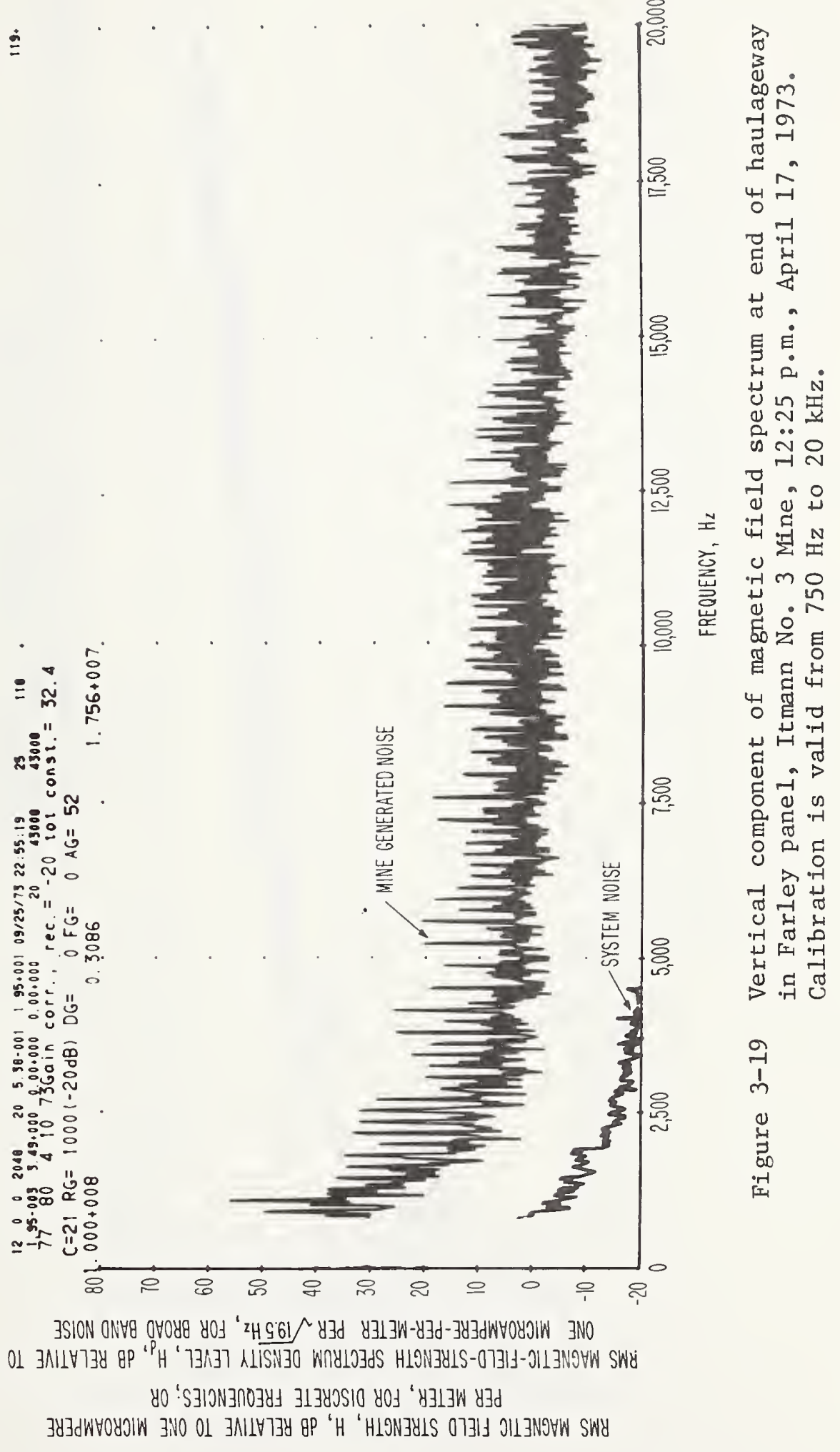




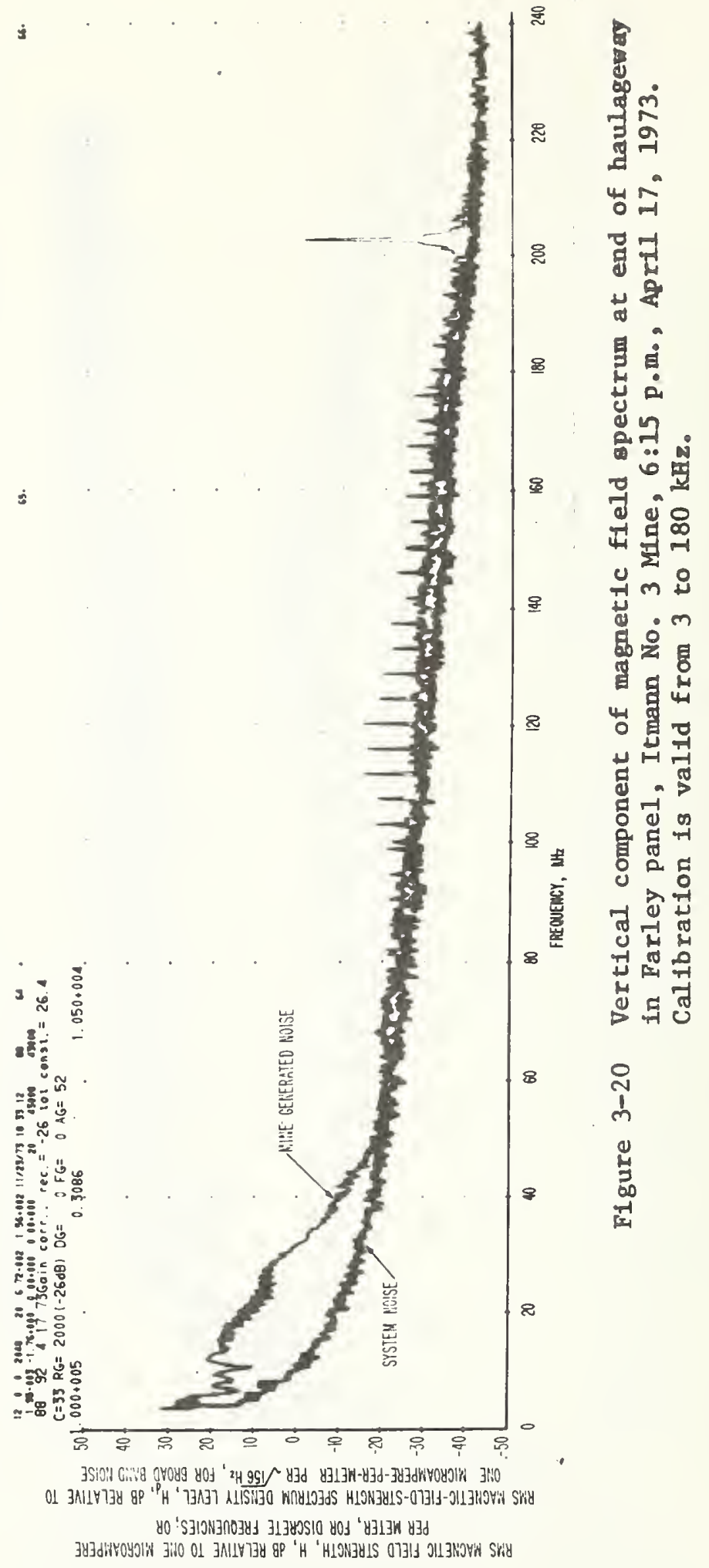




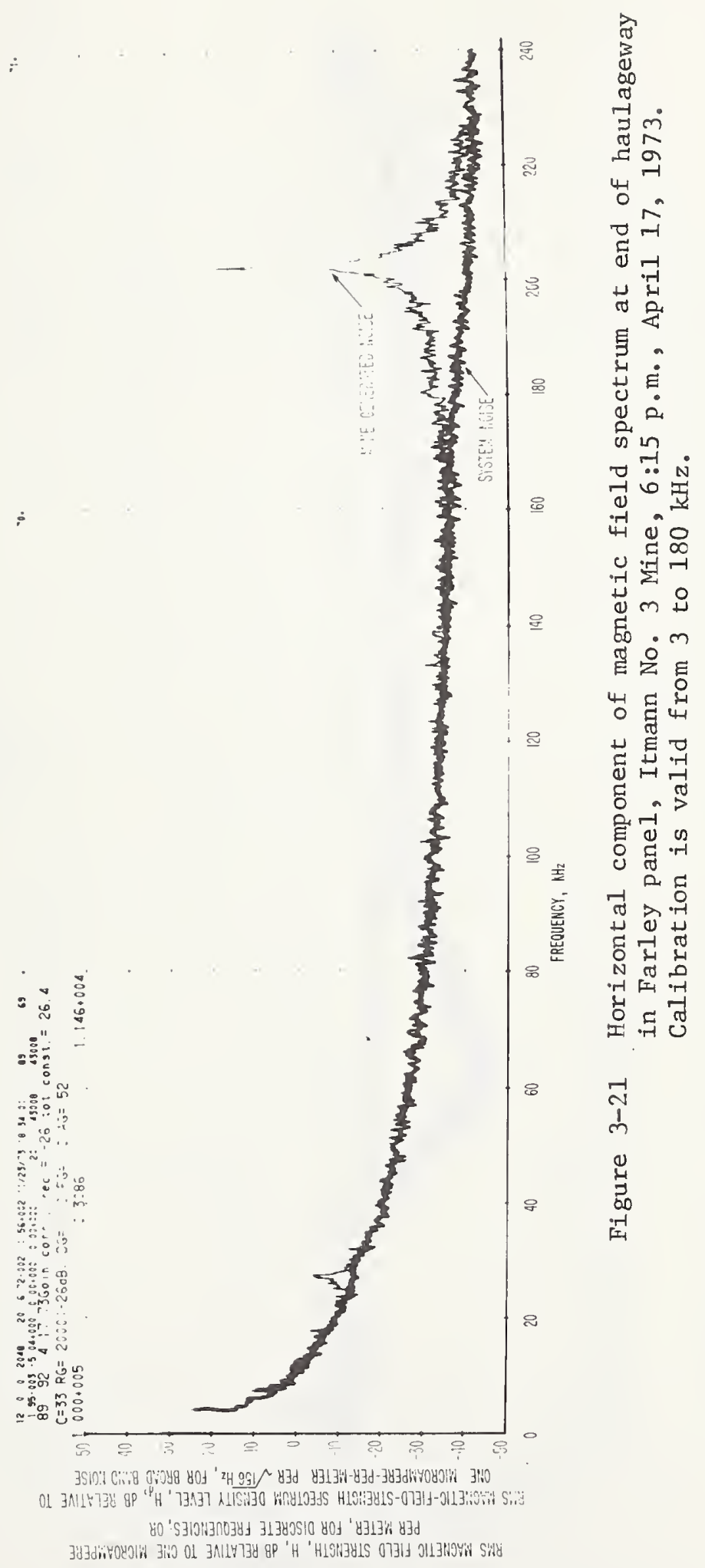




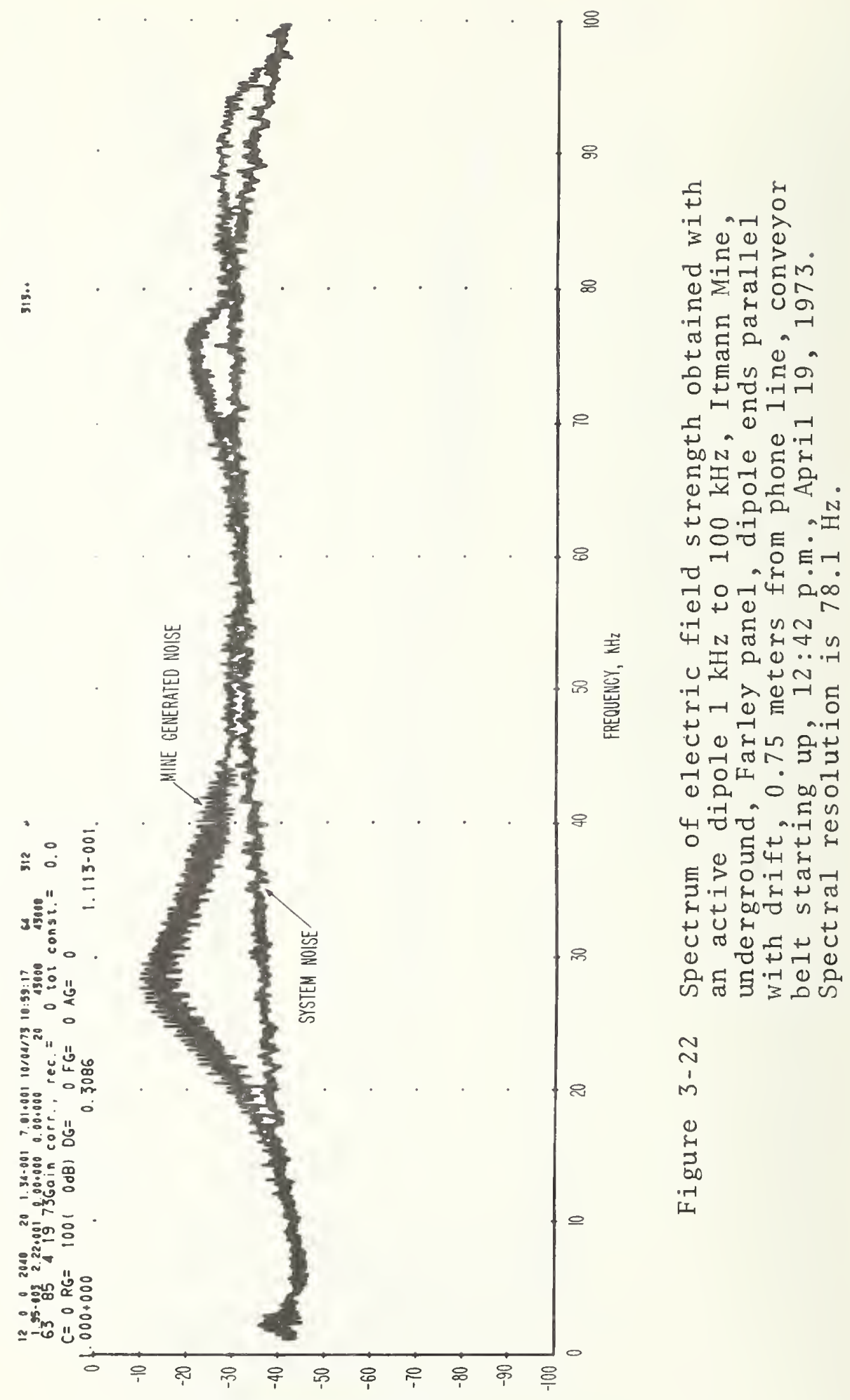

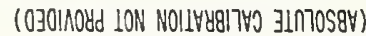

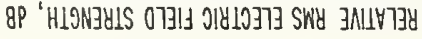




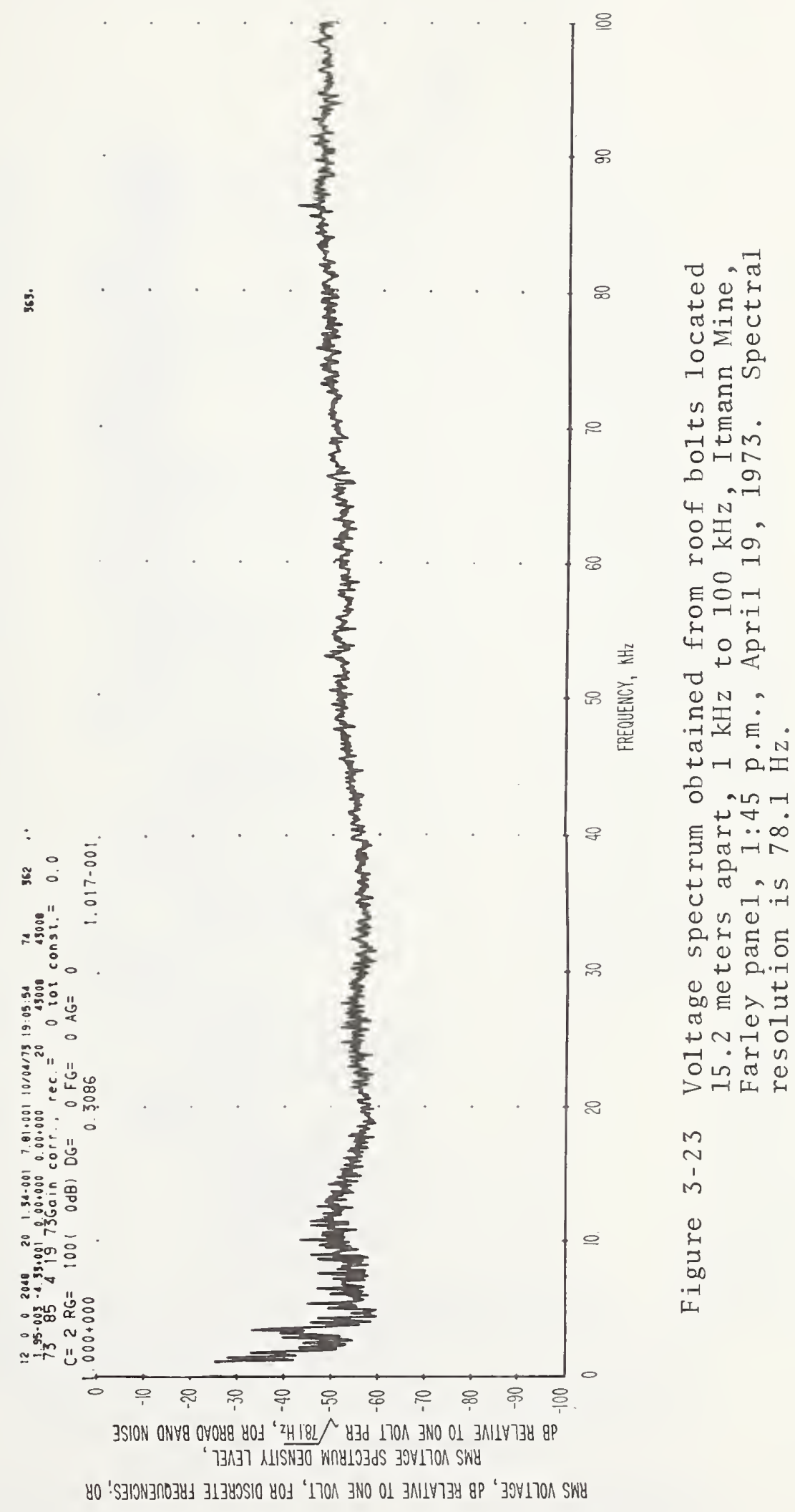




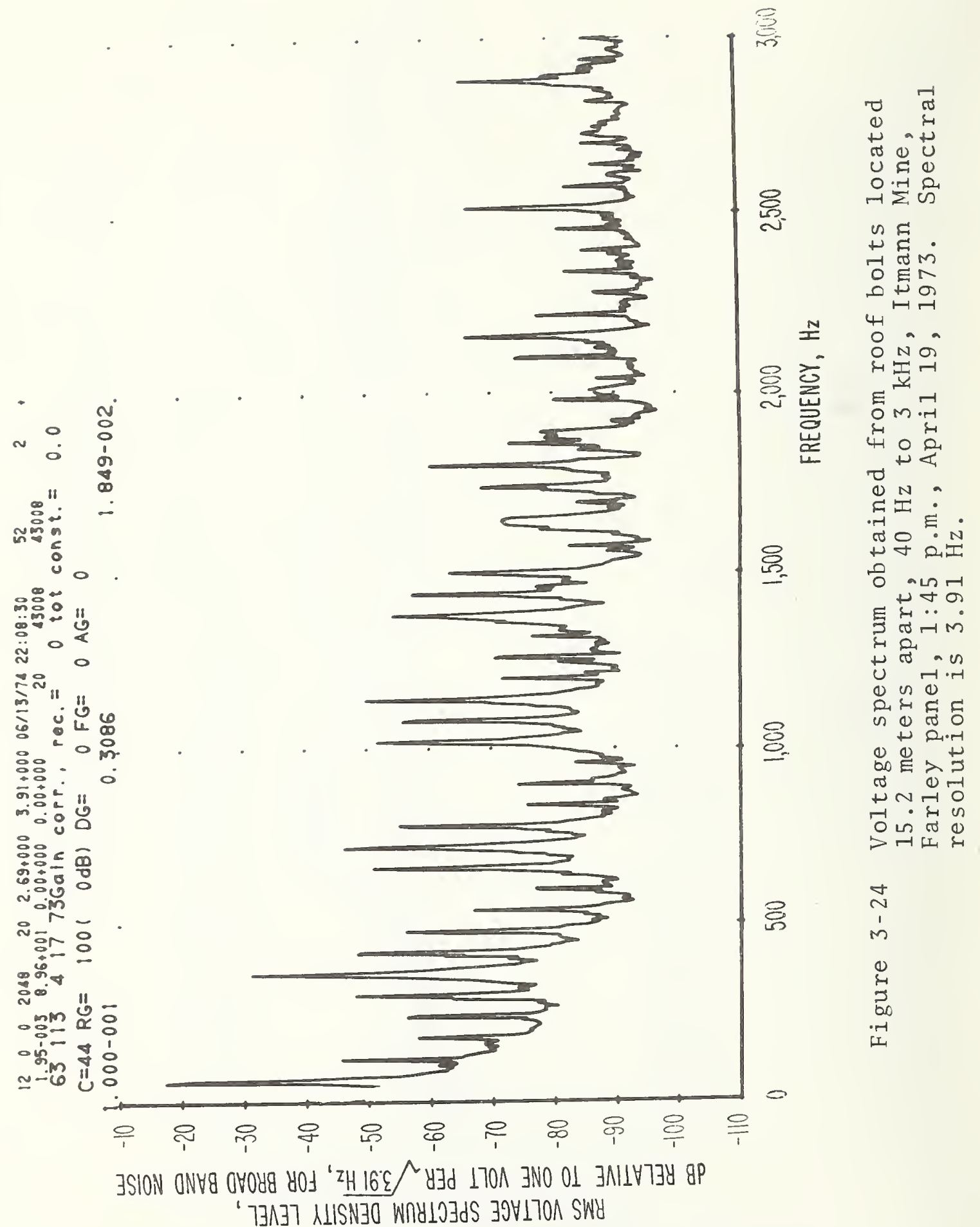

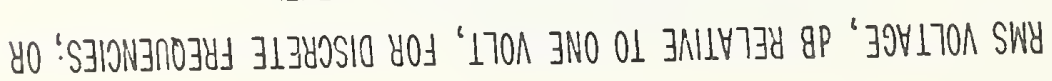




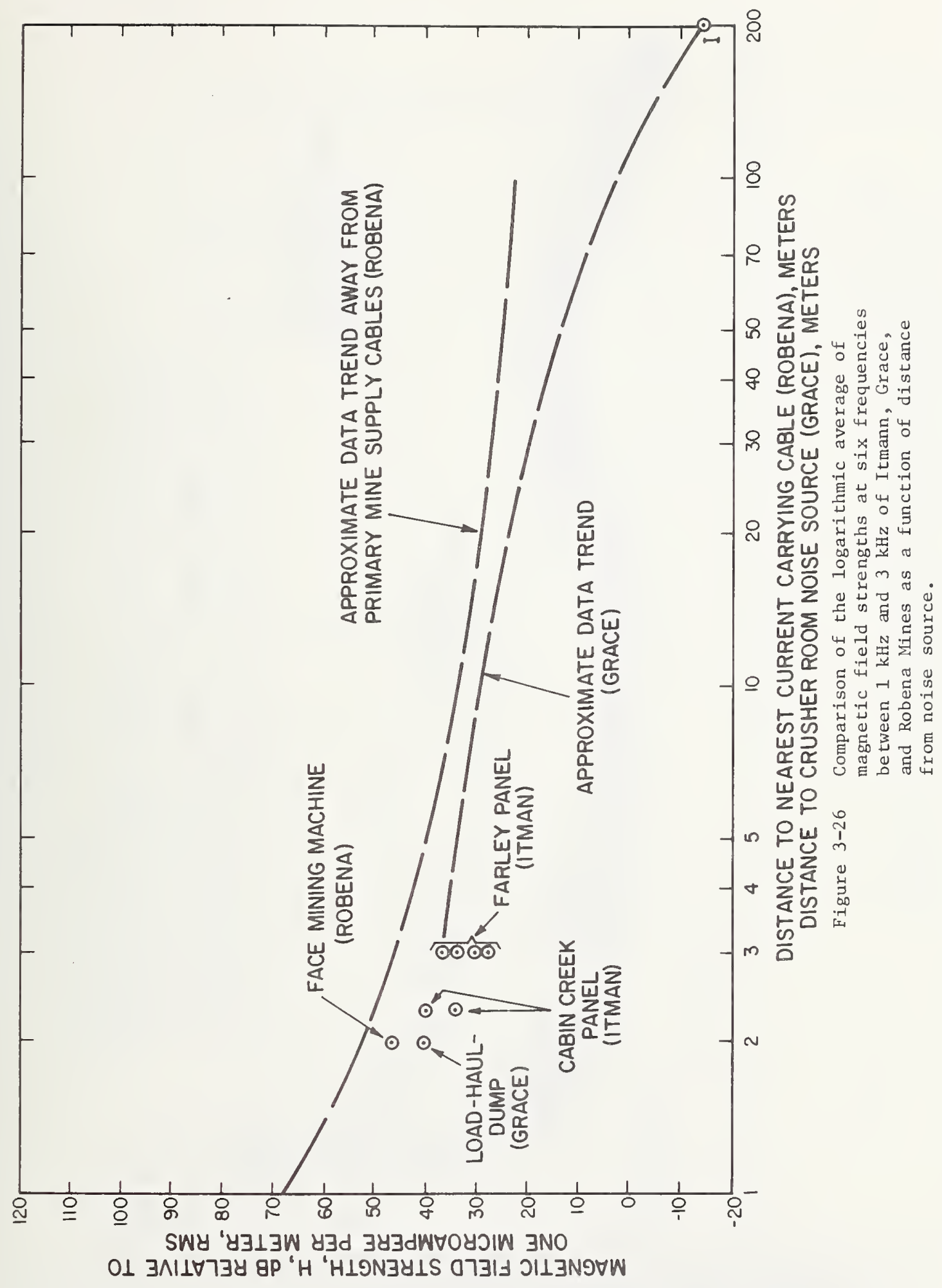




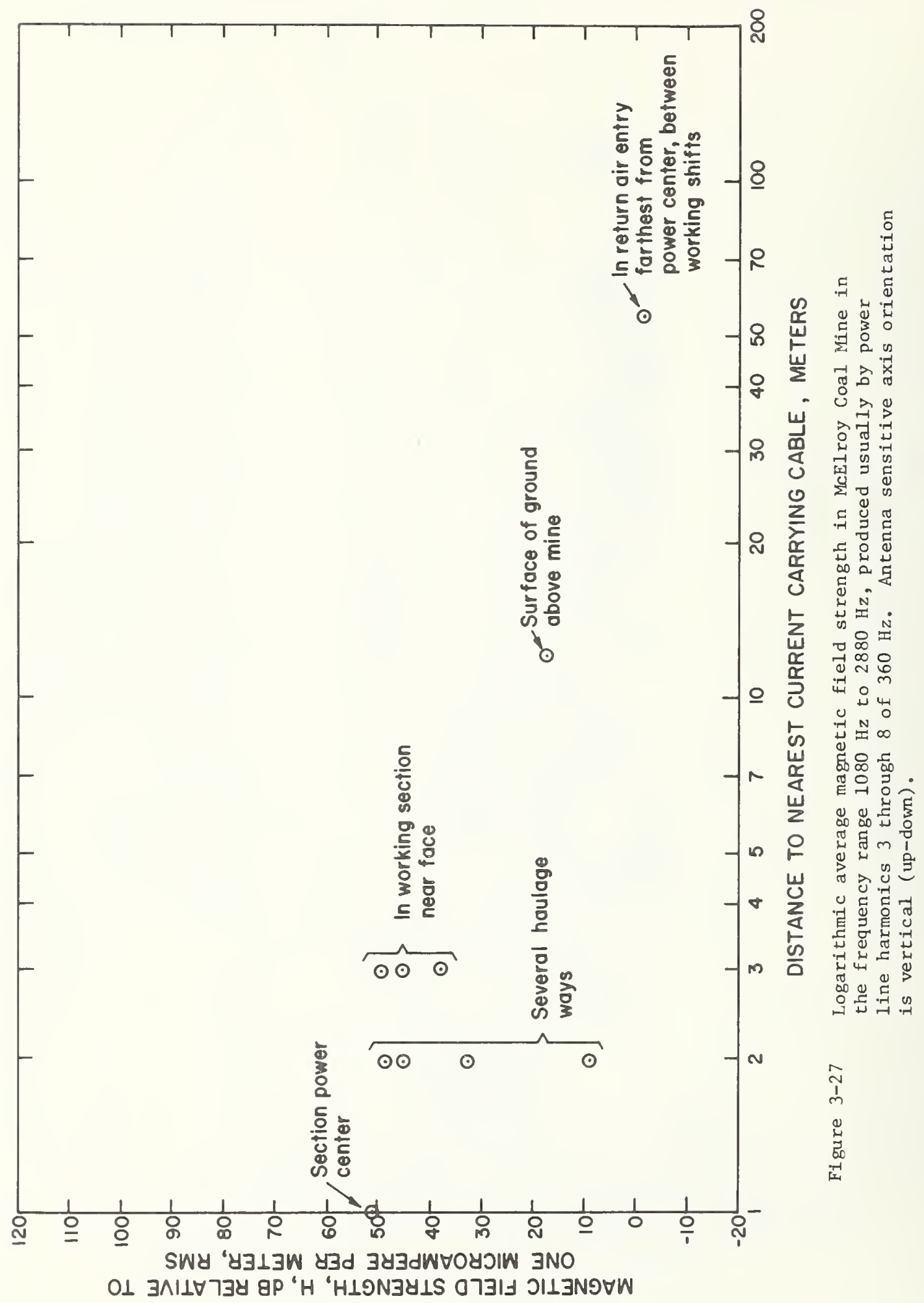




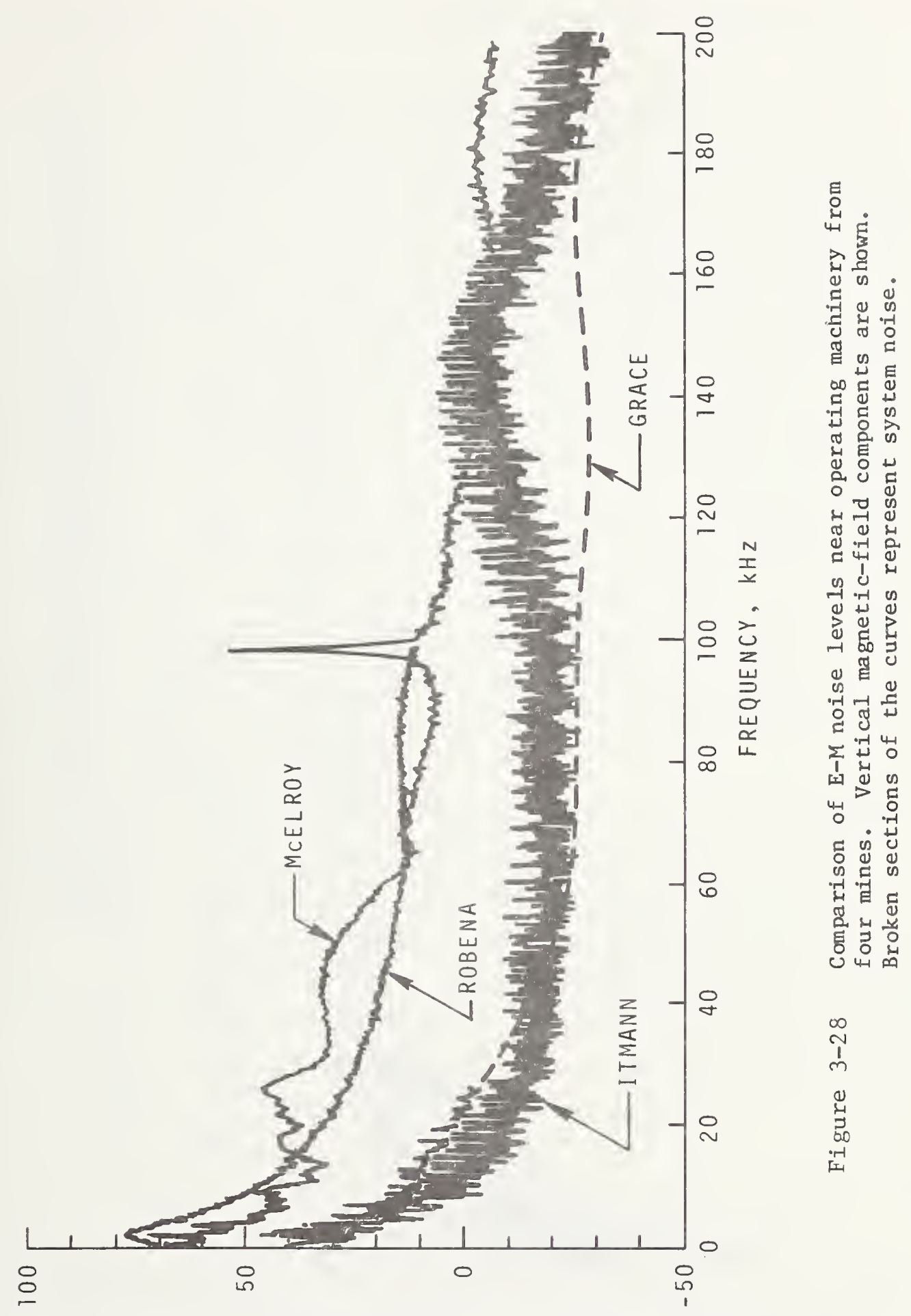

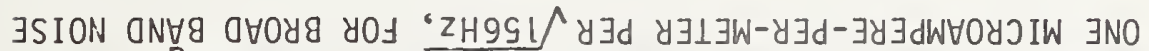

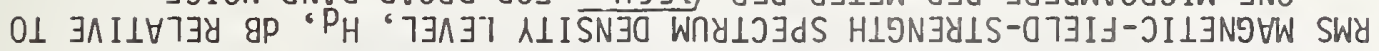

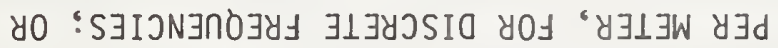

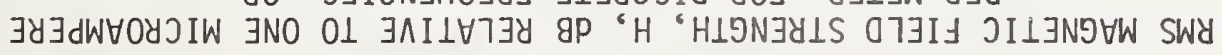




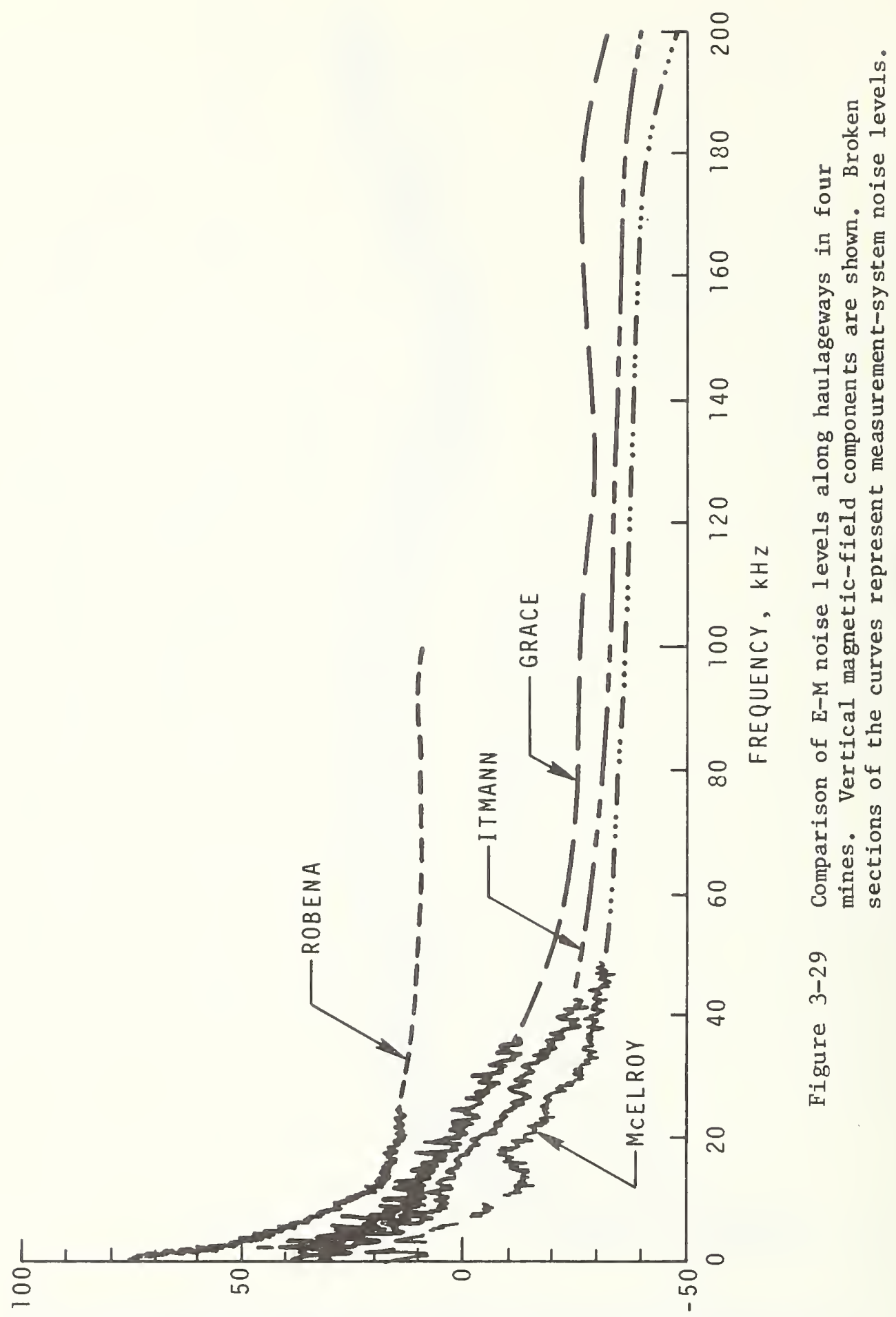

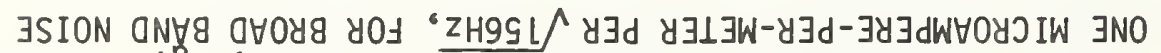

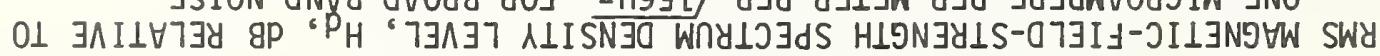
yо :S

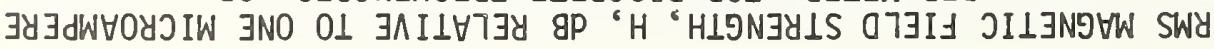




\subsection{Introduction and Uncertainties}

Statistical representations are required since the variations of field strength are, in general, random. The amplitude probability distribution (APD) of the received noise envelope is one of the most useful statistical descriptions of the noise process for the design and evaluation of a telecommunications system operating in a noisy environment $[5,6,8]$.

By plotting the cumulative APD on Rayleigh graph paper, one can show clearly the fraction of time that noise envelope exceeds various levels. Rayleigh graph paper is chosen with scales such that a Rayleigh distribution (i.e., envelope distribution of Gaussian noise) plots as a straight line with slope of $-1 / 2$. Noise with rapid large changes in amplitude (e.g., impulsive noise) then has a much steeper slope, typically -4 or -5 , depending on the impulsiveness of the noise and the receiver bandwidth.

With the exception of the roof-support bolt measurements, a11 APD measurements are reported in absolute quantities.

The estimated limits of error for the APD noise measurements are $\pm 5 \mathrm{~dB}$. Several sources of error that are critical to the overall accuracy of our measurements are listed below:

1. Use of a discrete, digital level counter (levels are $6 \mathrm{~dB}$ apart) contributes \pm 1 -dB quantization error limit. One-decibel step attenuators are used to achieve the \pm one decibel.

2. The system, i.e., recording, data transcribing, and data processing, has a calibration uncertainty of $\pm 0.5 \mathrm{~dB}[4]$.

3. The estimated uncertainty involved in using the portable and the laboratory tape recorders for record and playback is $\pm 0.5 \mathrm{~dB}$ due to harmonic distortion, flutter, dropout, cross-talk, etc. 
4. The gain instability during measurements, gain changes between measurements and calibration, and the non-linearity of electromagnetic interference and field strength (EIFS) meters and mixers, all combined, contribute $\pm 0.5 \mathrm{~dB}$ uncertainty.

5. The gain instability and non-linearity of the digita1 level counter, the tuned frequency converter, the amplifier, and attenuators, all combined, contribute $\pm 0.5 \mathrm{~dB}$ uncertainty .

6. Connector losses and BNC cable losses, particularly at higher frequencies above $100 \mathrm{kHz}$, contribute $\pm 2.0 \mathrm{~dB}$ uncertainty.

Some additional uncertainty beyond the stated measurement system uncertainty is caused by the in-mine environment. Care was taken to provide at least one meter separation from metallic objects wherever possible. However, coal, rock, or earth was sometimes immediately adjacent to a loop antenna. In all observed cases, this had no effect at frequencies up to $1 \mathrm{MHz}$. Above $1 \mathrm{MHz}$, earth and other reflections did in some cases cause \pm 1 dB variations, even with a shielded, balanced loop antenna. An estimate is that an additional $\pm 5 \mathrm{~dB}$ uncertainty might be advisable. However, due to the complexity of the shielded loop in the mine environment, this uncertainty cannot be rigorously bounded without substantial additional analysis .

\subsection{Results}

\subsubsection{Introduction}

APD measurements were made on Apri1 17. and 19, 1973, during operation in the Itmann \#3 Coal Mine located near Mullens, southwest of Beckley, West Virginia. Descriptions of this mine are given in section 1.2. APD measurements were 
made at three locations. The first set of APD measurements was made on April 17, 1973, at Cabin Creek panel. Here, APD measurements were made both during the operation of the mine and during a period when the mining equipment was turned off. In addition, APD measurements between roof-support bolts were performed. The second set of APD measurements was made on April 17 at Farley panel, and the third set of measurements was made on April 19 at the headpiece for the main conveyor belt for Farley panel beside the mainline rail haulage. In these sets of APD measurements, only the vertical components of magnetic field were measured. In addition, APD measurements between roof-support bolts were performed at the Farley headpiece on Apri1 19, 1973.

\subsubsection{Measurement Results}

Figures 4-1 through 4-12 show the APD's of the vertical component of the magnetic rield noise measured during operation of the mine at Cabin Creek panel, location A, figure 3-1, on Apri1 17, 1973. APD's measured during a period when mining equipment was not operating are shown in figures 4-13 through 4-19. In these "quiet" measurements (with levels that are sometimes higher than during normal operation), the vertical components of magnetic noise were measured at frequencies ranging from $10 \mathrm{kHz}$ to $6 \mathrm{MHz}$. Above $100 \mathrm{kHz}$, the magnetic field strength levels are not substantially different during quiet time compared to normal operation. The harmonics of $88 \mathrm{kHz}$ trolley phones extend to $8 \mathrm{MHz}$, and there are other higher frequency carriers, e.g., $202.5 \mathrm{kHz}$.

Figure 4-20 shows the roof-support bolt measurement made at Cabin Creek pane1, location A in figure 3-1, on April 17, 1973. The separation between the two roof-support bolts was 1.5 meters, and the APD's were measured using non-shielded copper wire connected between the roof-support bolts and 
the electromagnetic intensity and field strength (EIFS) meter. The dc resistance measured with a dc ohmmeter connected to these roof-support bolts was $30 \mathrm{k} \Omega$. The RF impedance measured at $10 \mathrm{kHz}$ using a CW generator, RF voltmeter, and RF current meter was $8 \mathrm{k} \Omega$. It is not easy to analyze what was measured through non-shielded copper wires. It is a combination of electric field coupled through a dipole with a lossy surrounding medium (i.e., coal) and of magnetic field through a lossy loop antenna, and of voltage induced by current flowing through the medium between the roof bolts. Therefore, relative voltage is the parameter given. The rms value is arbitrarily assigned the value $0 \mathrm{~dB}$.

Figures 4-21 through 4-28 show APD measurements of the vertical component of magnetic field noise measured about 70 meters (230 ft.) from the longwall face in Farley panel on April 17, 1973. Figures 4-29 through 4-40 show APD's of the vertical component of magnetic field noise measured at the headpiece for Farley main conveyor belt on April 19, 1973. Generally, the levels at the headpiece are about $20 \mathrm{~dB}$ higher than the levels 70 meters from the face. The length of time for each APD measurement is nominally 20 minutes; for the relatively long work cycle in a longwall mine, 20 minutes is insufficient time to provide statistical validity. Also, along main haulageways, the time required may be much longer than 20 minutes.

Figure 4-41 shows the roof-support bolt measurements made at the Farley headpiece on April 19, 1973. The separation between the two roof-support bolts was one meter, the dc resistance between these roof bolts was $30 \mathrm{k} \Omega$, whereas the RF impedance at $10 \mathrm{kHz}$ was $5.5 \mathrm{k} \Omega$. Again, the units are relative voltage, with the rms value arbitrarily assigned the value $0 \mathrm{~dB}$. 
The APD's are integrated to give rms and average values of the field strength, according to the equations

$$
\mathrm{H}_{\text {avg }}=-\int_{0}^{\infty} \mathrm{H} \mathrm{dp}(\mathrm{H})
$$

and

$$
\mathrm{H}_{\mathrm{rms}}=\left(-\int_{0}^{\infty} \mathrm{H}^{2} \mathrm{dp}(\mathrm{H})\right)^{\frac{1}{2}},
$$

where $H$ represents the magnetic field strength of the noise, and $\mathrm{p}$ is the probability that the measured field strength exceeds the value $H$. These quantities are also dependent on the measurement bandwidth, the length of the data run, and possibly other parameters. Finite series are actually used for the numerical integration. The rms and average values so arrived at are identified on each graph and are time averages (23 minutes) of these time-dependent parameters. If the tapes are played into ordinary rms-reading meters, the meter readings will vary 10 to $20 \mathrm{~dB}$ over fractions of a second. The rms value is directly relatable to noise power. With these wide variations of field strength with time, the most suitable presentations are statistical.

Excursions of field strength between 0.001 and 99 percent, as well as rms and average values, are summarized in figures 4-42 through 4-45. The predetection bandwidth for these APD measurements either is $1 \mathrm{kHz}$ or is normalized to $1 \mathrm{kHz}$. Figure 4-42, vertical component, Cabin Creek, is the summary figure for curves shown in figures 4-1 through 4-12. Figure 4-43, vertical component, quiet time, Cabin Creek, is the summary figure for curves shown in figures 4-13 through 4-19. Figure 4-44, vertical component, Farley Pane1, is the summary figure for curves shown in figures 4-21 through 4-28. Figure 4-45, 
vertical component, Farley Headpiece, is the summary figure for curves shown in figures 4-27 through 4-40.

Magnetic field strength generally decreases monotonically with increasing frequency at $20 \mathrm{~dB}$ per decade. A significant exception occurred during "quiet" time. Possibly due to the heavy use of $88 \mathrm{kHz}$ trolley phones (with their attendant harmonics), during this period, the levels from $100 \mathrm{kHz}$ to $6 \mathrm{MHz}$ were frequency independent, and higher than during normal operation at the higher frequencies. 


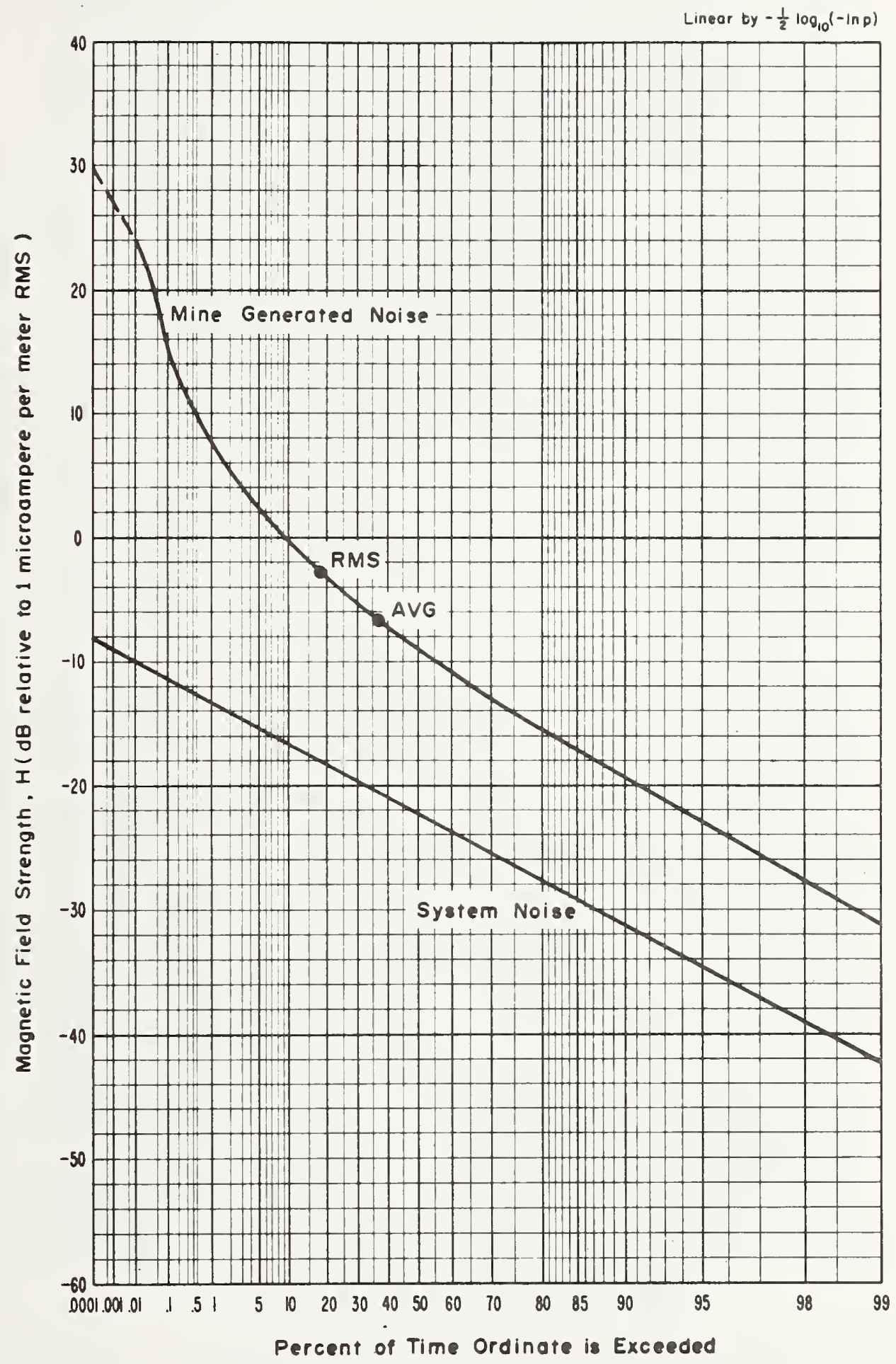

Figure 4-1 APD, $10 \mathrm{kHz}$, vertical component, $1.0 \mathrm{kHz}$ predetection bandwidth, Apr11 17, 1973, 11:40 a.m., Cabin Creek, Itmann \$3. 


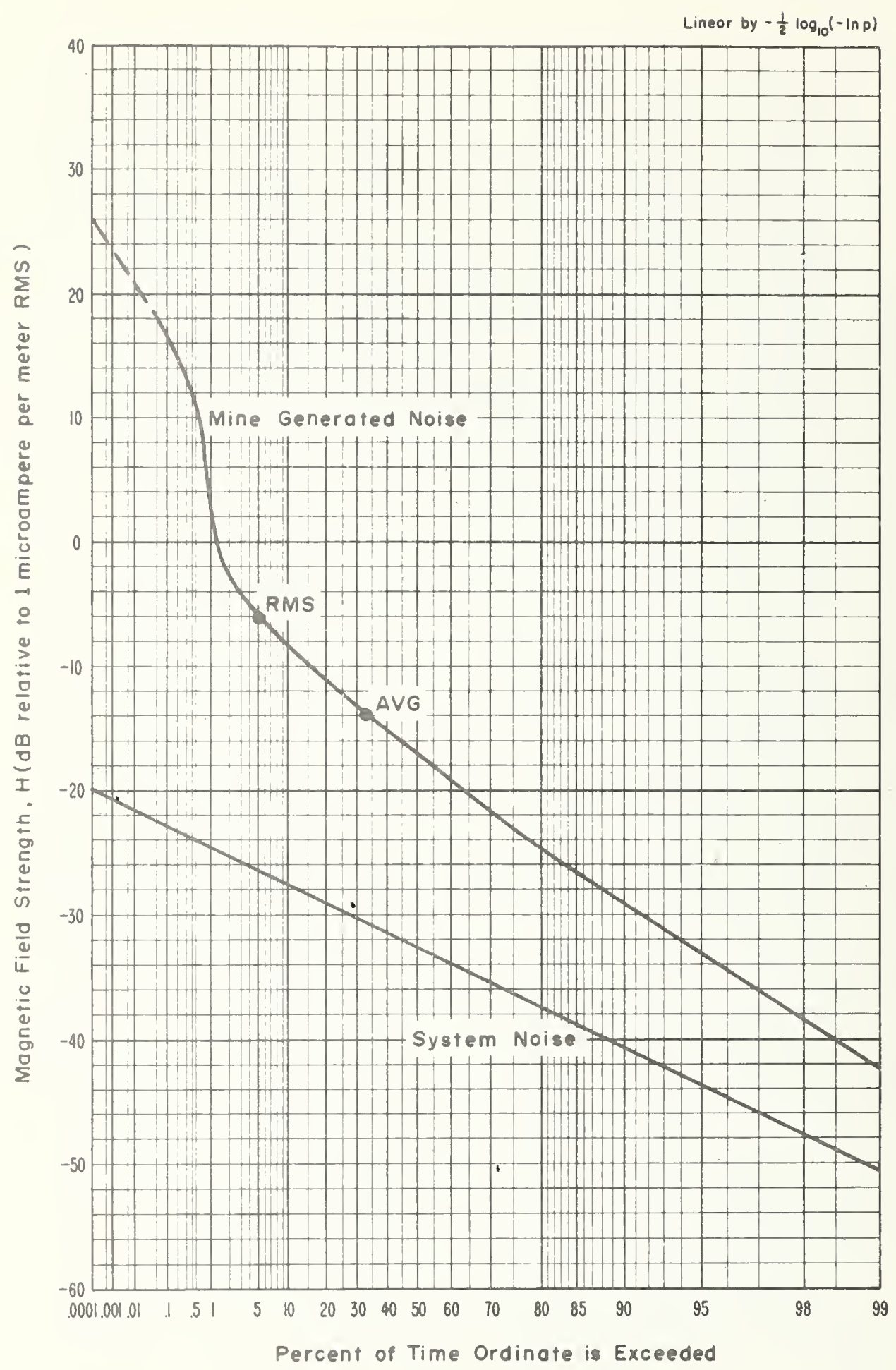

Figure 4-2 APD, $30 \mathrm{kHz}$, vertical component, $1.0 \mathrm{kHz}$ predetection bandwidth, Apri1 17, 1973, 12: 20 p.m., Cabin Creek, Itmann \#3. 


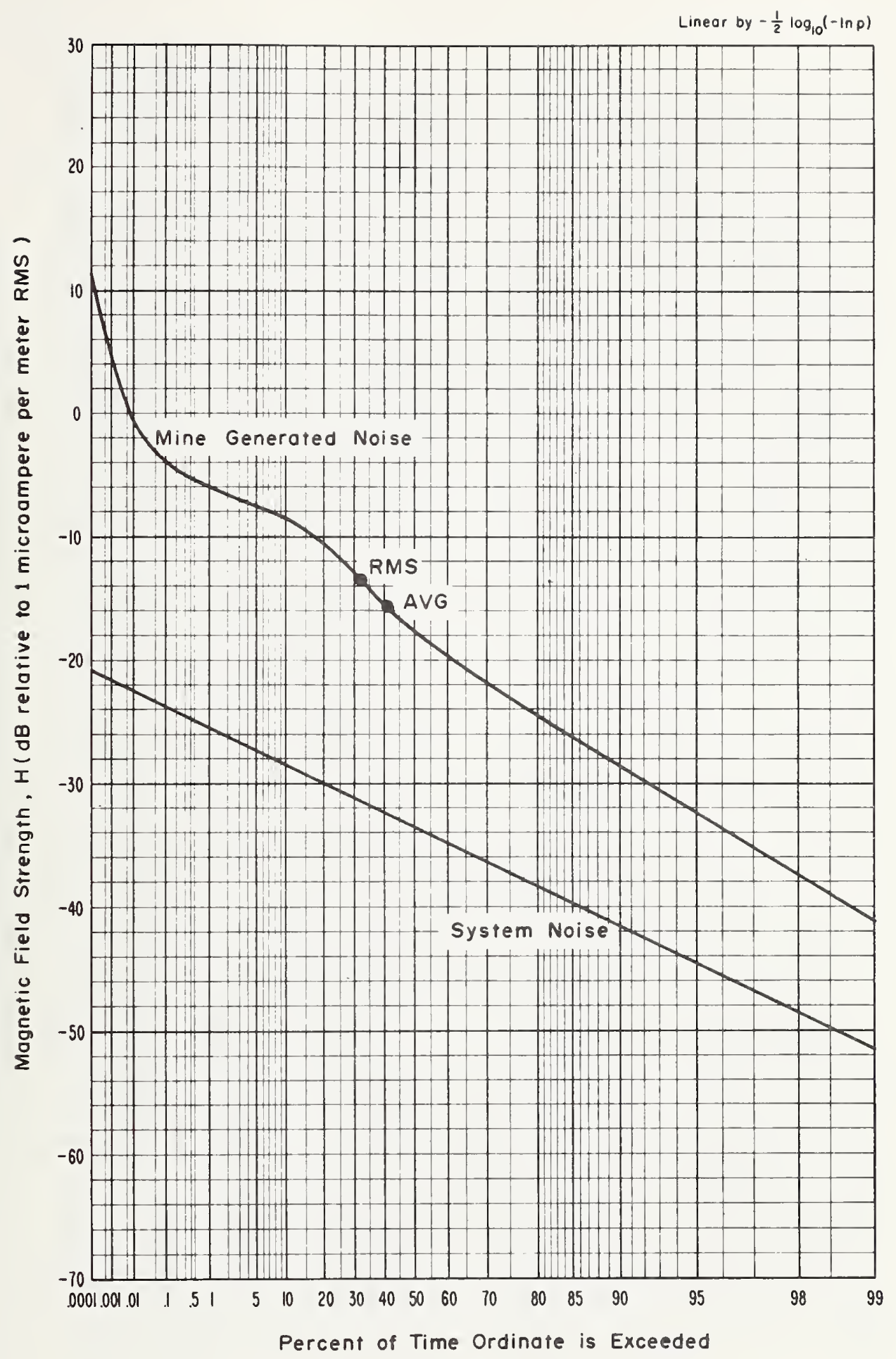

Figure 4-3 APD, $70 \mathrm{kHz}$, vertical component, $1.0 \mathrm{kHz}$ predetection bandwidth, Apri1 17, 1973, 12:50 p.m., Cabin Creek, Itmann \#3. 


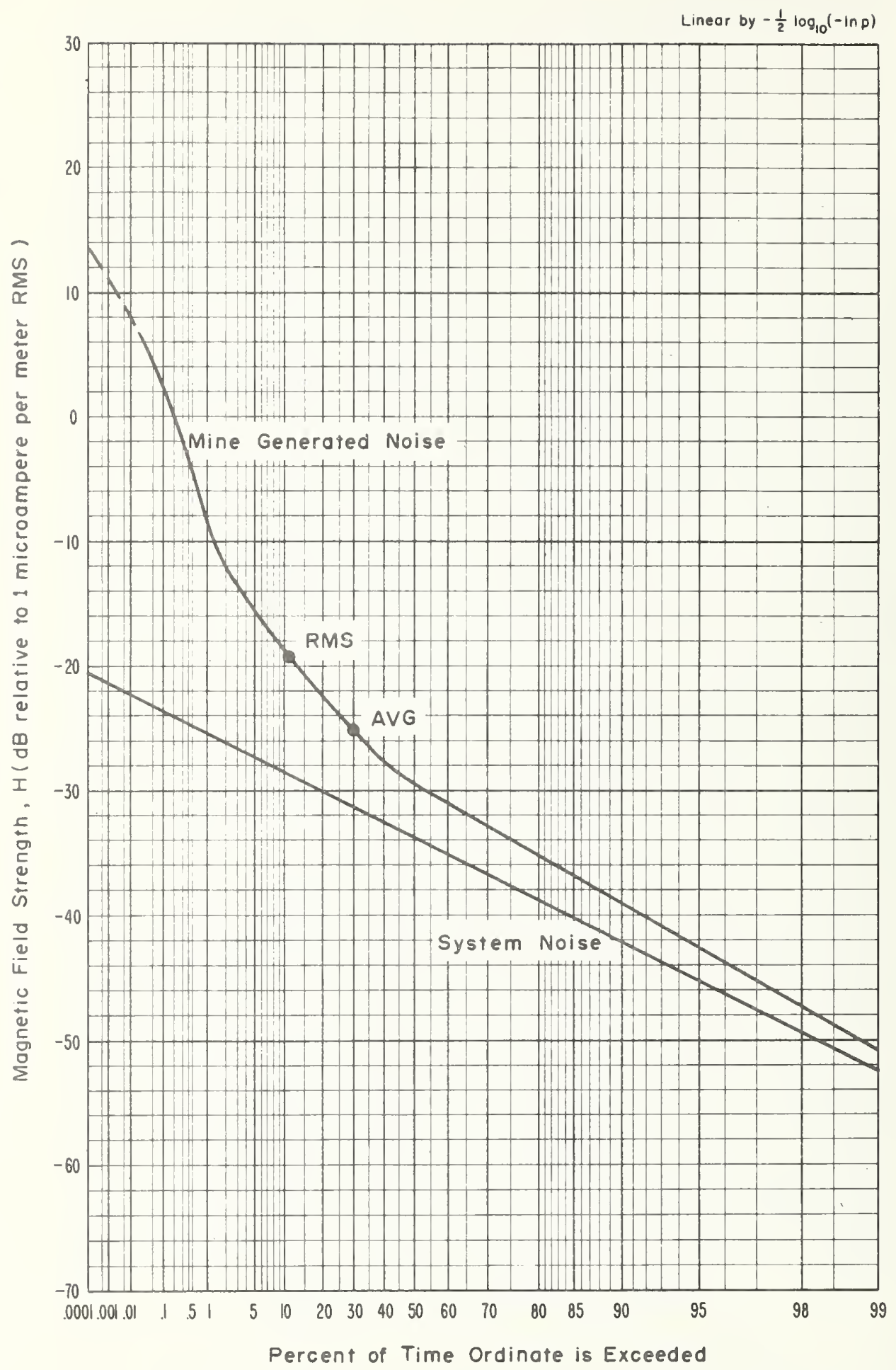

Figure 4-4 APD, $130 \mathrm{kHz}$, vertical component, $1.0 \mathrm{kHz}$ predetection bandwidth, Apri1 17, 1973, 1:30 p.m., Cabin Creek, I tmann \#3. 


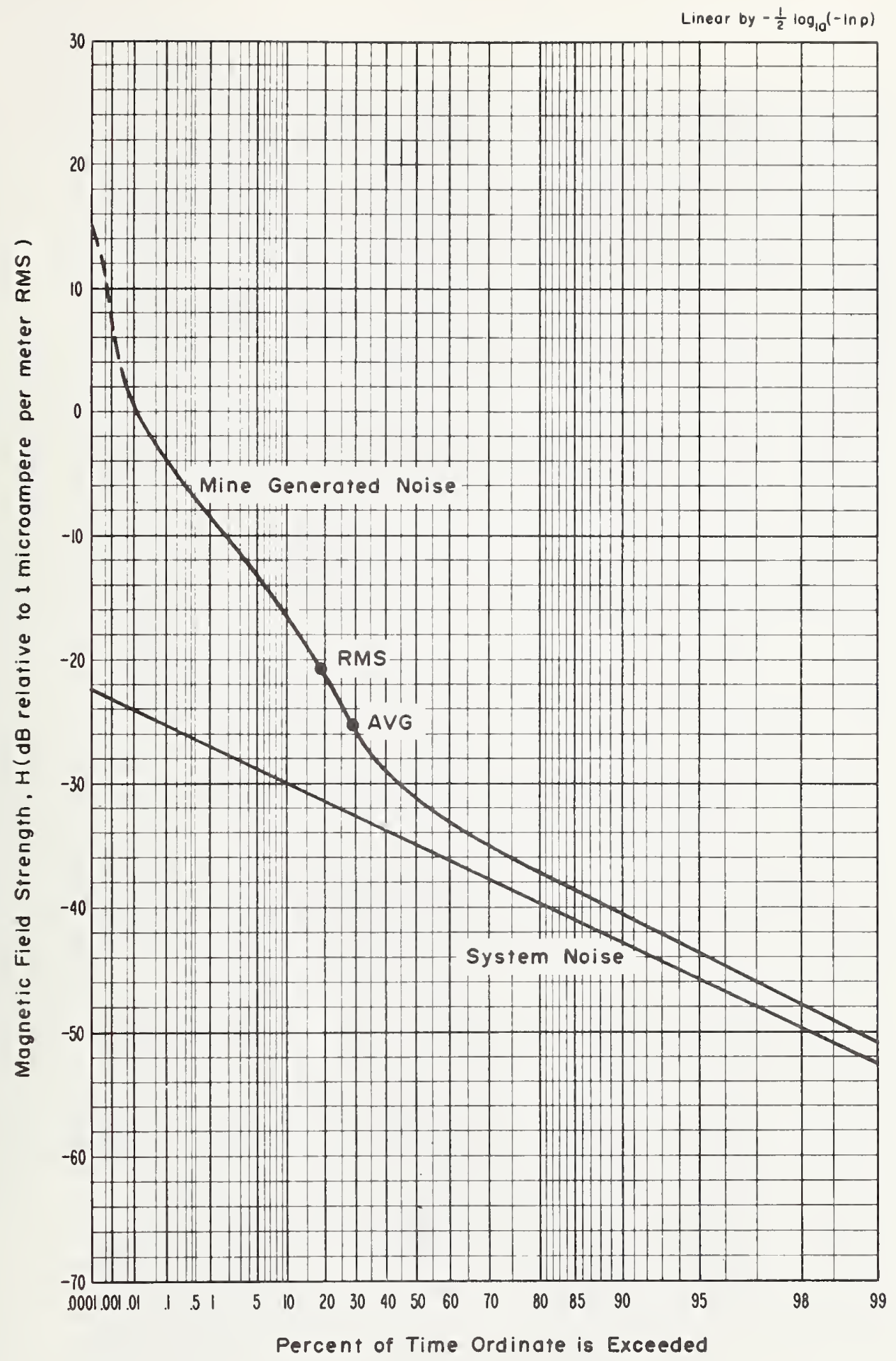

Figure 4-5 APD, $160 \mathrm{kHz}$, vertical component, $1.0 \mathrm{kHz}$ predetection bandwidth, April 17, 1973, 2: 20 p.m., Cabin Creek, Itmann \#3. 


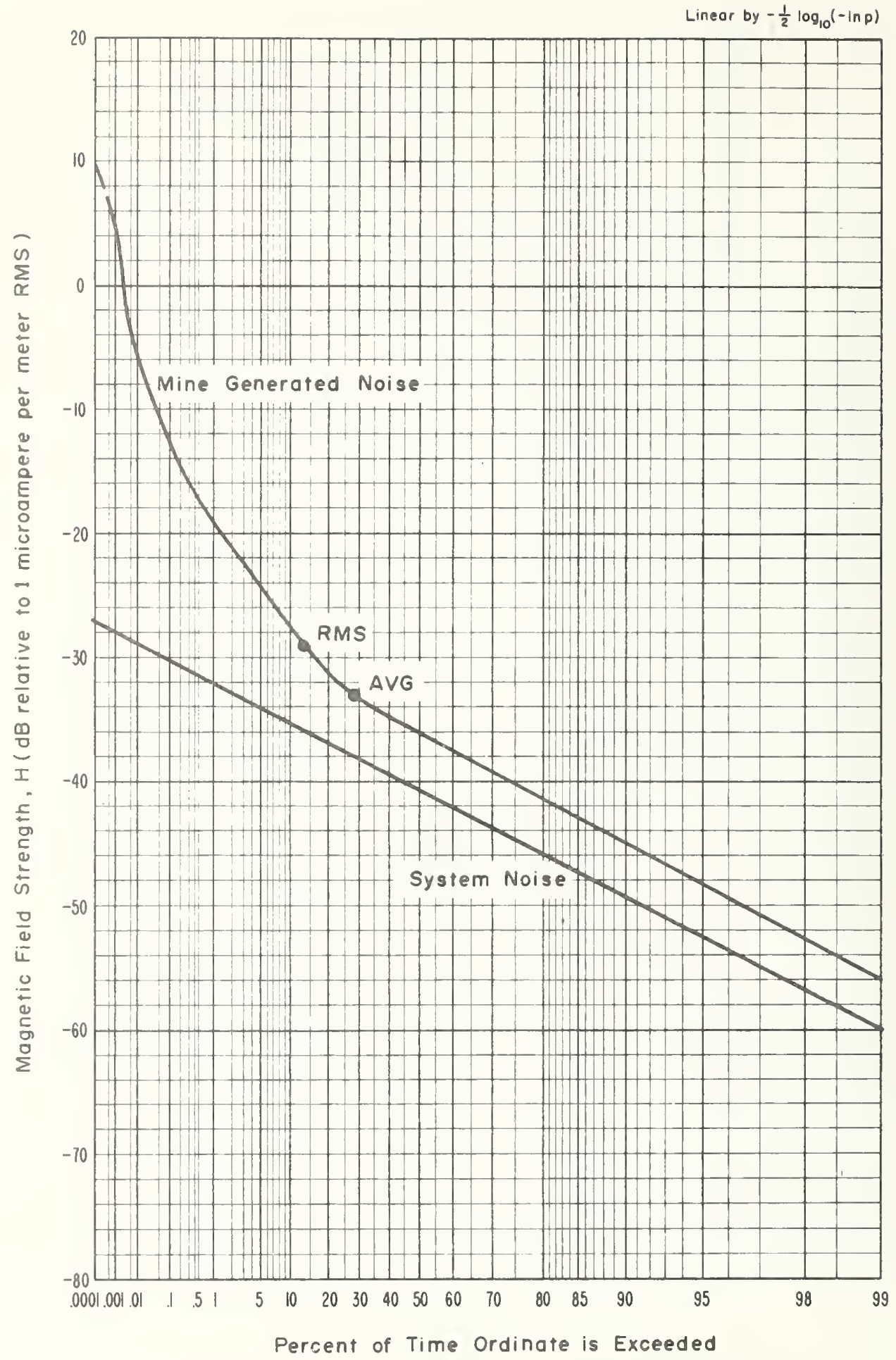

Figure 4-6 APD, $250 \mathrm{kHz}$, vertical component, $1.0 \mathrm{kHz}$ predetection bandwidth, Apri1 17, 1973, 3:00 p.m., Cabin Creek, Itmann \#3. 


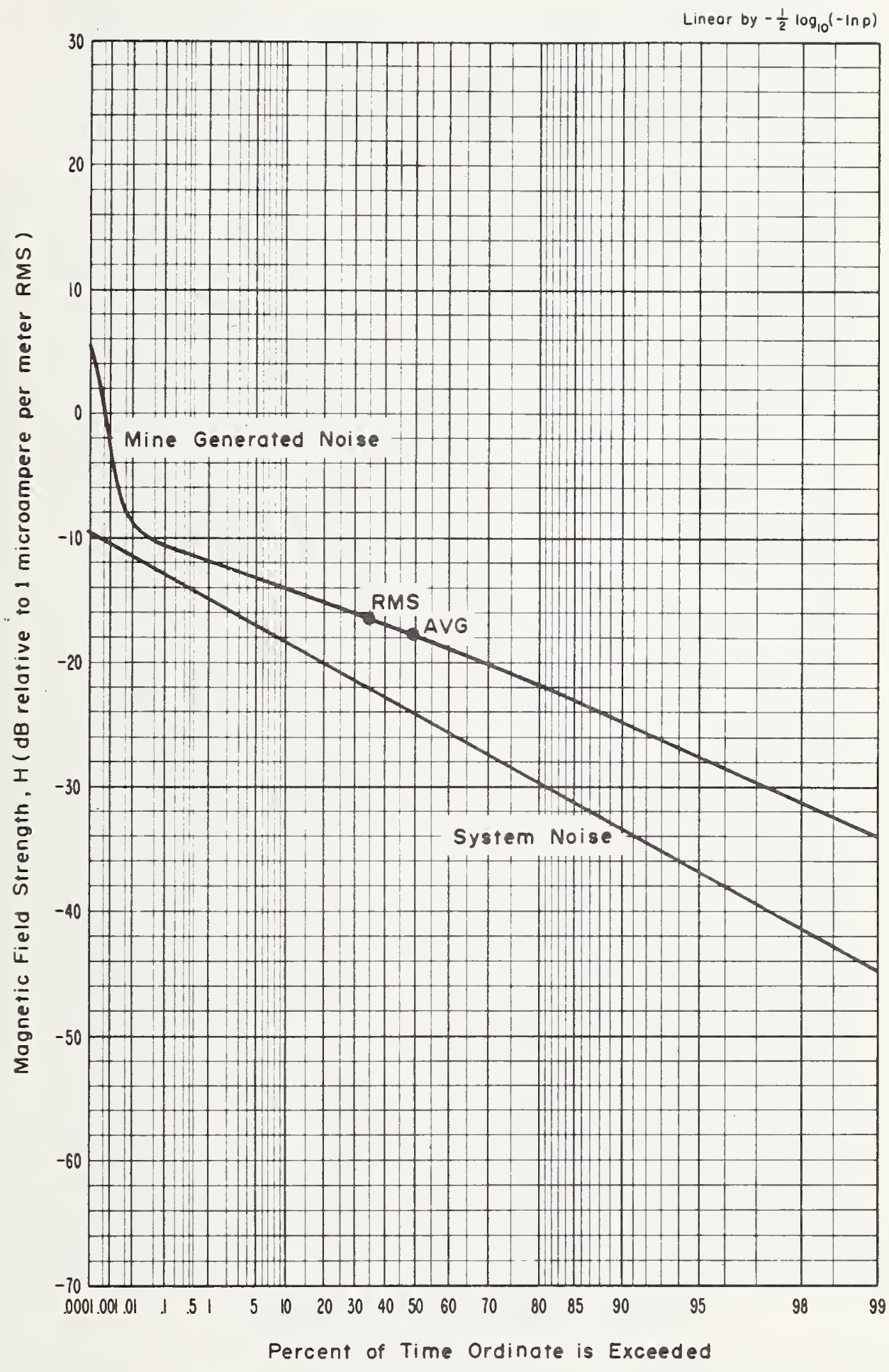

Figure 4-7 APD, $500 \mathrm{kHz}$, vertical component, $1.2 \mathrm{kHz}$ predetection bandwidth, April 17, 1973, 11:40 a.m., Cabin Creek, Itmann \#3. 


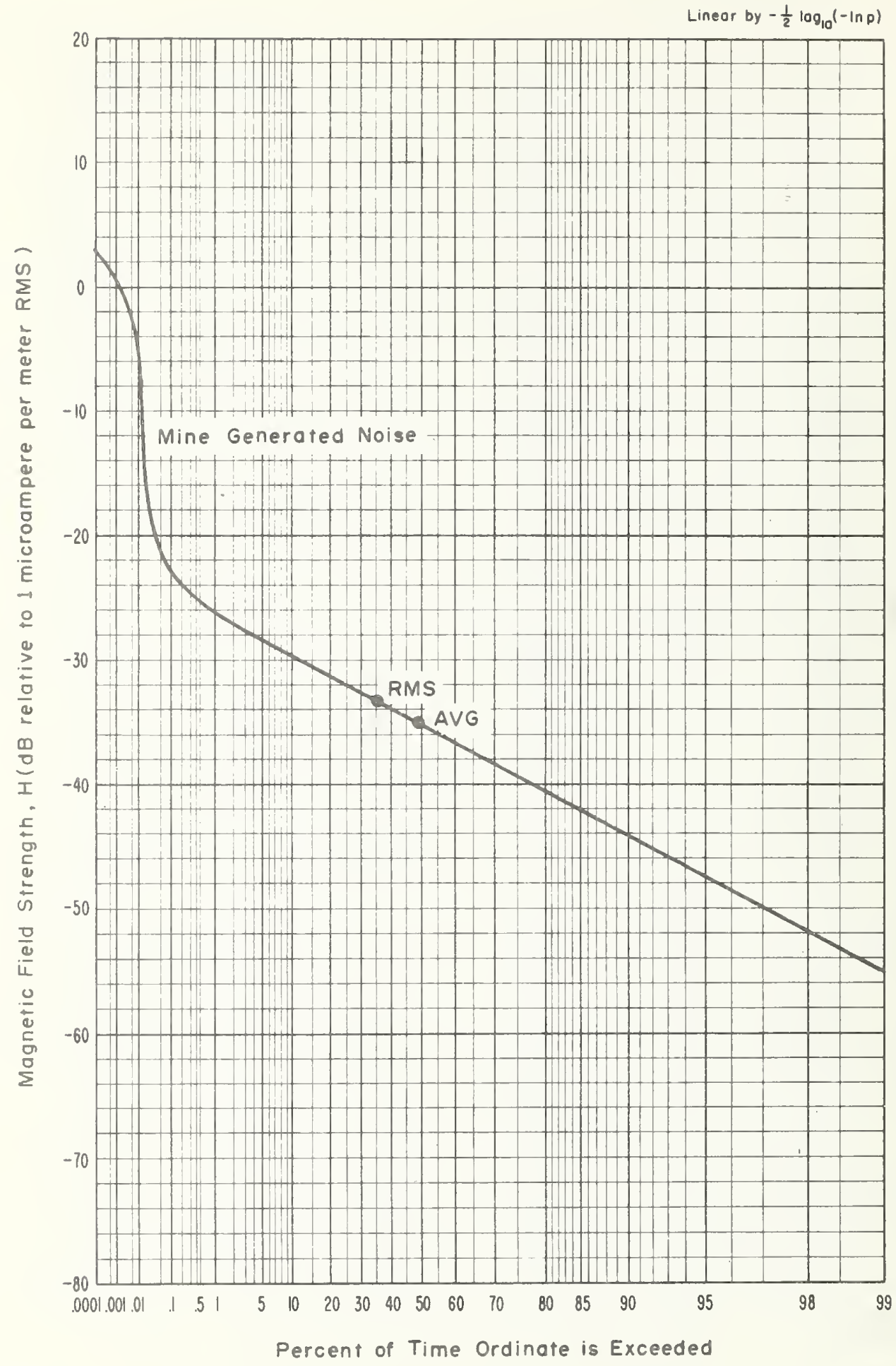

Figure 4-8 APD, I MHz, vertical component, $1.2 \mathrm{kHz}$ predetection bandwidth, April 17, 1973, 12:20 p.m., Cabin Creek, Itmann \#3. 


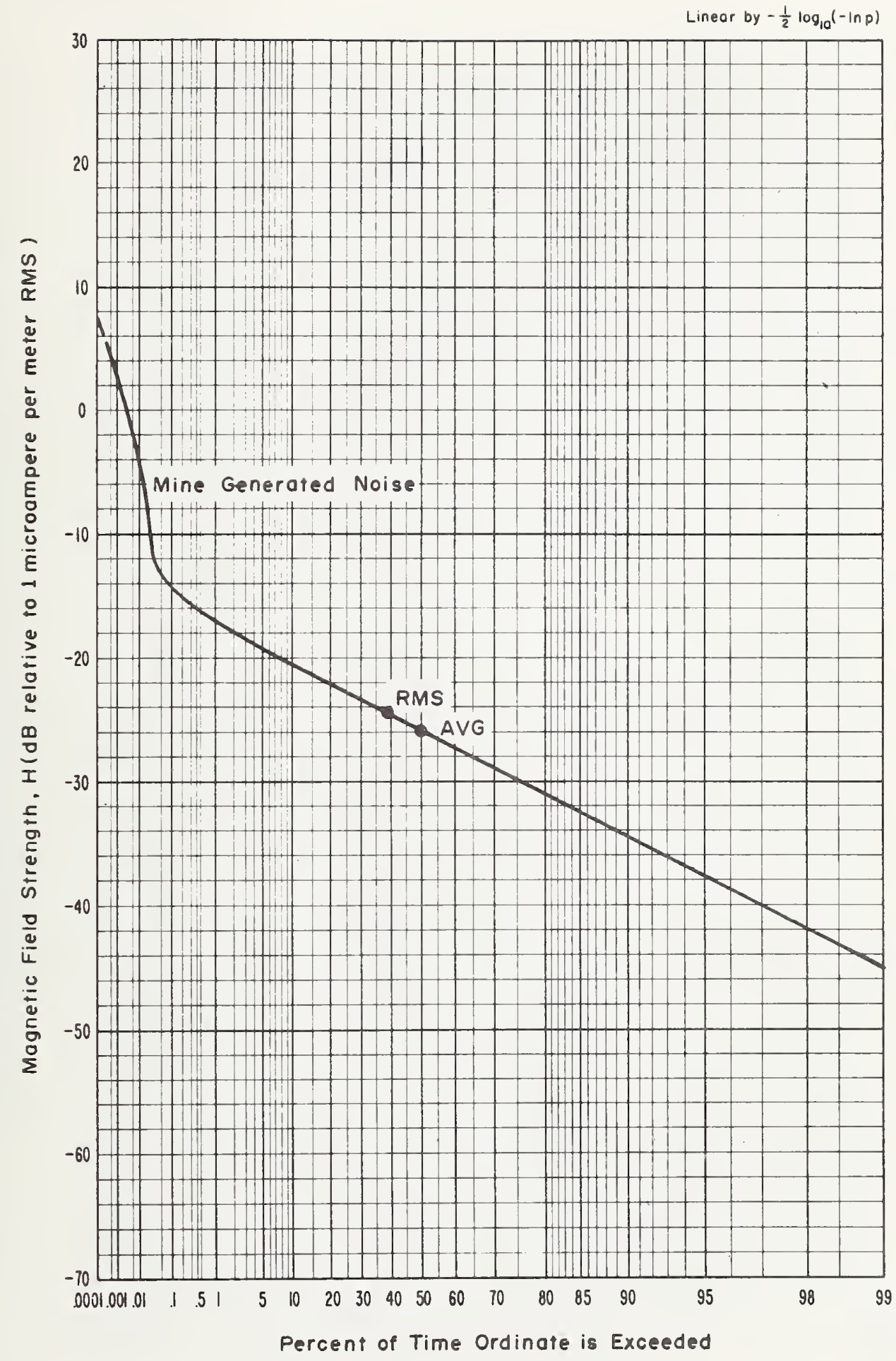

Figure 4-9 APD, $2 \mathrm{MHz}$, vertical component, $1.2 \mathrm{kHz}$ predetection bandwidth, Apri1 17, 1973, 12:50 p.m., Cabin Creek, Itmann \#3. 


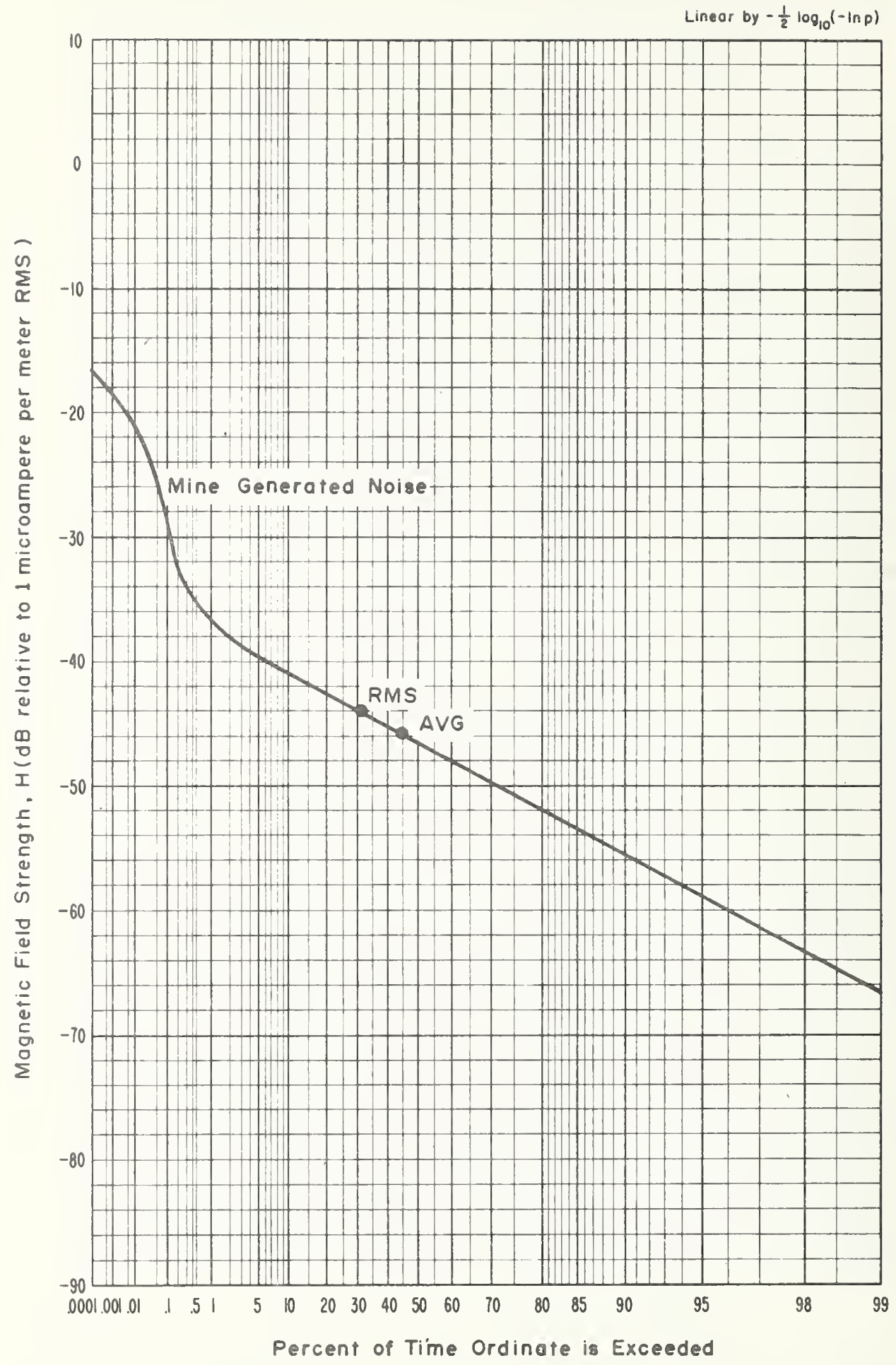

Figure 4-10 APD, $6 \mathrm{MHz}$, vertical component, $1.2 \mathrm{kHz}$ predetection bandwidth, Apri1 17, 1973, 1:30 p.m., Cabin Creek, Itmann \#3. 


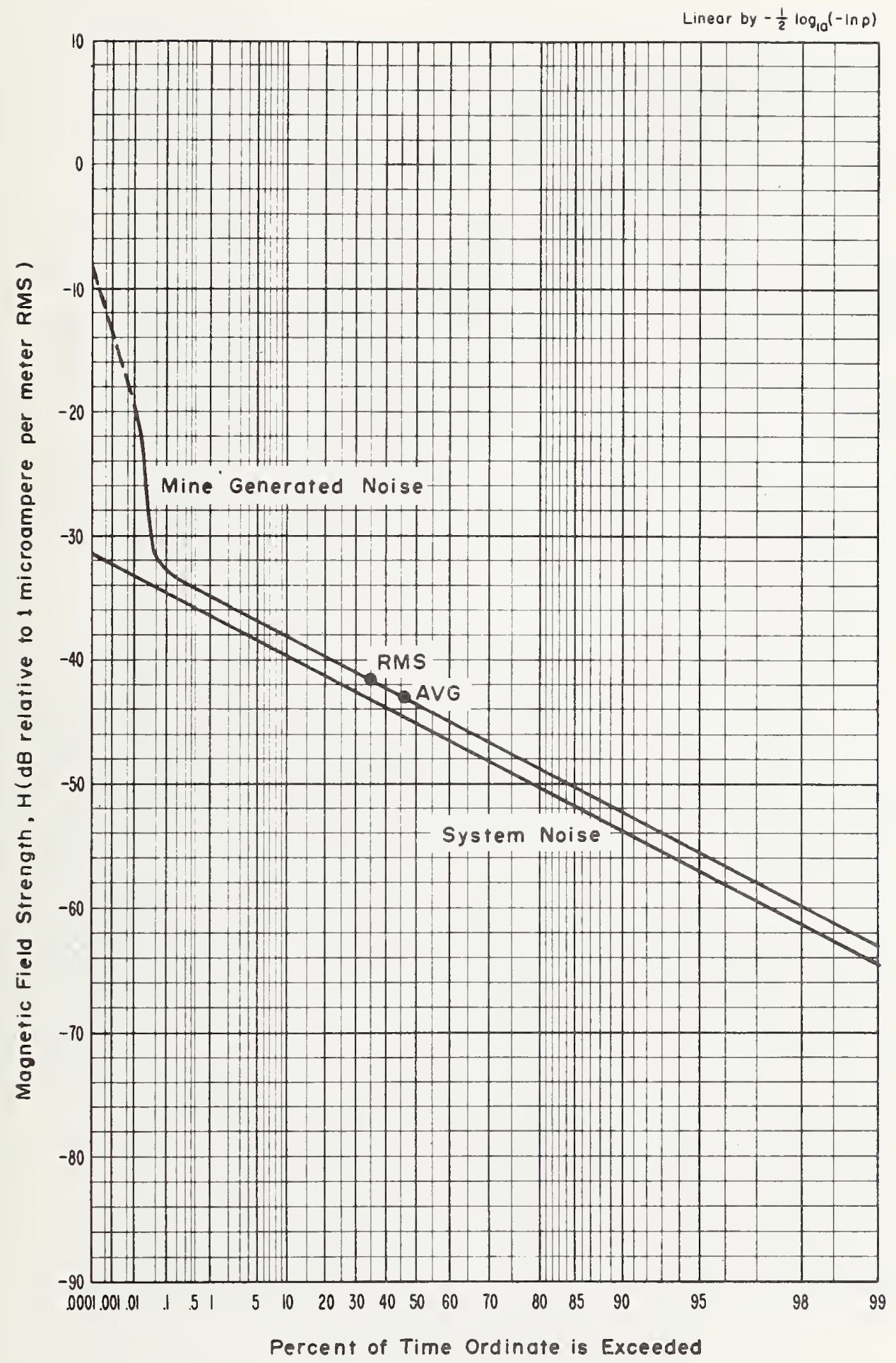

Figure 4-11 APD, $14 \mathrm{MHz}$, vertical component, $1.2 \mathrm{kHz}$ predetection bandwidth, Apri1 17, 1973, 2:20 p.m., Cab1n Creek, Itmann \#3. 


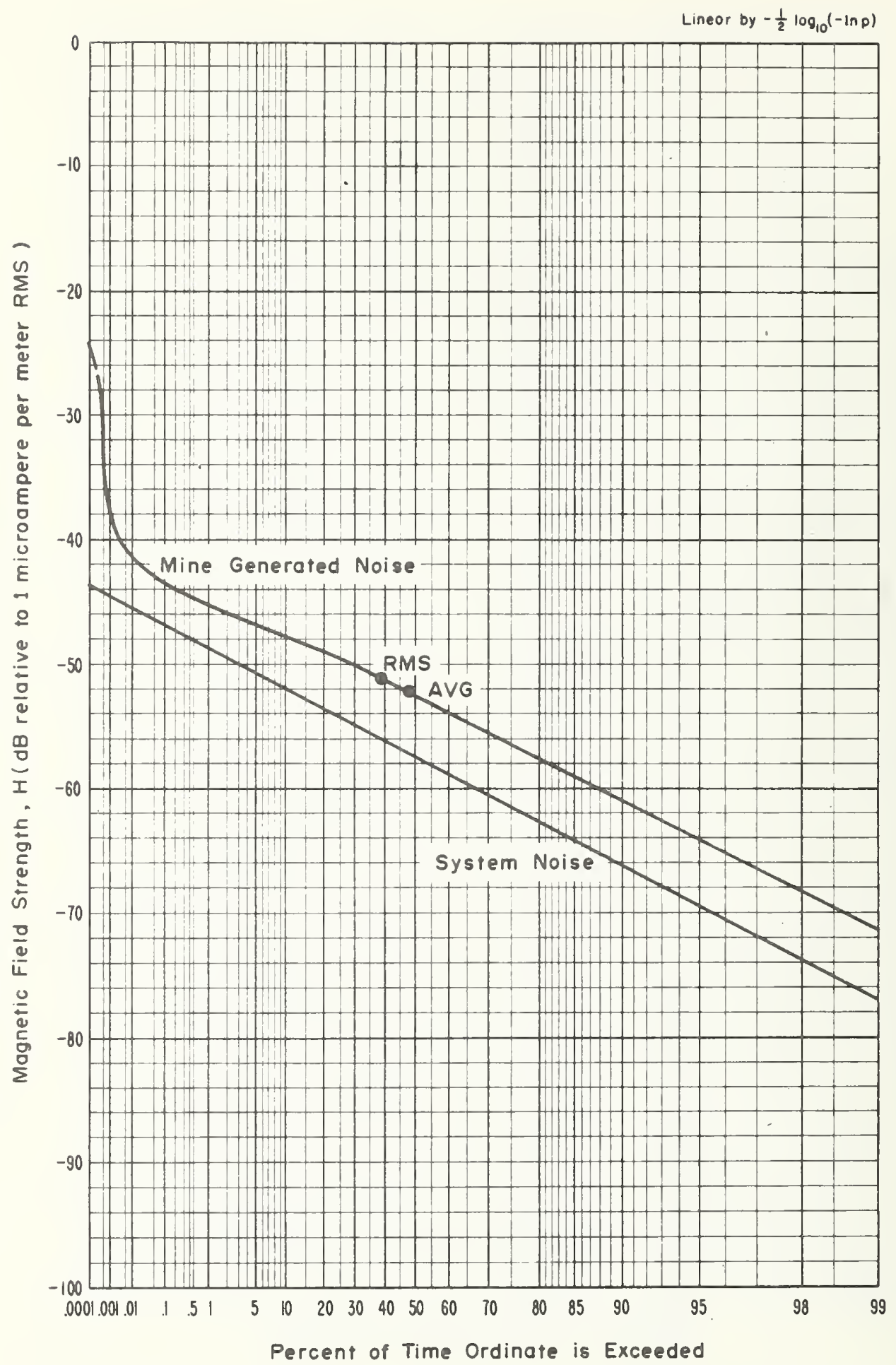

Figure 4-12 APD, $32 \mathrm{MHz}$, vertical component, $1.2 \mathrm{kHz}$ predetection bandwidth, Apri1 17, 1973, 3:00 p.m., Cabin Creek, Itmann 非. 


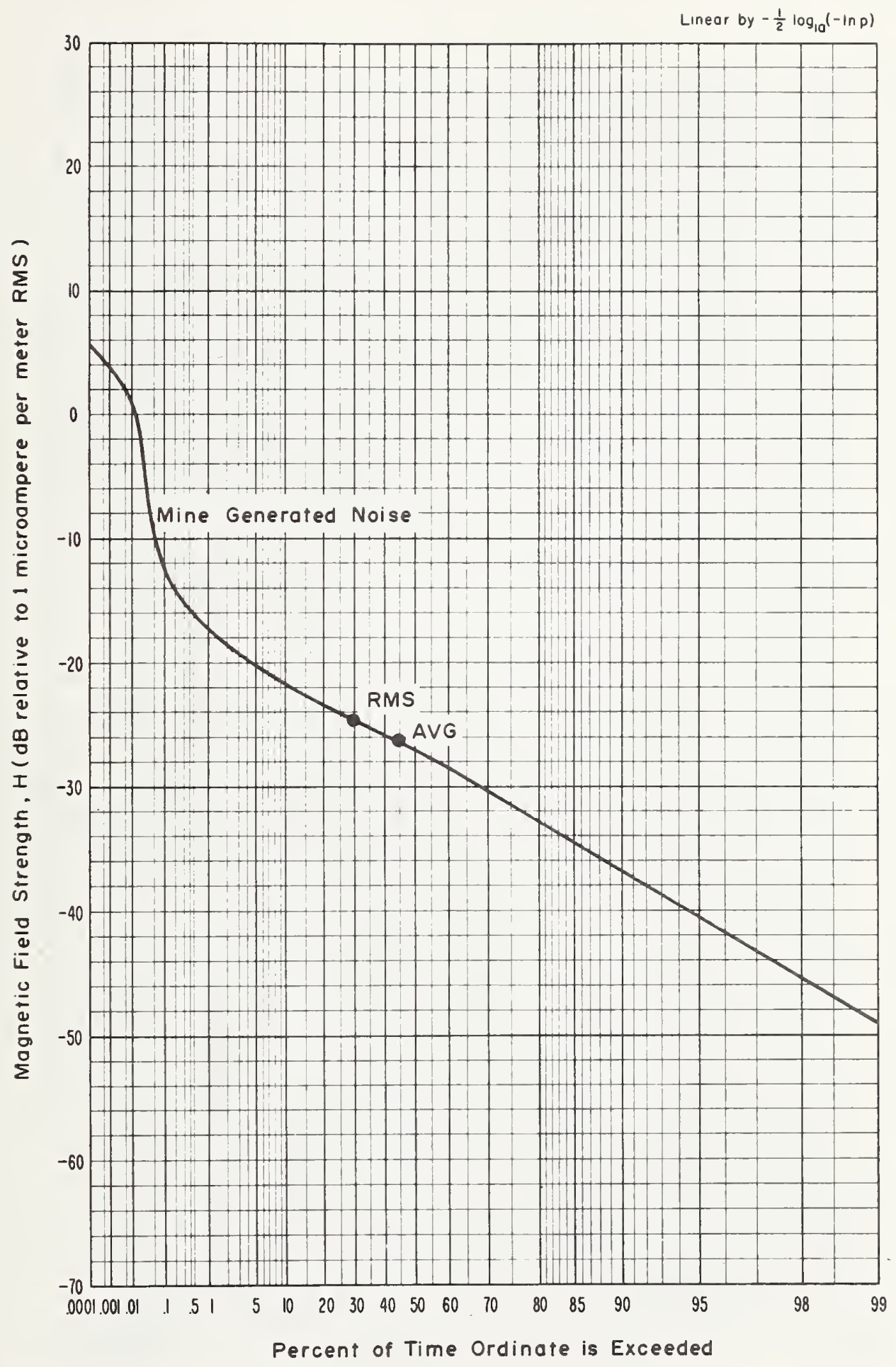

Figure 4-13 APD, $10 \mathrm{kHz}$, vertical component, $1.0 \mathrm{kHz}$ predetection bandwidth, April 17, 1973, 3:40 p.m., Quiet Time Measurement, Cabin Creek, Itmann 非3. 
Lineor by $-\frac{1}{2} \log _{10}(-\ln p)$

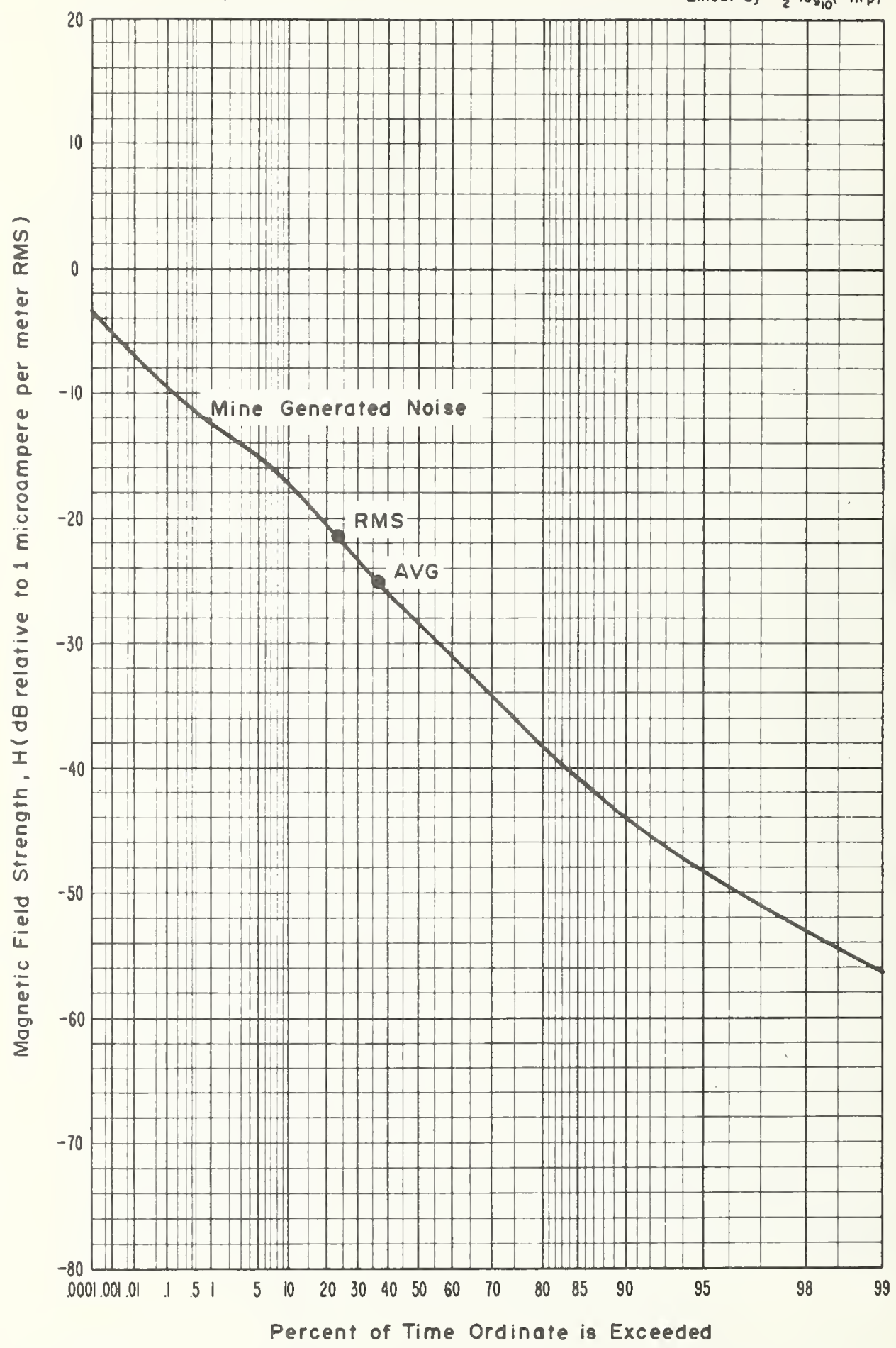

Figure 4-14 APD, $30 \mathrm{kHz}$, vertical component, $1.0 \mathrm{kHz}$ predetection bandwidth, April 17, 1973, 3:50 p.m., Qulet Time Measurement, Cabin Creek, I tmann 非3. 


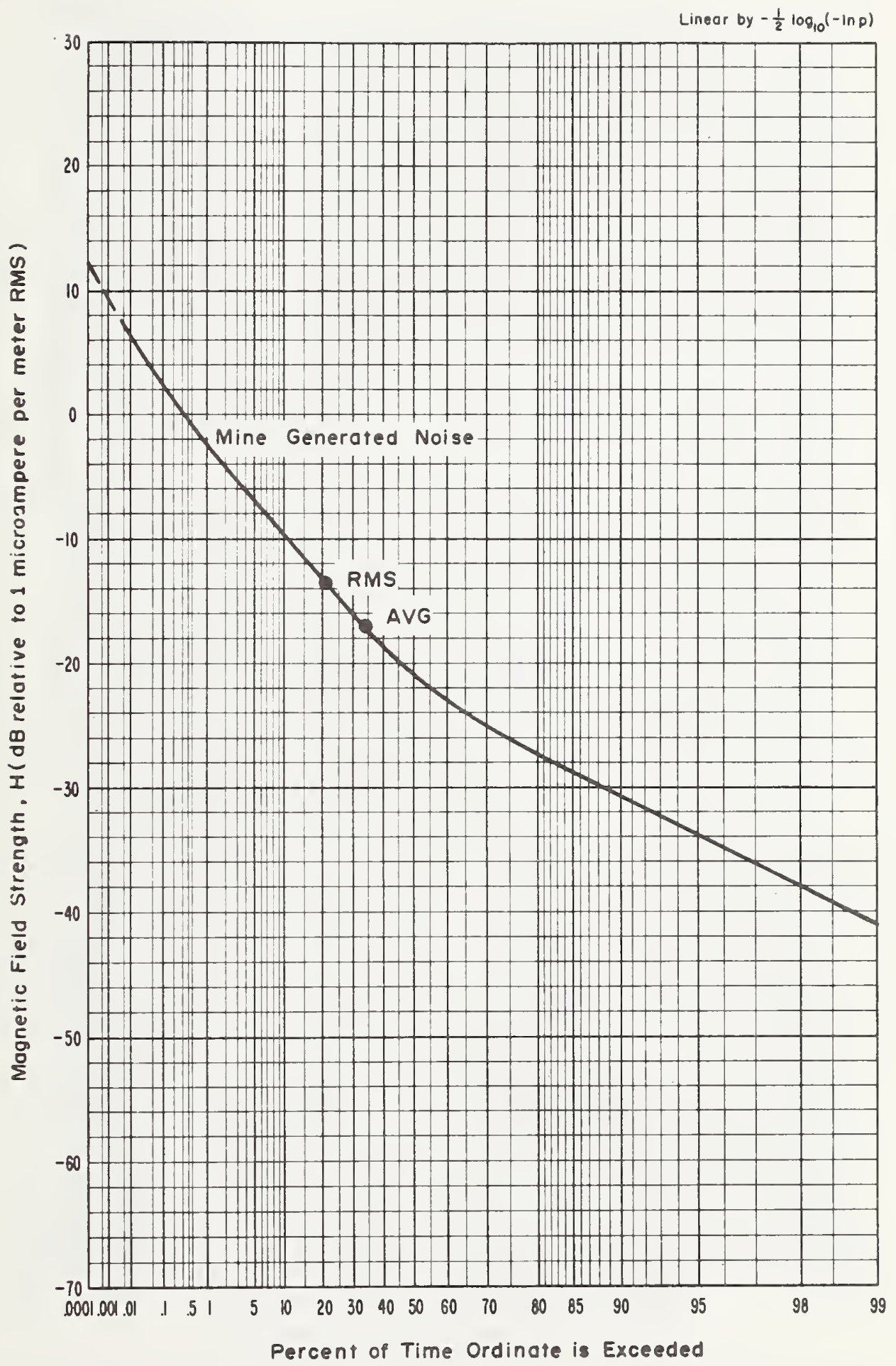

Figure 4-15 APD, $130 \mathrm{kHz}$, vertical component, $1.0 \mathrm{kHz}$ predetection bandwidth, April 17, 1973, 4:05 p.m., Quiet TIme Measurement, Cabin Creek, Itmann \#3. 


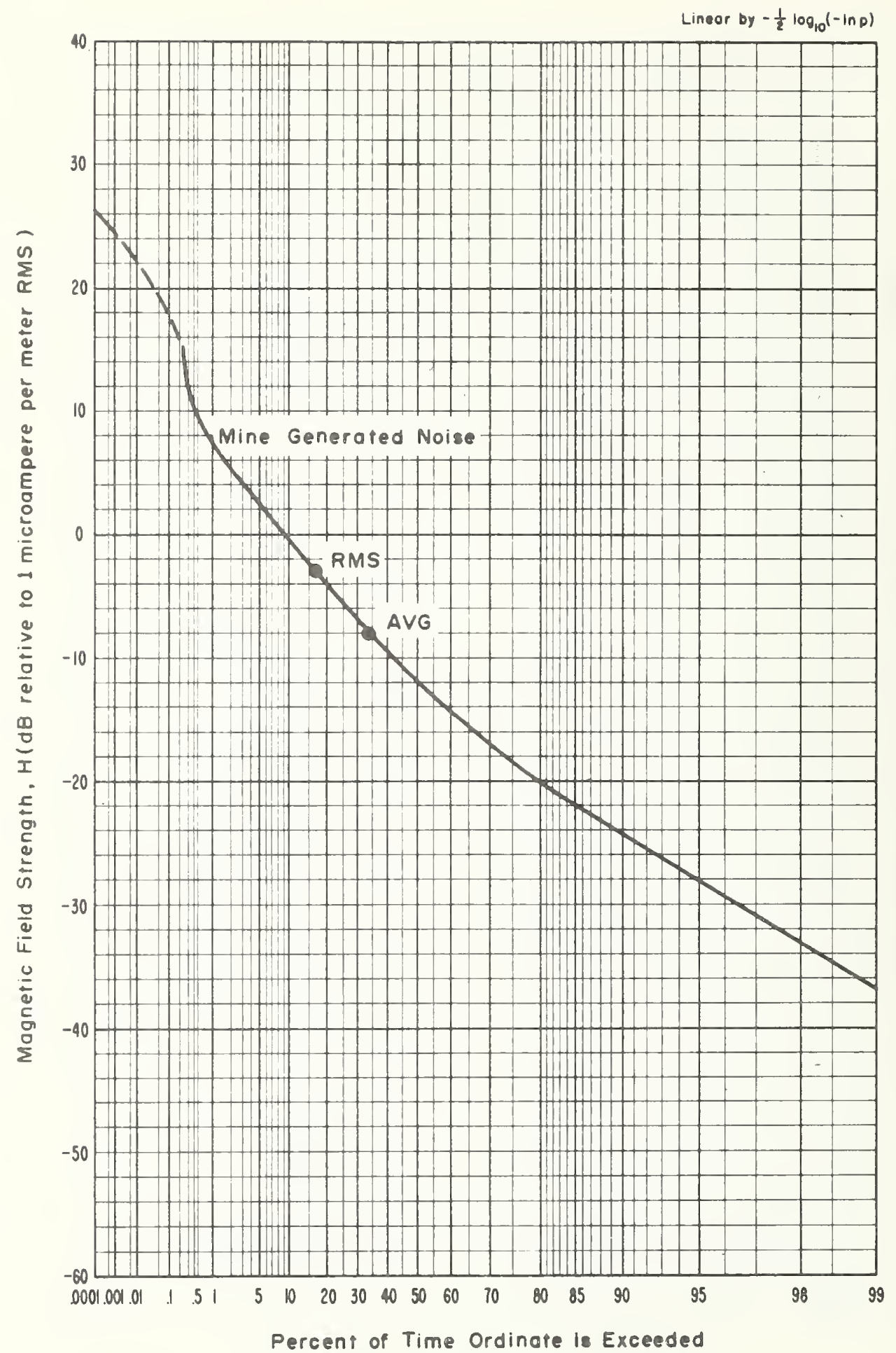

Figure 4-16 APD, $500 \mathrm{kHz}$, vertical component, $1.2 \mathrm{kHz}$ predetection bandwidth, April 17, 1973, 3:40 P.⿴., Quiet Time Measurement, Cab1n Creek, Itmann \#3. 


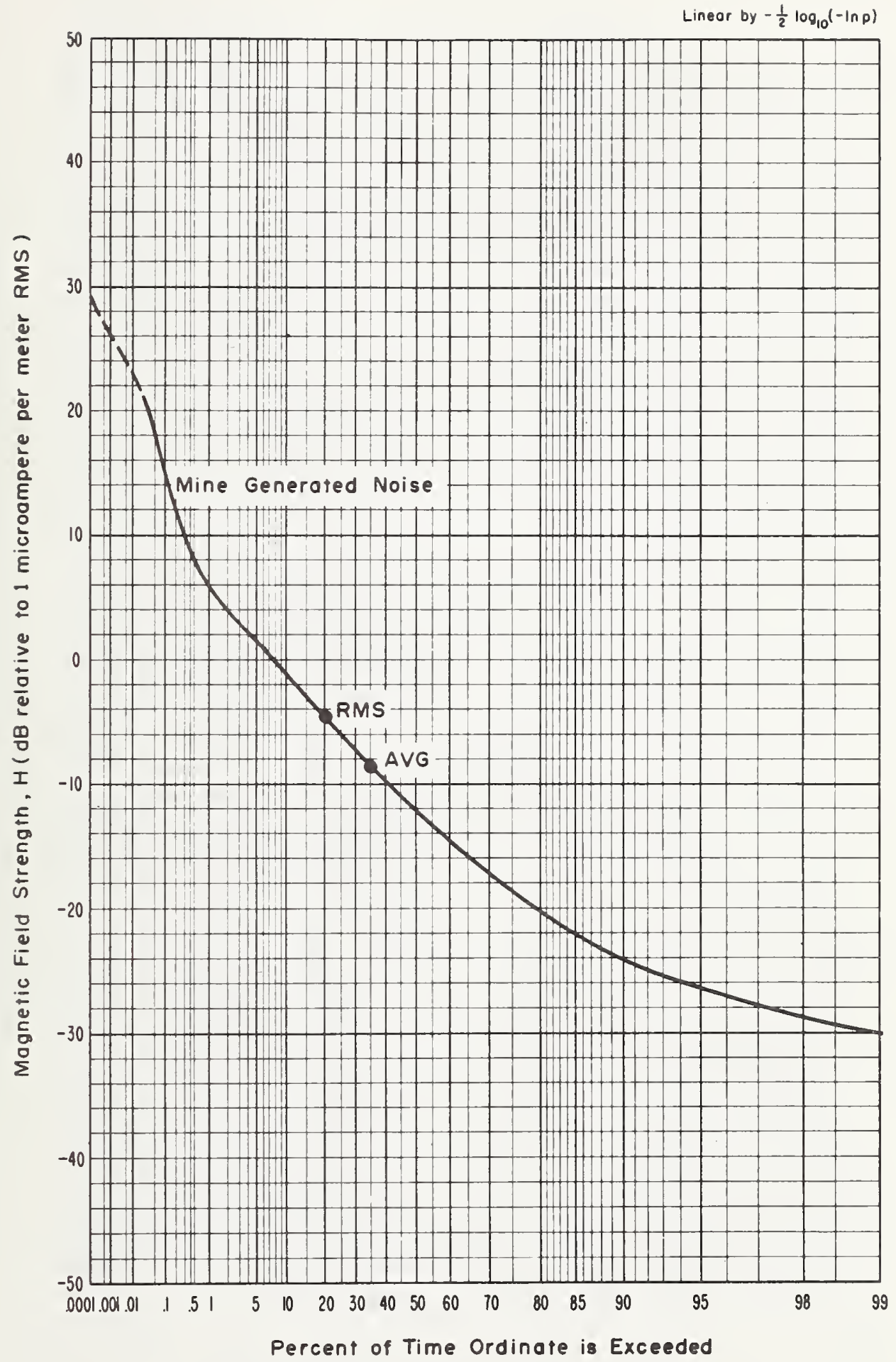

Figure 4-17 APD, I MHz, vertical component, $1.2 \mathrm{kHz}$ predetection bandwidth, April 17, 1973, 3:50 p.m., Quiet Time Measurement, Cabin Creek, Itmann \#3. 


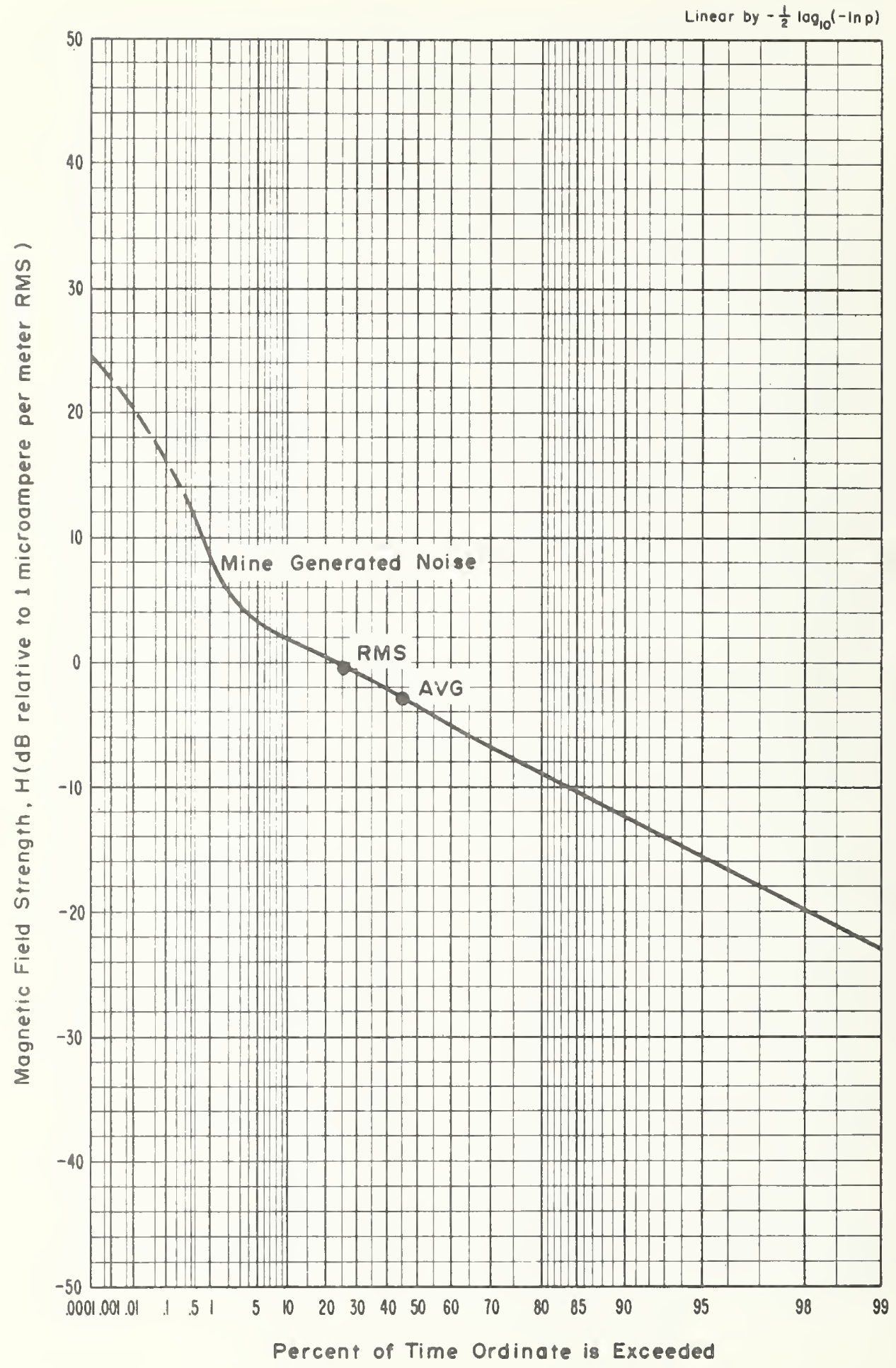

Figure 4-18 APD, $2 \mathrm{MHz}$, vertical component, $1.2 \mathrm{kHz}$ predetection bandwidth, Apri1 17, 1973, 4:00 p.m., Qulet Time Measurement, Cab1n Creek, Itmann 非3. 


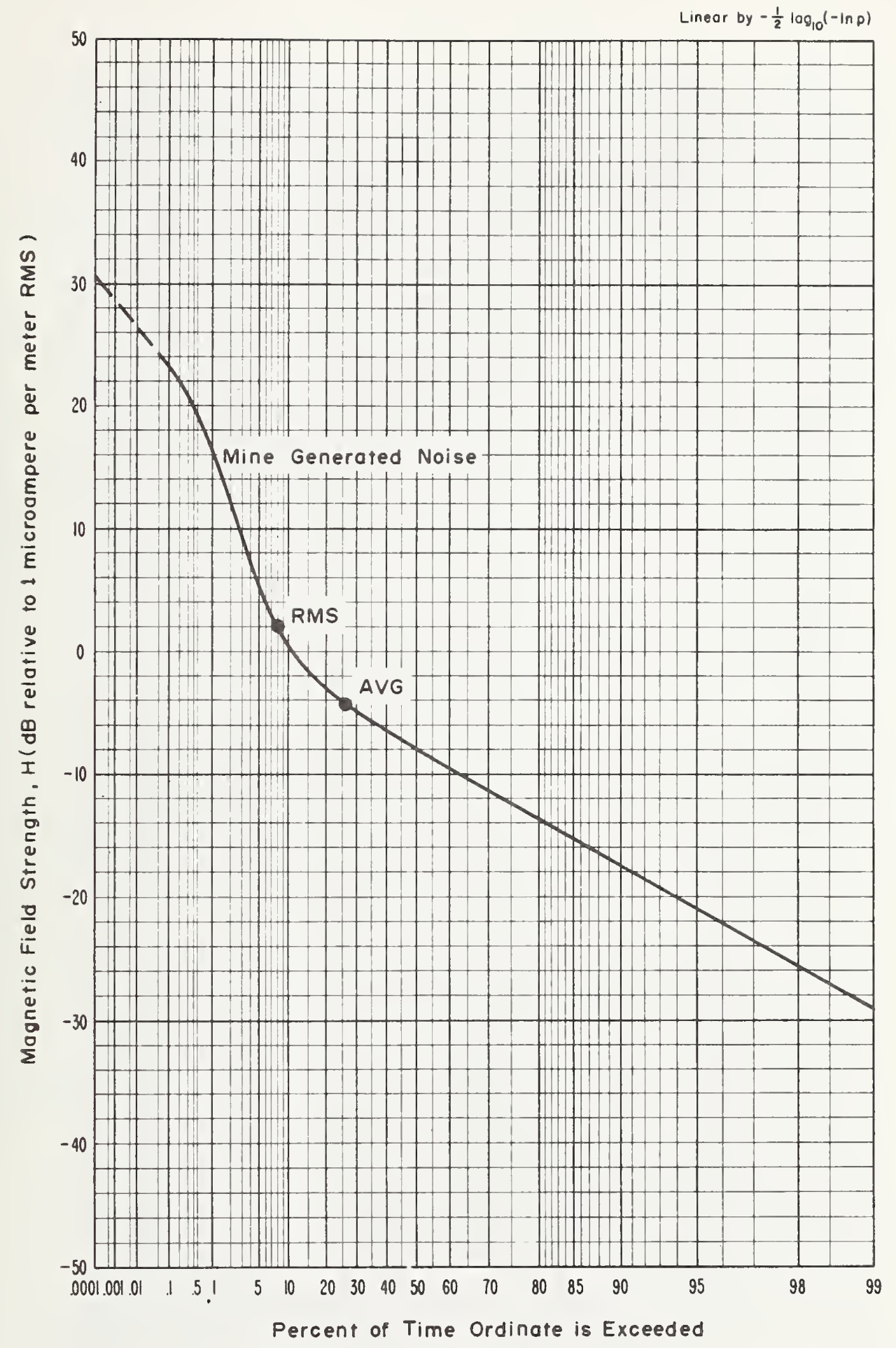

Figure 4-19 APD, $6 \mathrm{MHz}$, vertical component, $1.2 \mathrm{kHz}$ predetection bandwidth, Apr11 17, 1973, 4:05 p.m., Quiet Time Measurement, Cab1n Creek, Itmann 非3. 


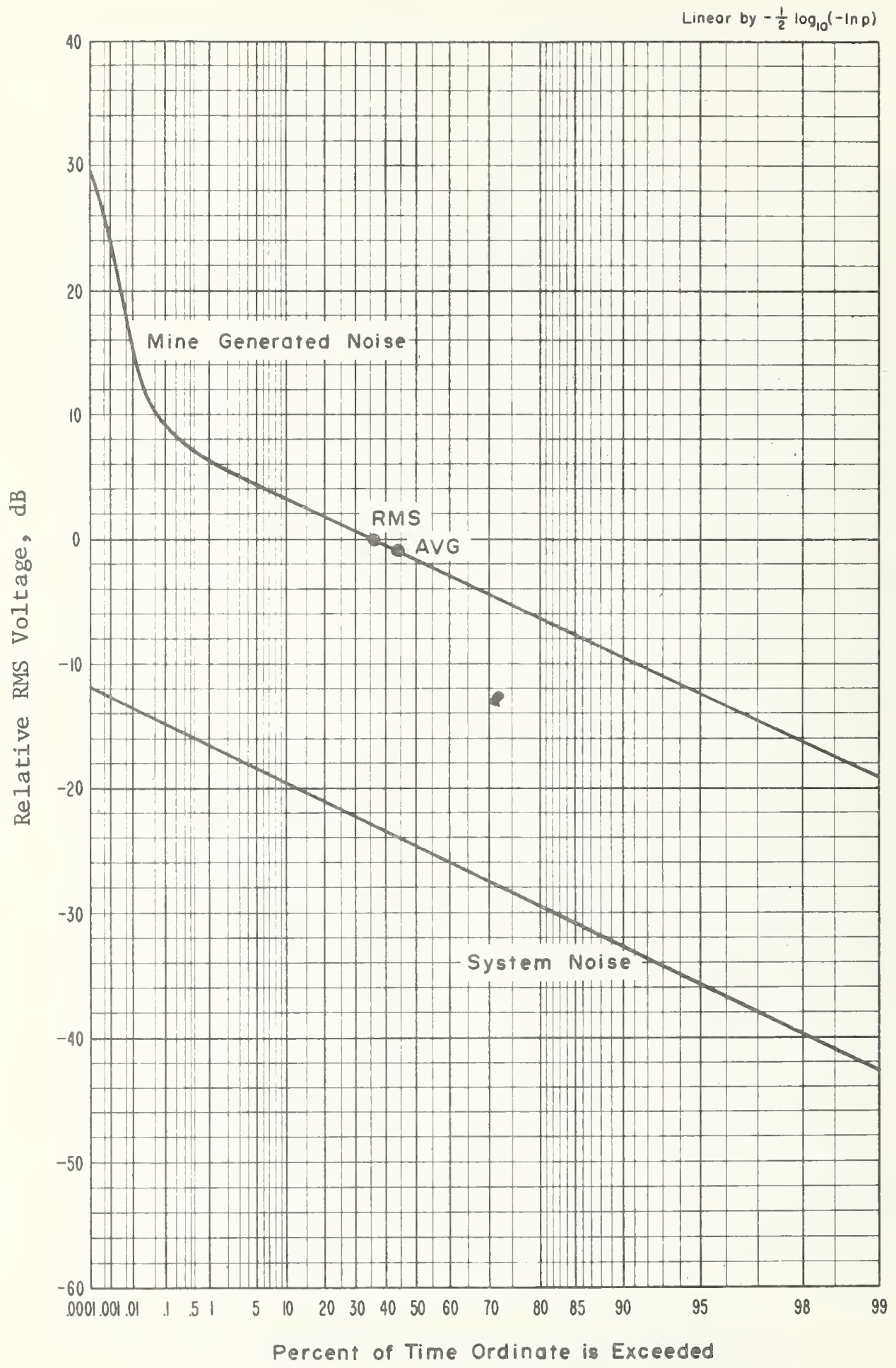

Figure 4-20 APD, $10 \mathrm{kHz}$, roof bolt measurement, $1.0 \mathrm{kHz}$ predetection bandwidth, Apri1 17, 1973, 5:00 P.m., Cab1n Creek, Itmann 非3. 


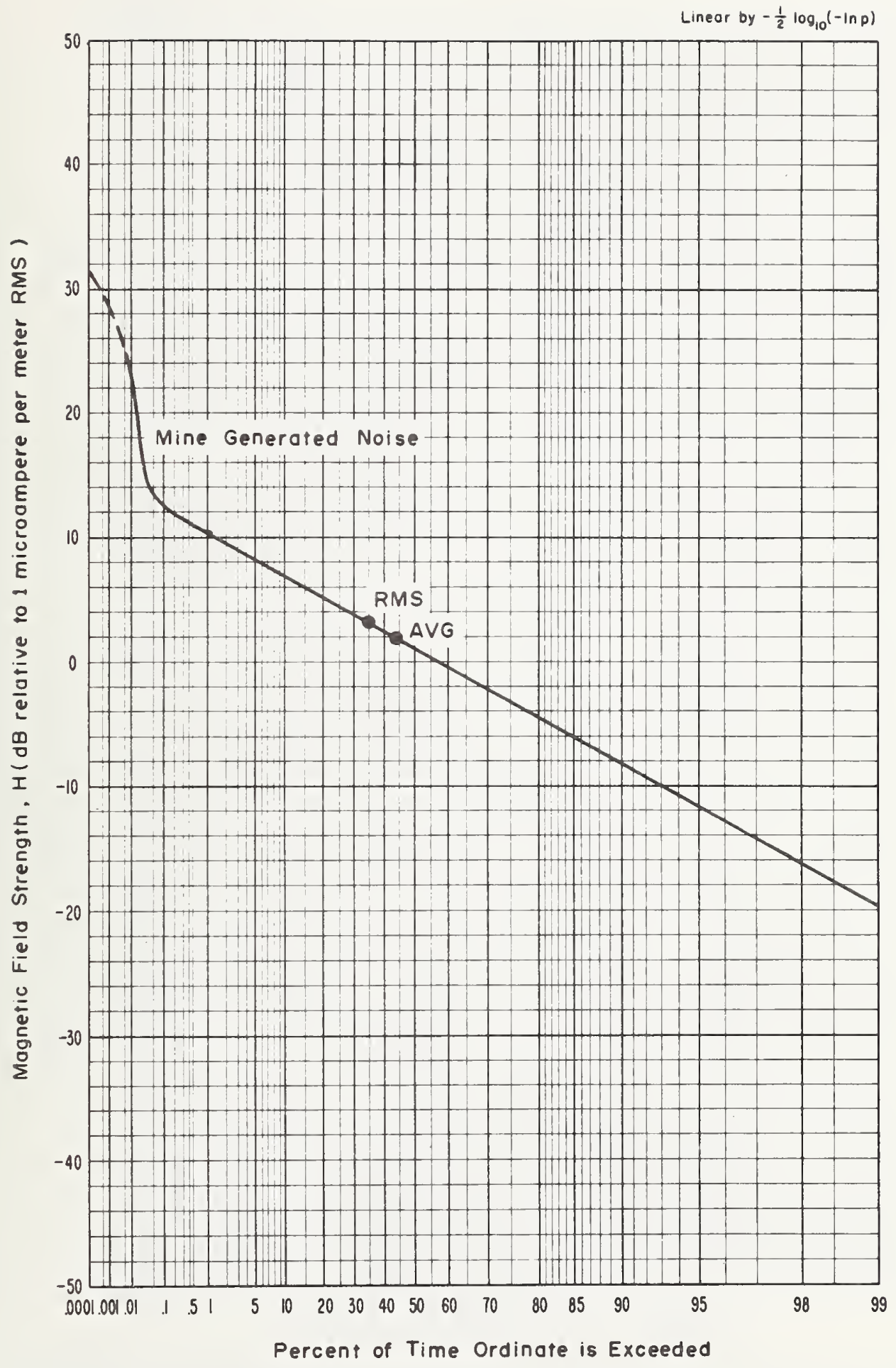

Figure 4-21 APD, $10 \mathrm{kHz}$, vertical component, $1.0 \mathrm{kHz}$ predetection bandwidth, Apr11 17, 1973, 12:30 p.m., Farley Panel, Itmann 非. 


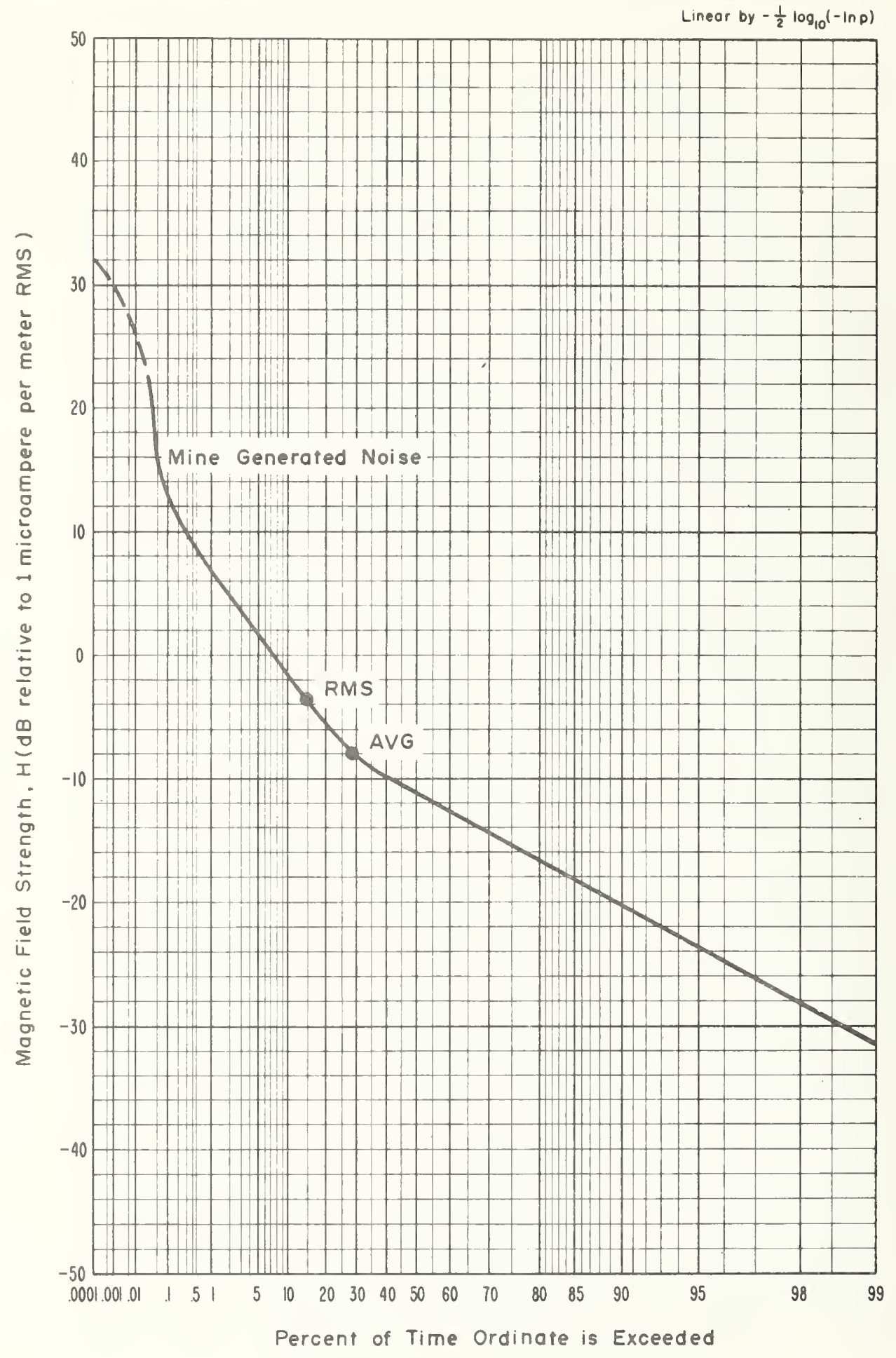

Figure 4-22 APD, $30 \mathrm{kHz}$, vertical component, $1.0 \mathrm{kHz}$ predetection bandwidth, April 17, 1973, 1:15 p.m., Farley Panel, Itmann \#3. 


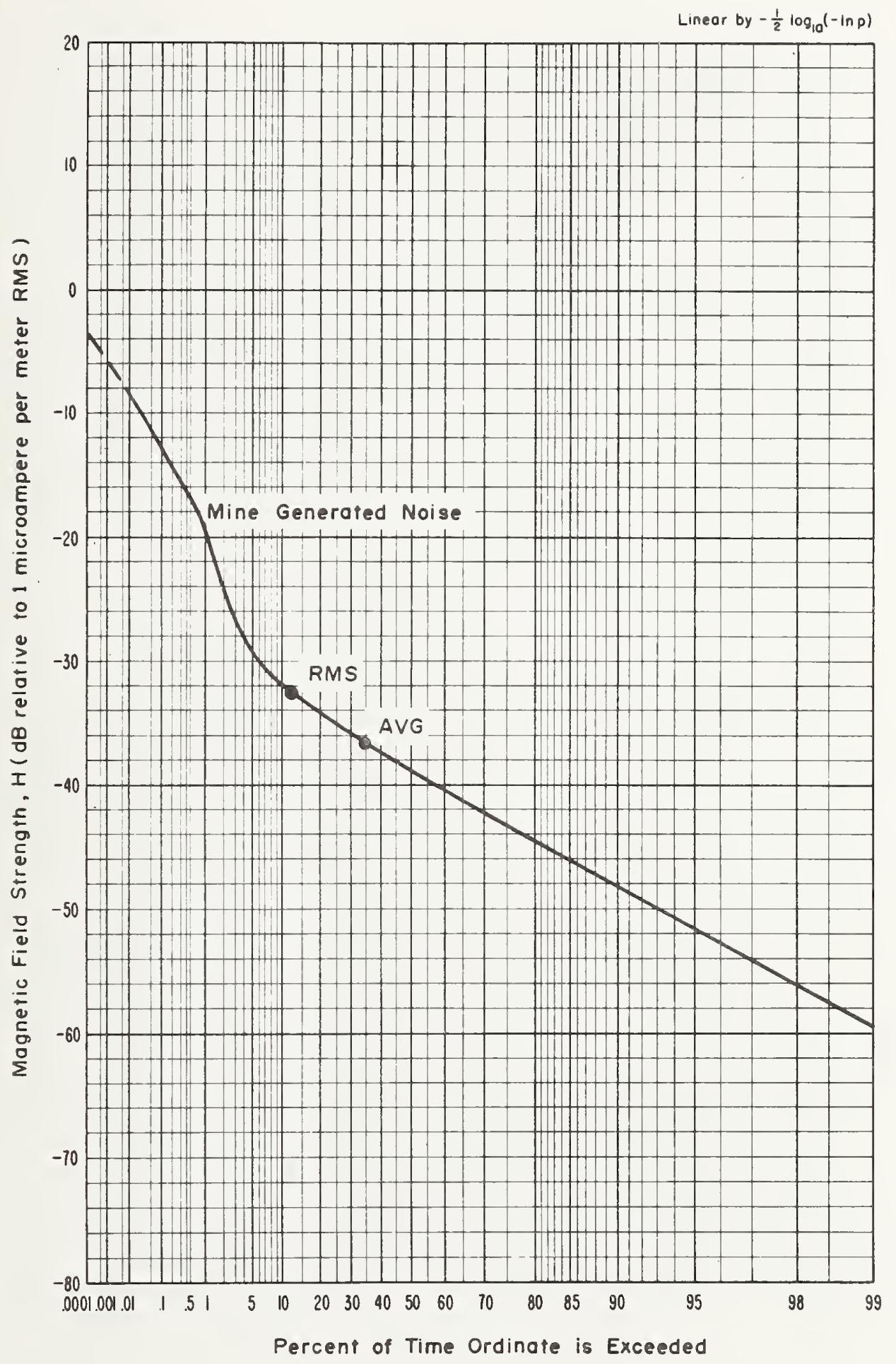

F1gure 4-23 APD, $70 \mathrm{kHz}$, vertical component, $1.0 \mathrm{kHz}$ predetection bandwidth, April 17, 1973, 2:00 p.m., Farley Panel, Itmann \#3. 


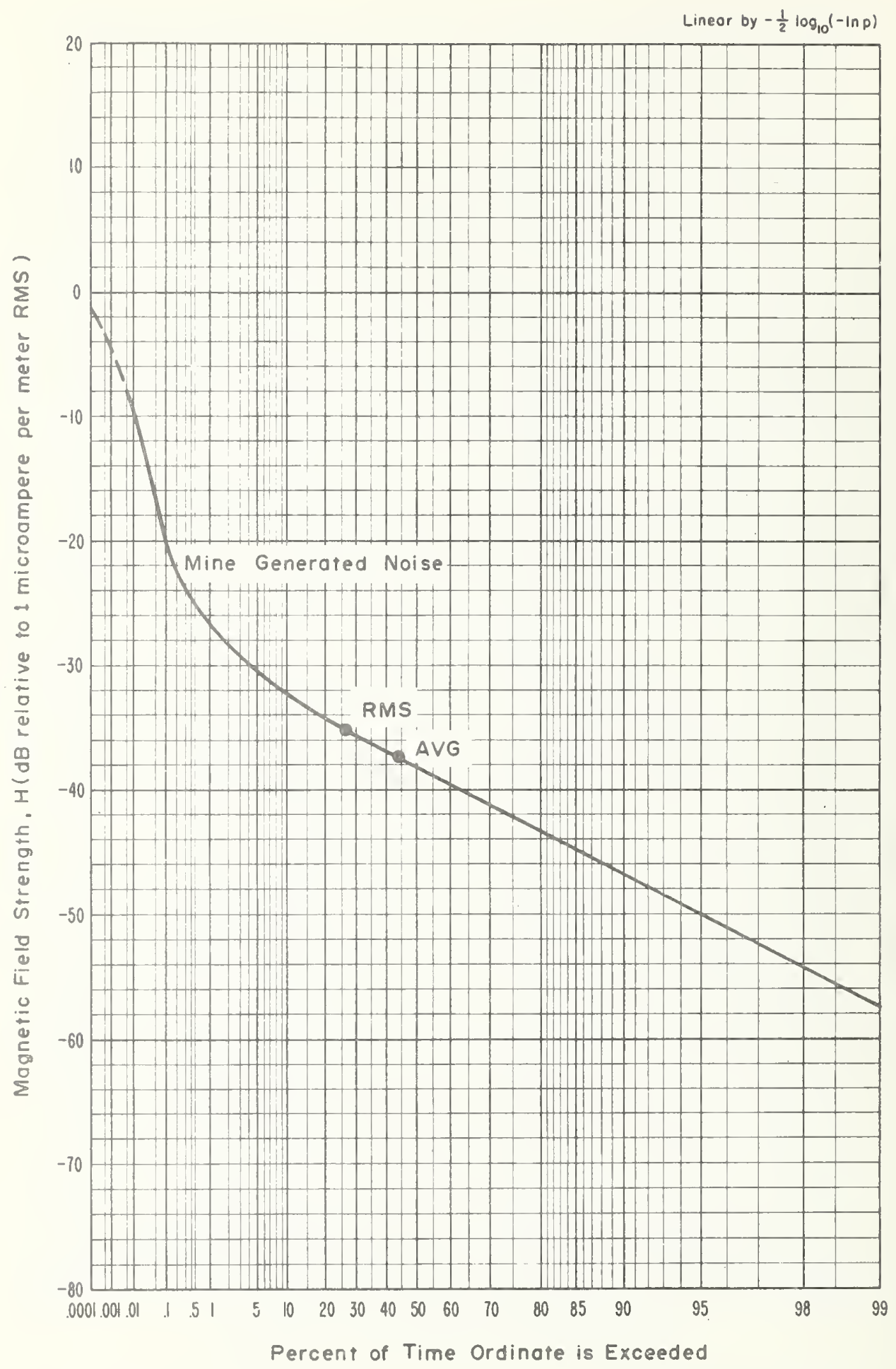

Figure 4-24 APD, $130 \mathrm{kHz}$, vertical component, $1.0 \mathrm{kHz}$ predetection bandwidth, April 17, 1973, 2:45 p.m., Farley Panel, I tmann \#3. 


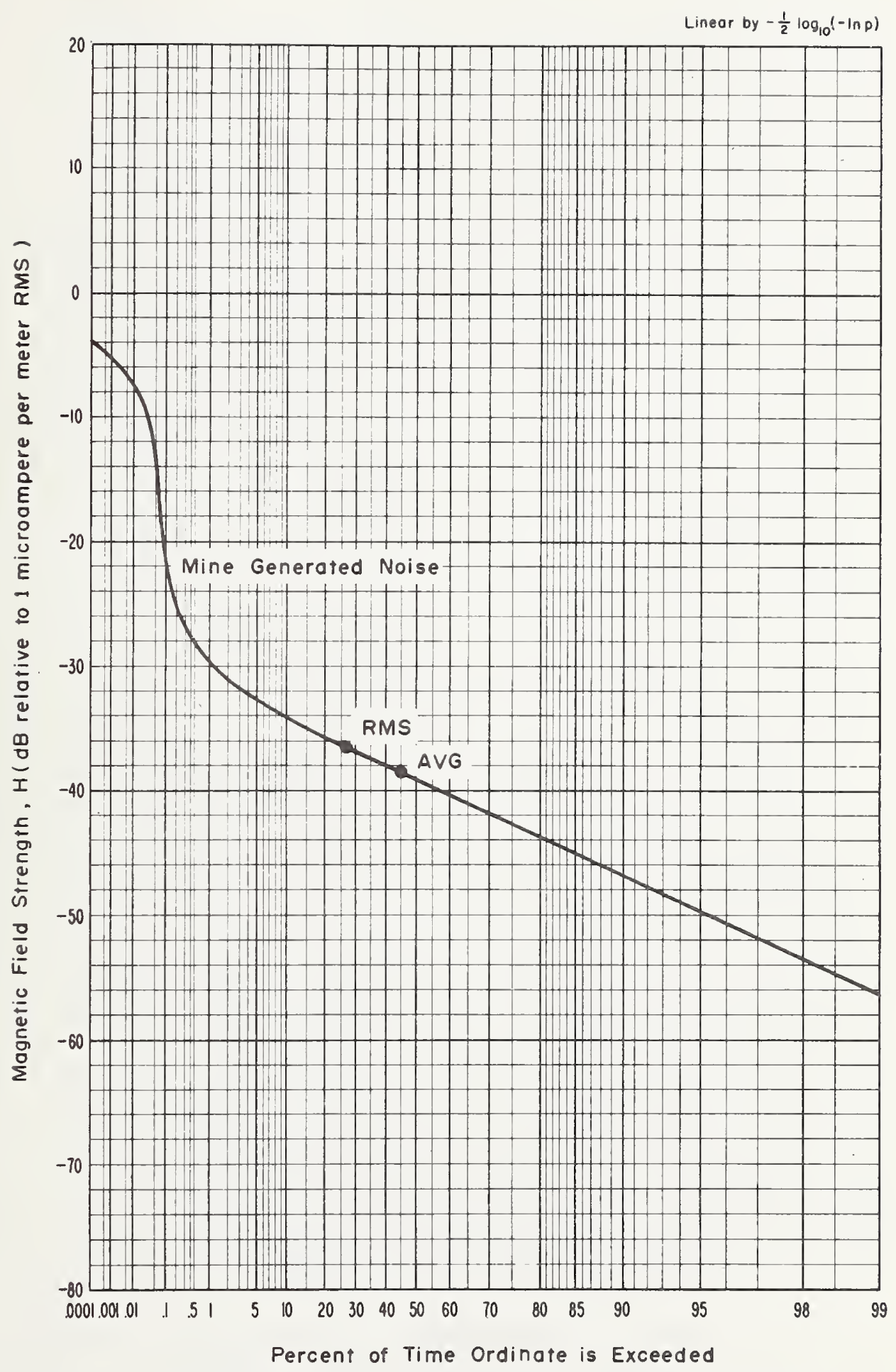

Figure 4-25 APD, $250 \mathrm{kHz}$, vertical component, $1.2 \mathrm{kHz}$ predetection bandwidth, Apri1 17, 1973, 12: 30 p.m., Farley Panel, Itmann 非3. 


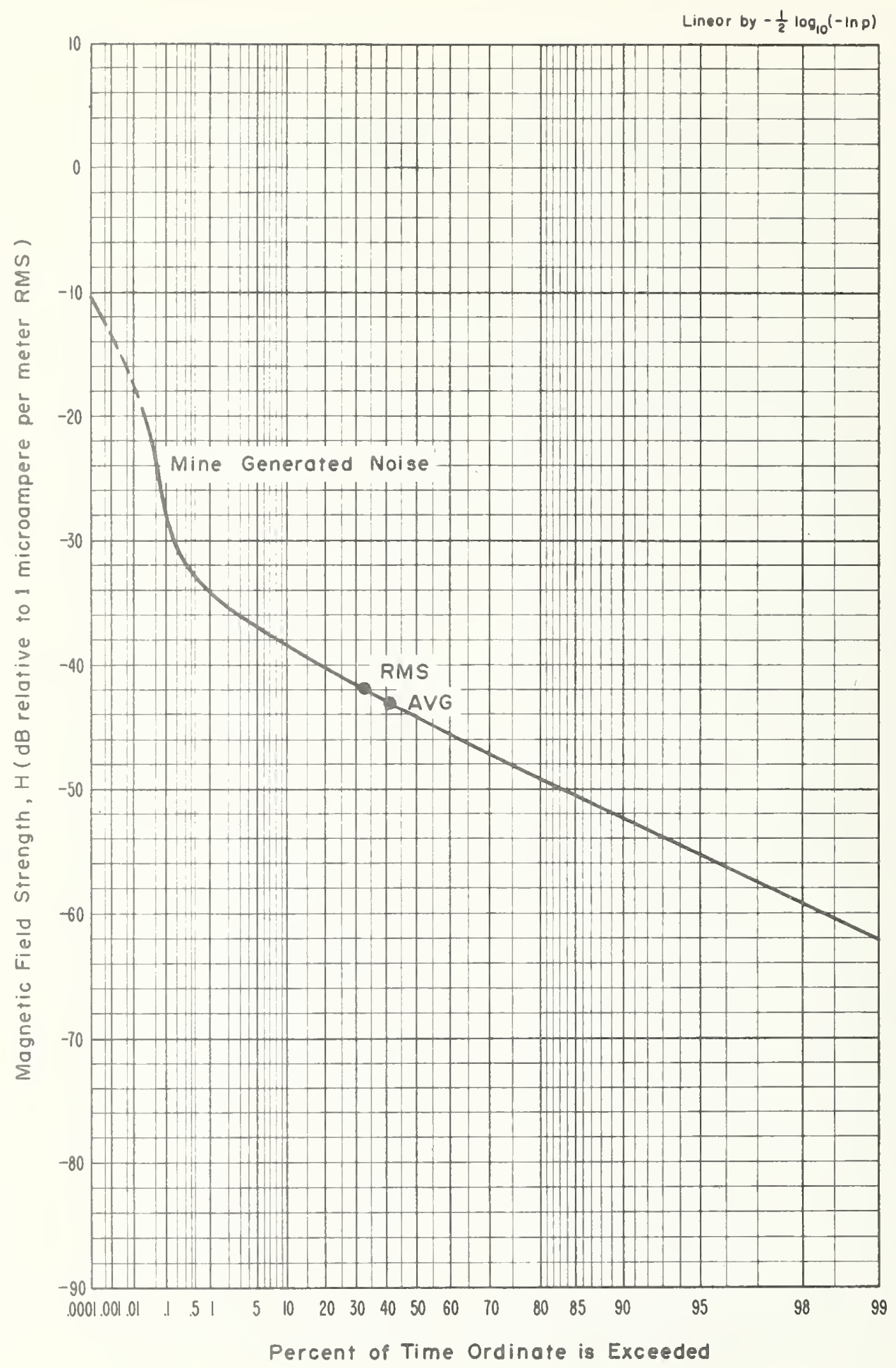

Figure 4-26 APD, $500 \mathrm{kHz}$, vertical component, $1.2 \mathrm{kHz}$ predetection bandwidth, April 17, 1973, 1:15 p.m., Farley Panel, Itmann \#3. 


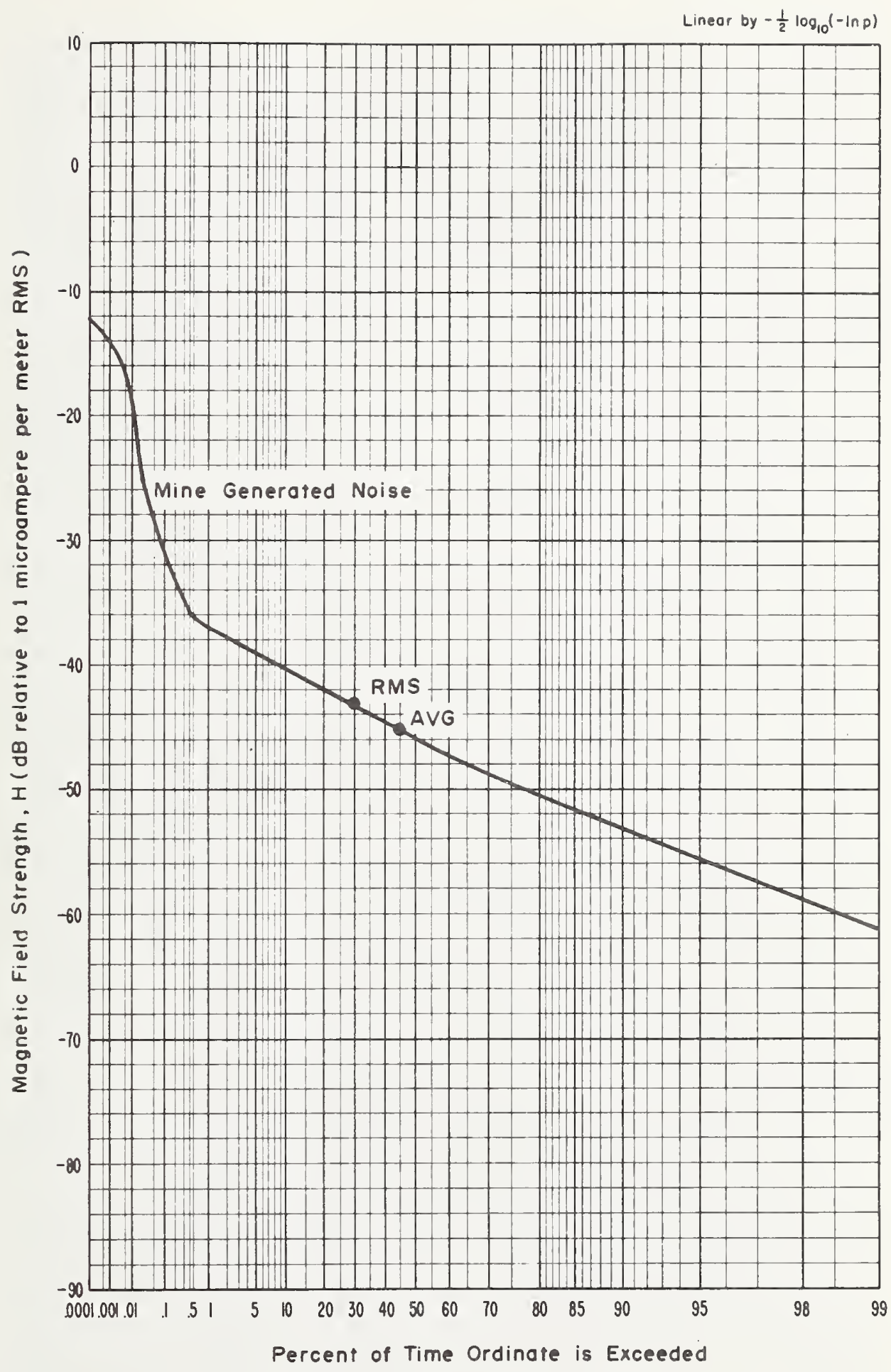

Figure 4-27 APD, $1 \mathrm{MHz}$, vertical component, $1.2 \mathrm{kHz}$ predetection bandwidth, April 17, 1973, 2:00 p.m., Farley Panel, Itmann $\#$ 3. 


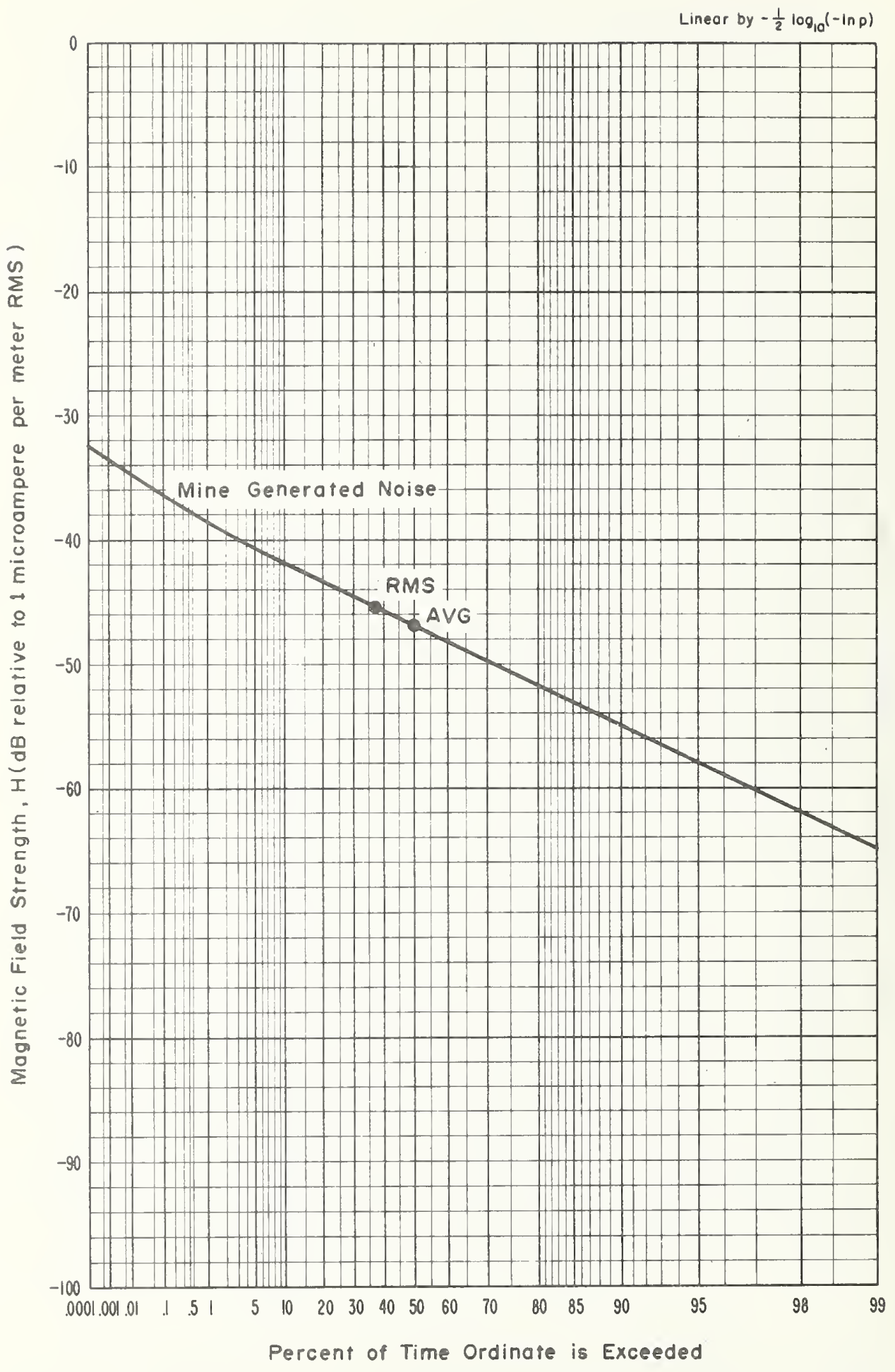

Figure 4-28 APD, $2 \mathrm{MHz}$, vertical component, $1.2 \mathrm{kHz}$ predetection bandwidth, Apr11 17, 1973, 2:45 p.m., Farley Pane1, Itmann \#3. 


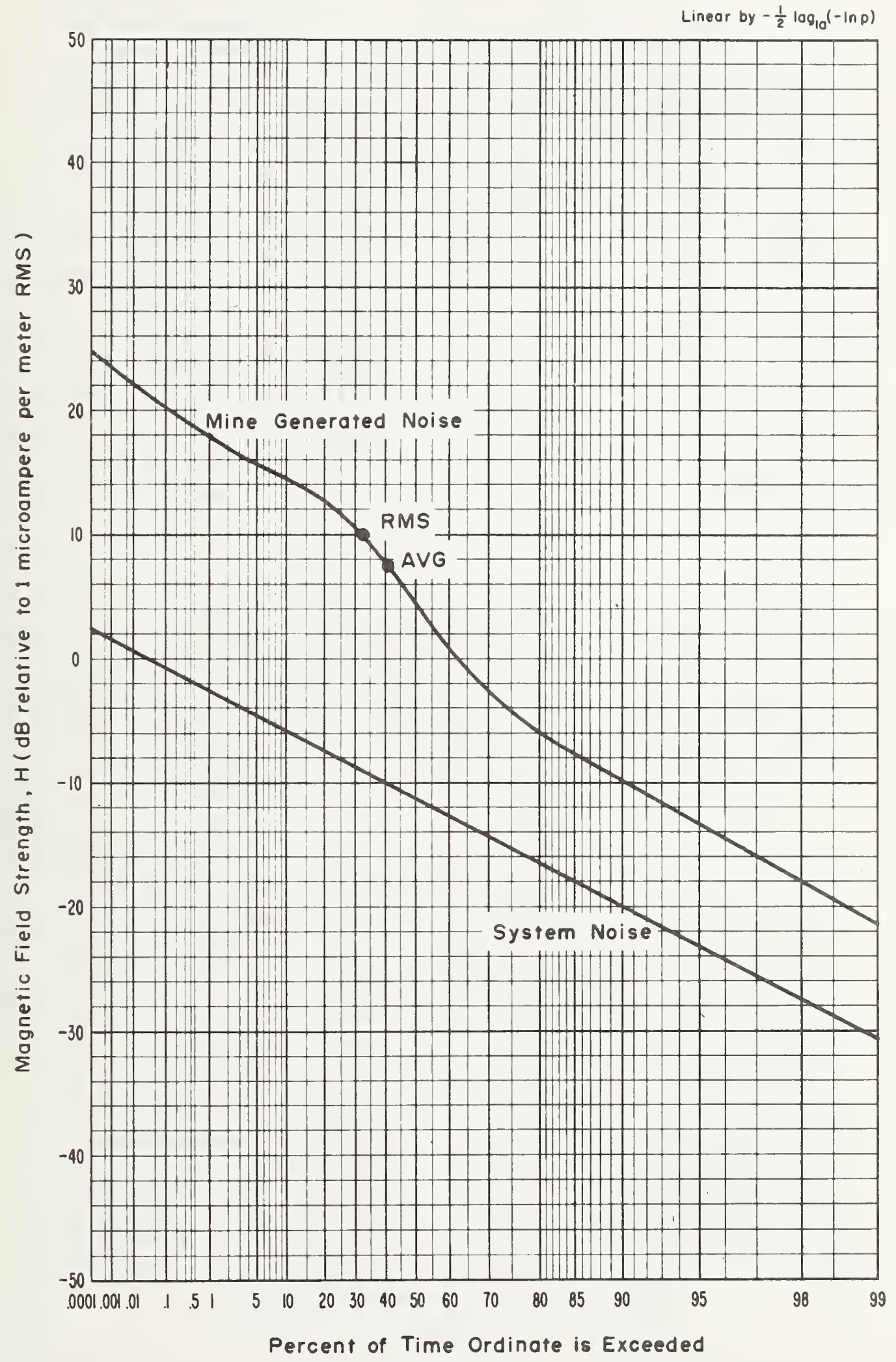

Figure 4-29 APD, $10 \mathrm{kHz}$, vertical component, $1.0 \mathrm{kHz}$ predetection bandwidth, Apri1 19, 1973, 10:20 a.m.. Farley Headplece, Itaann \#3. 81 
Lineor by $-\frac{1}{2} \log _{10}(-\ln p)$

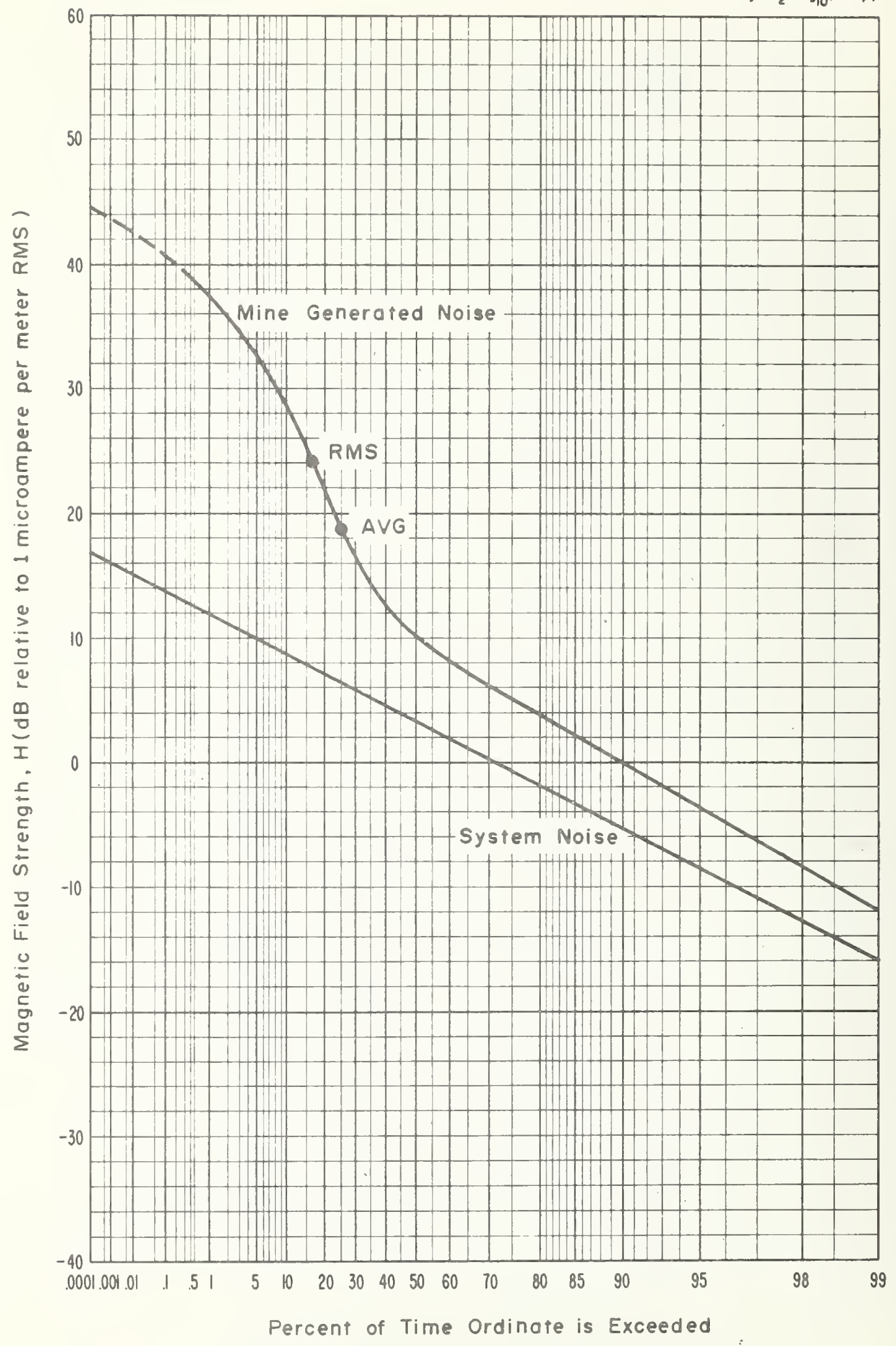

Figure 4-30 APD, $30 \mathrm{kHz}$, vertical component, $1.0 \mathrm{kHz}$ predetection bandwidth, April 19, 1973, 10:50 a.m., Farley Headpiece, Itmann \#3. 


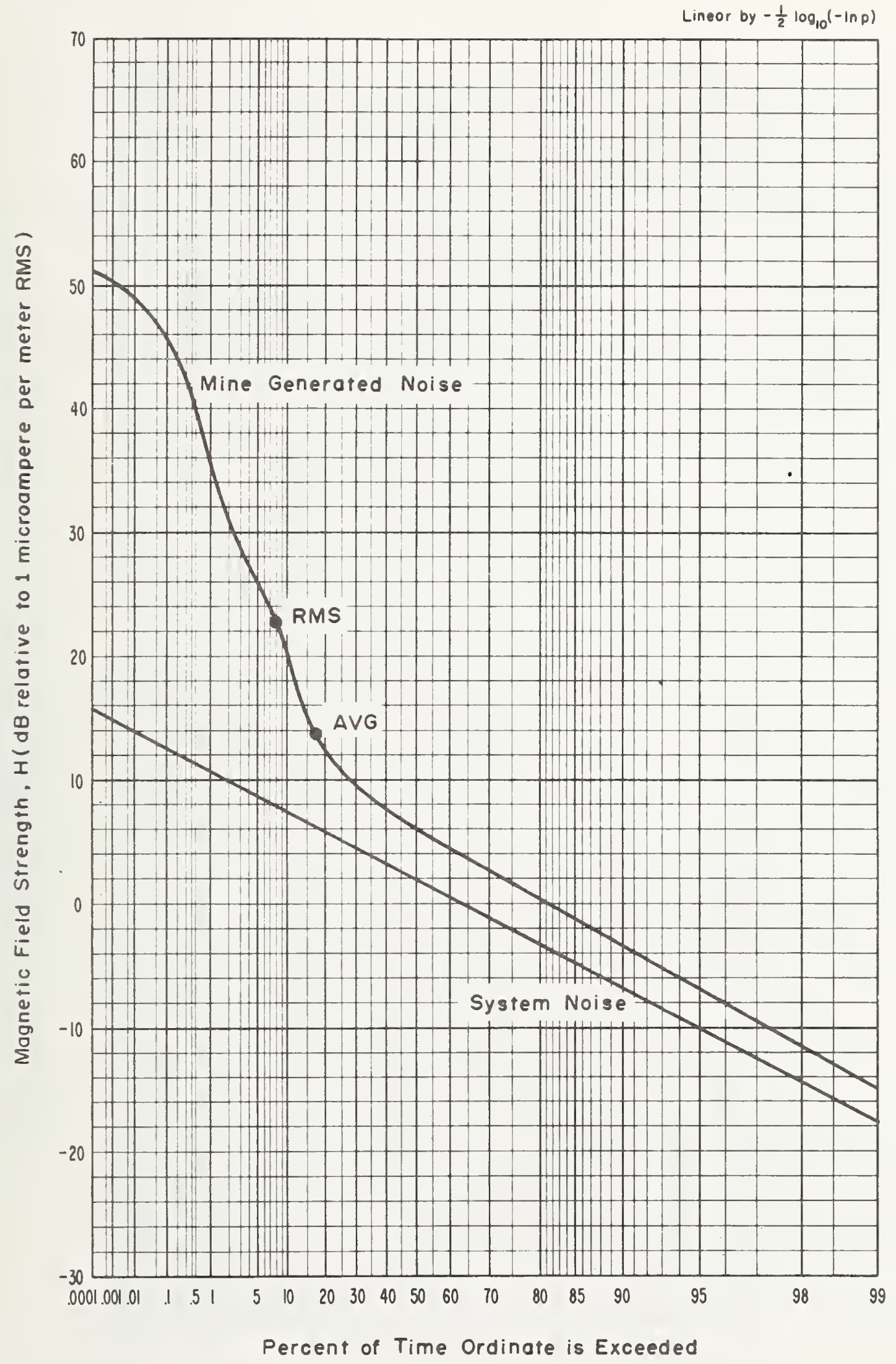

Figure 4-31 APD, $70 \mathrm{kHz}$, vertical component, $1.0 \mathrm{kHz}$ predetection bandwidth, Apri1 19, 1973, 11:25 a.m., Farley Headpiece, Itmann 非3. 


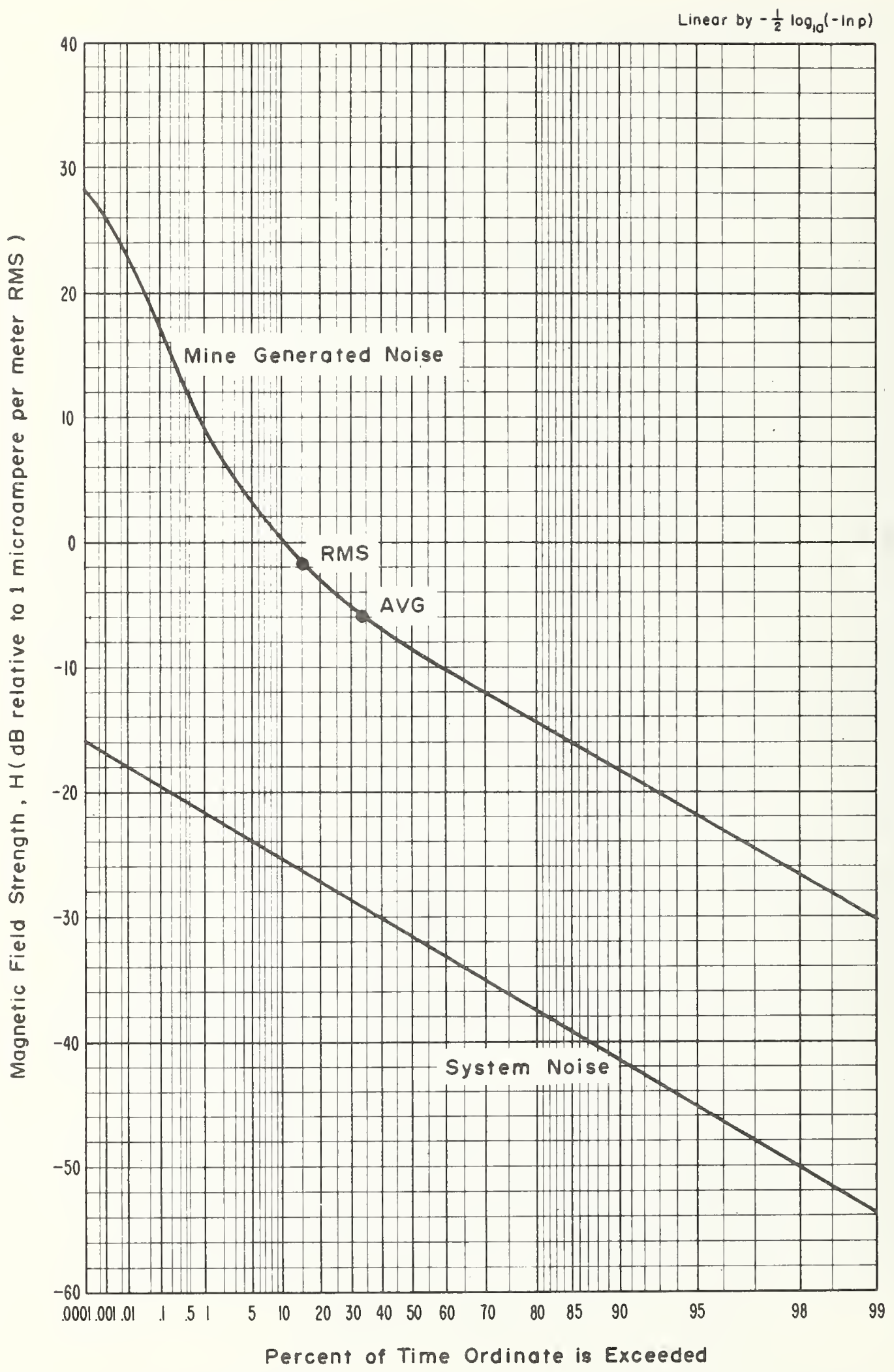

Figure 4-32 APD, $130 \mathrm{kHz}$, vertical component, $1.0 \mathrm{kHz}$ predetection bandwidth, April 19, 1973, 12:00 p.m., Farley Headpiece, Itmann 非 


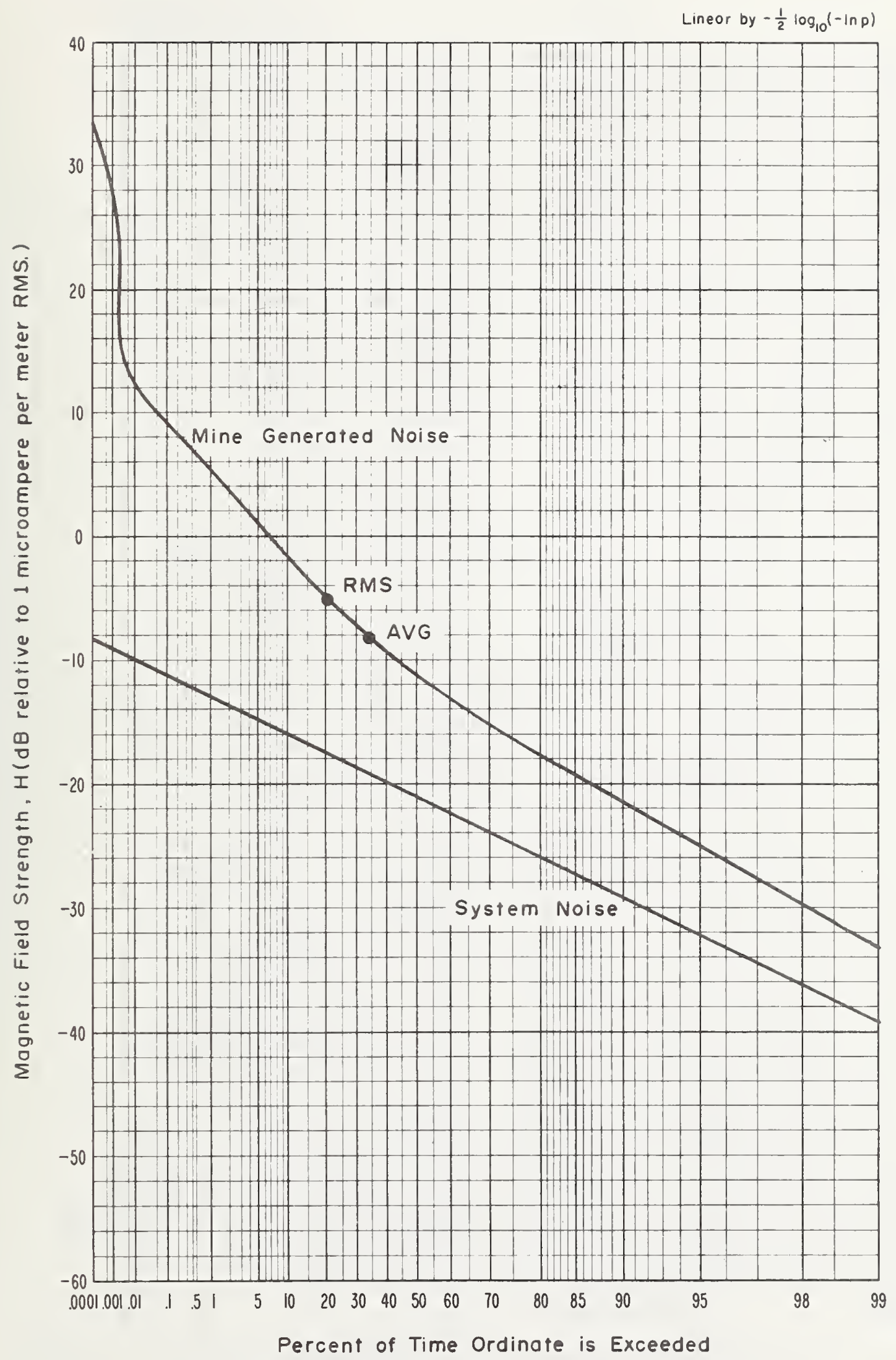

Figure 4-33 APD, $160 \mathrm{kHz}$, vertical component, $1.0 \mathrm{kHz}$ predetection bandwidth, April 19, 1973, 12:30 p.m., Farley Headpiece, Itmann 非3. 


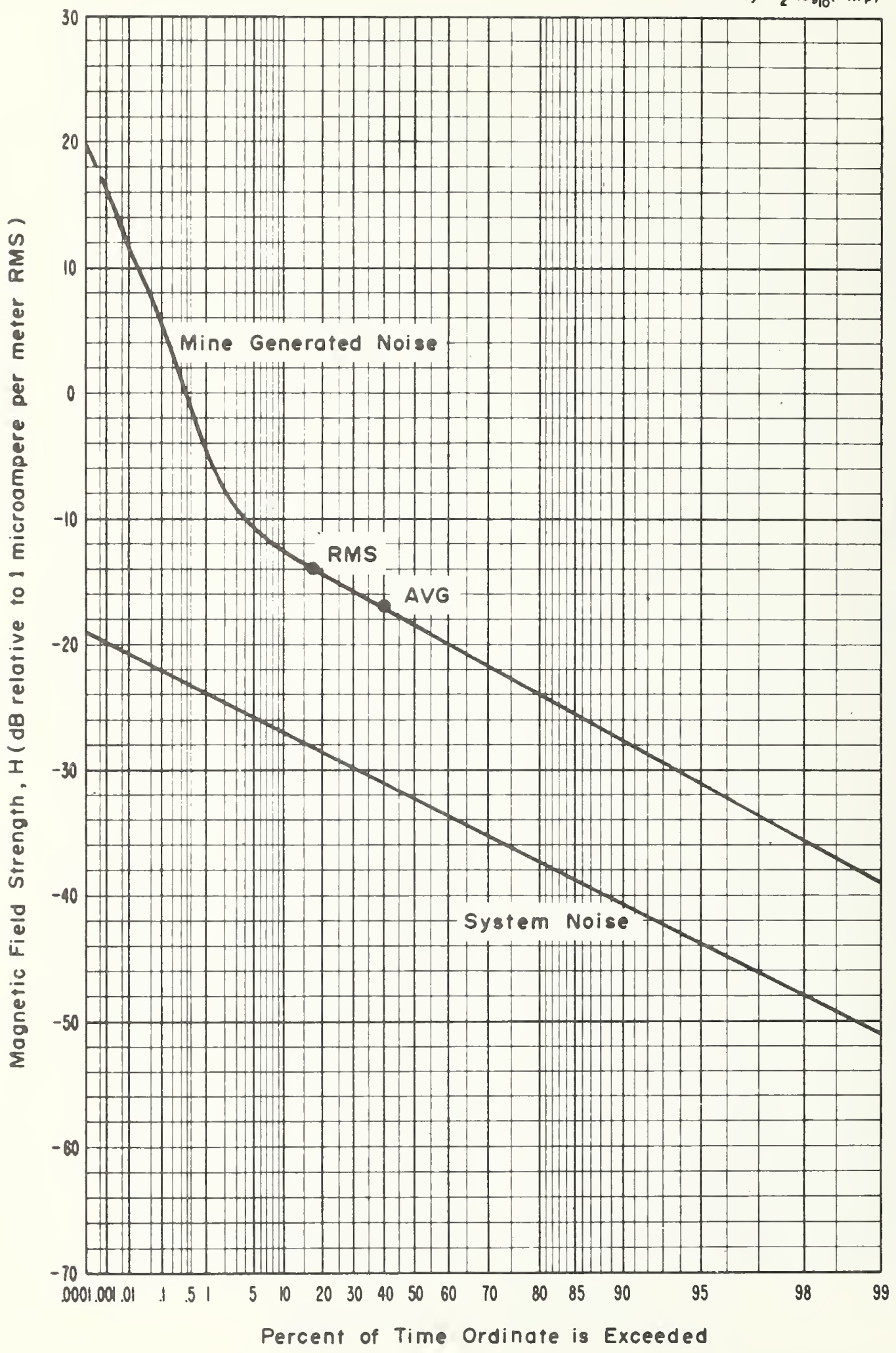

F1gure 4-34 APD, $250 \mathrm{kHz}$, vertical component, $1.0 \mathrm{kHz}$ predetection bandwidth, Apri1 19, 1973, 1:00 p.m., Farlev Headplece, Itmann 非. 


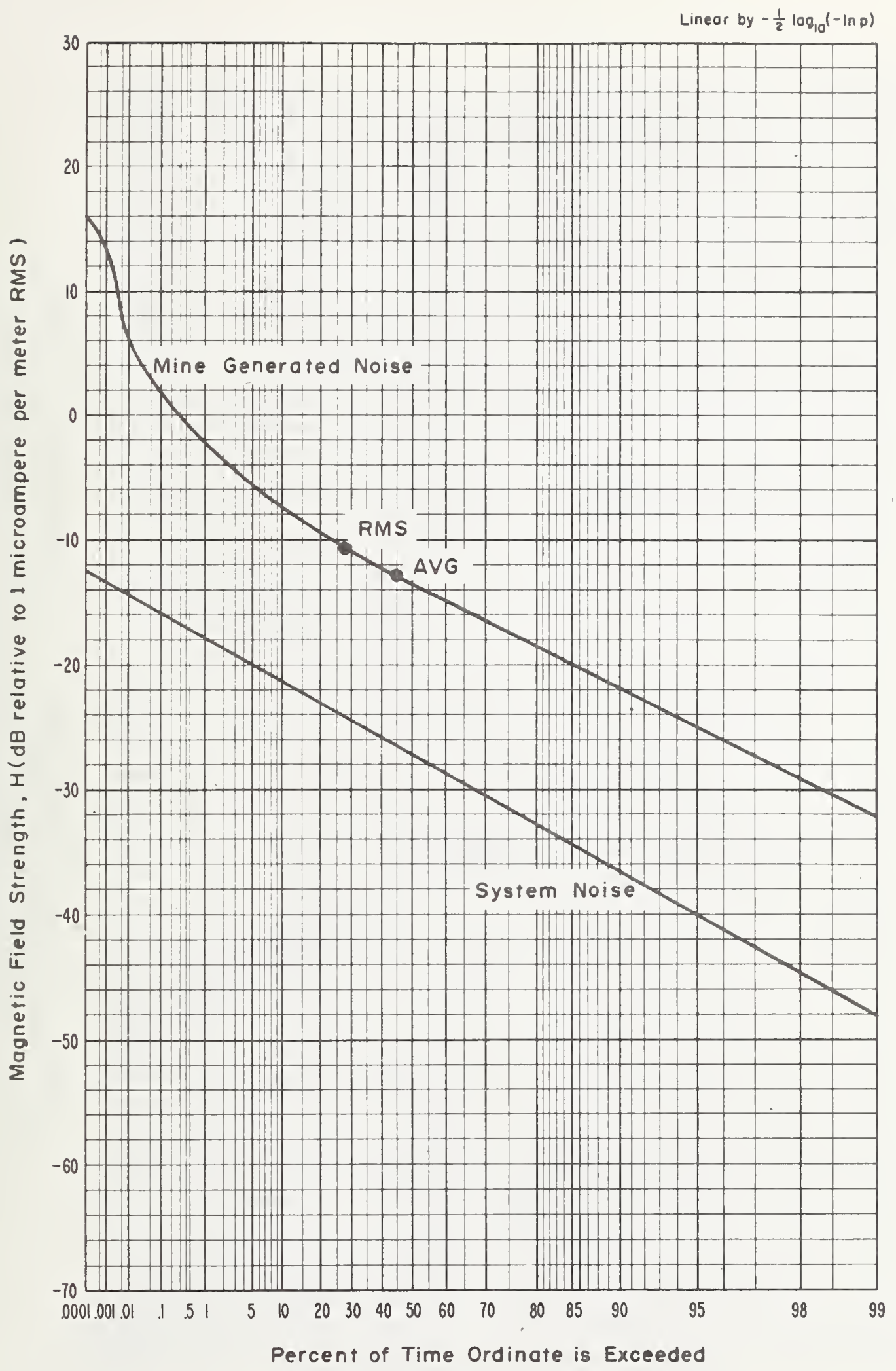

Figure 4-35 APD, $500 \mathrm{kHz}$, vertical component, $1.2 \mathrm{kHz}$ predetection bandwidth, April 19, 1973, 10:20 a.m., Farley Headplece, Itmann \#3. 


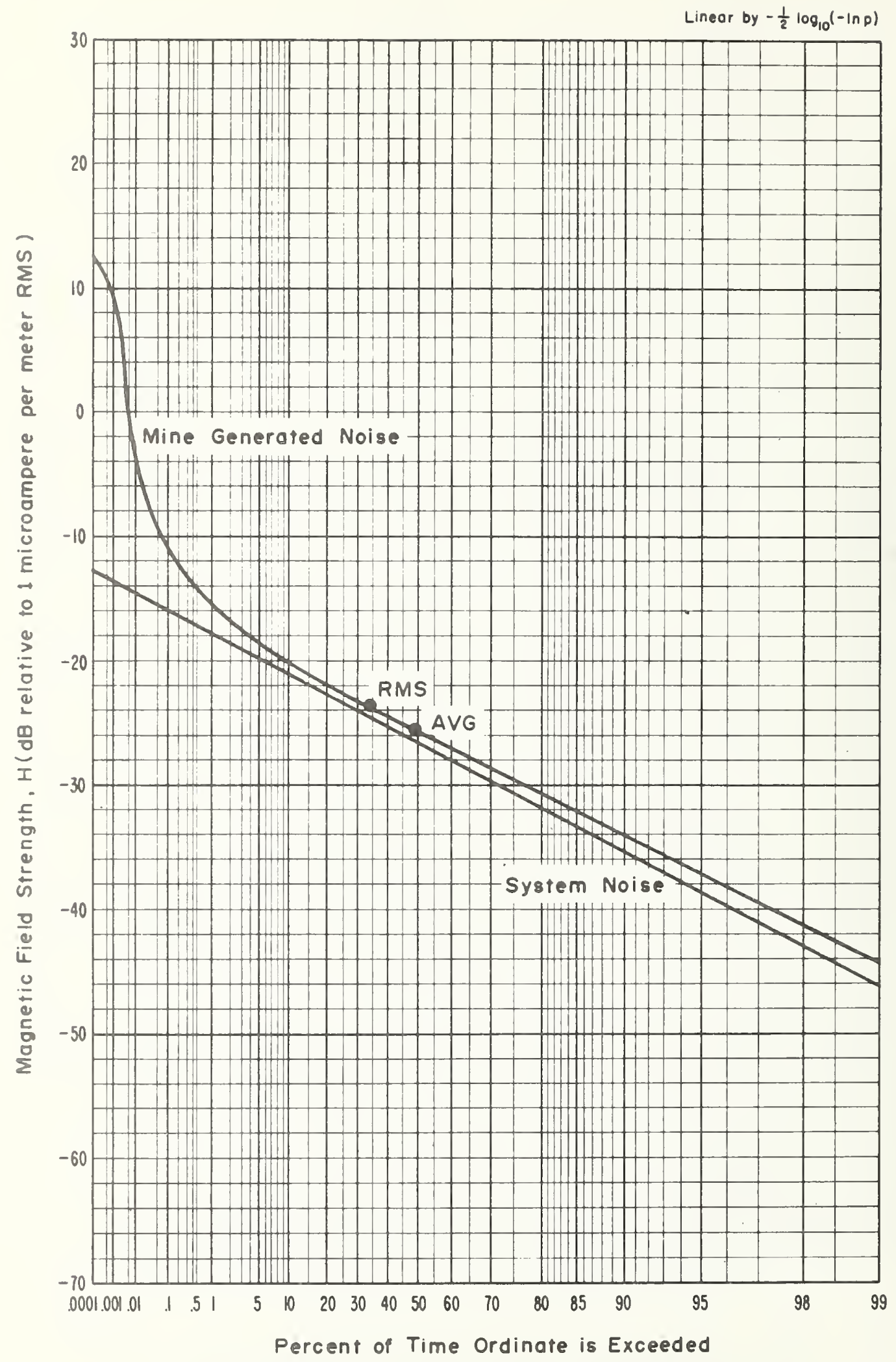

Figure 4-36 APD, $1 \mathrm{MHz}$, vertical component, $1.2 \mathrm{kHz}$ predetection bandwidth, Apri1 19, 1973, 10:50 a.m., Farley Headplece, Itmann \#3. 


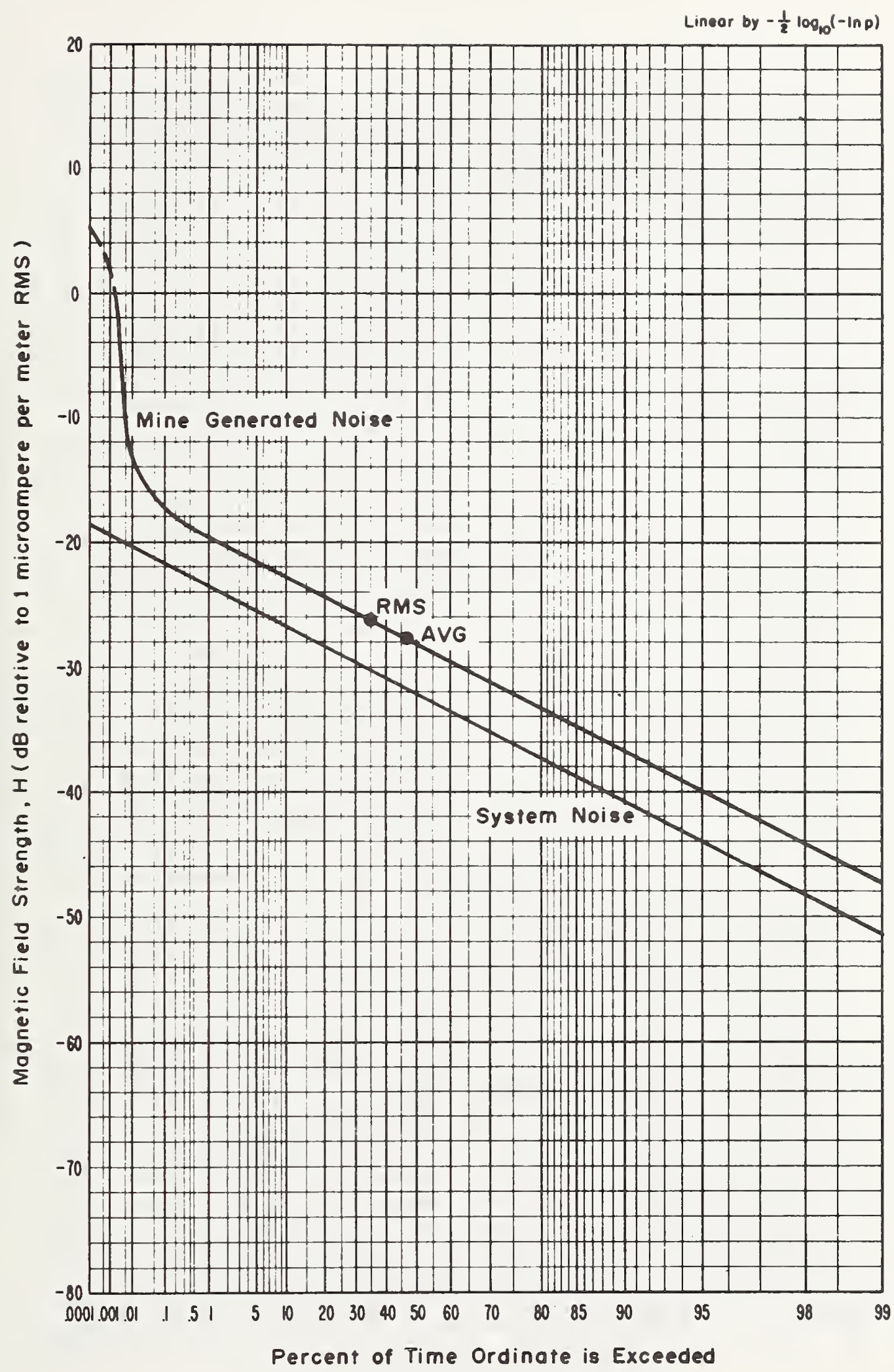

Figure 4-37 APD, $2 \mathrm{MHz}$, vertical component, $1.2 \mathrm{kHz}$ predetection bandwidth, April 19, 1973, 11:25 a.m., Farley Headplece, I tmann \#3. 


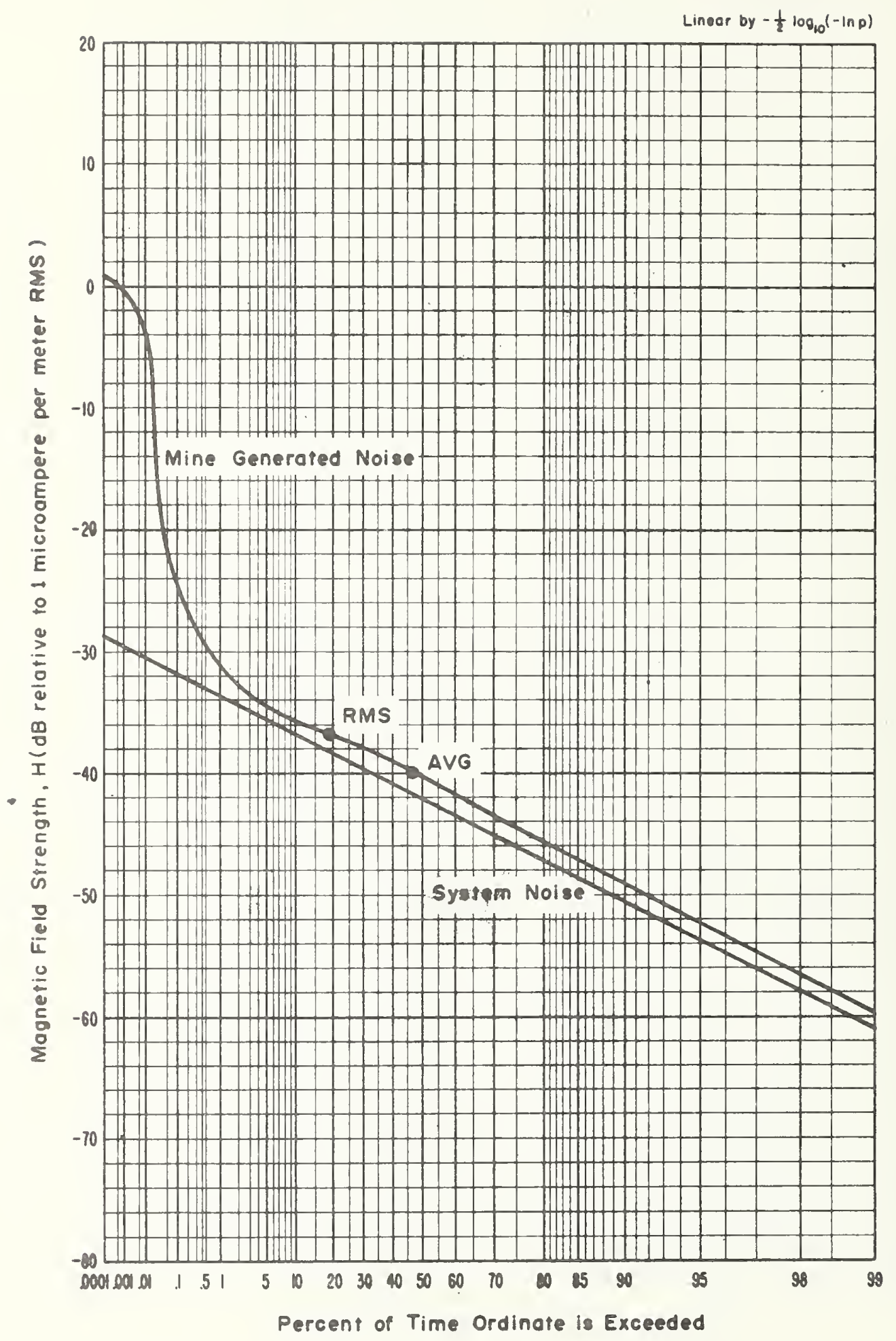

Figure 4-38 APD, $6 \mathrm{MHz}$, vertical component, $1.2 \mathrm{kHz}$ predetection bandwidth, Apr11 19, 1973, 12:00 p.m., Farley Headplece, Imann 3. 


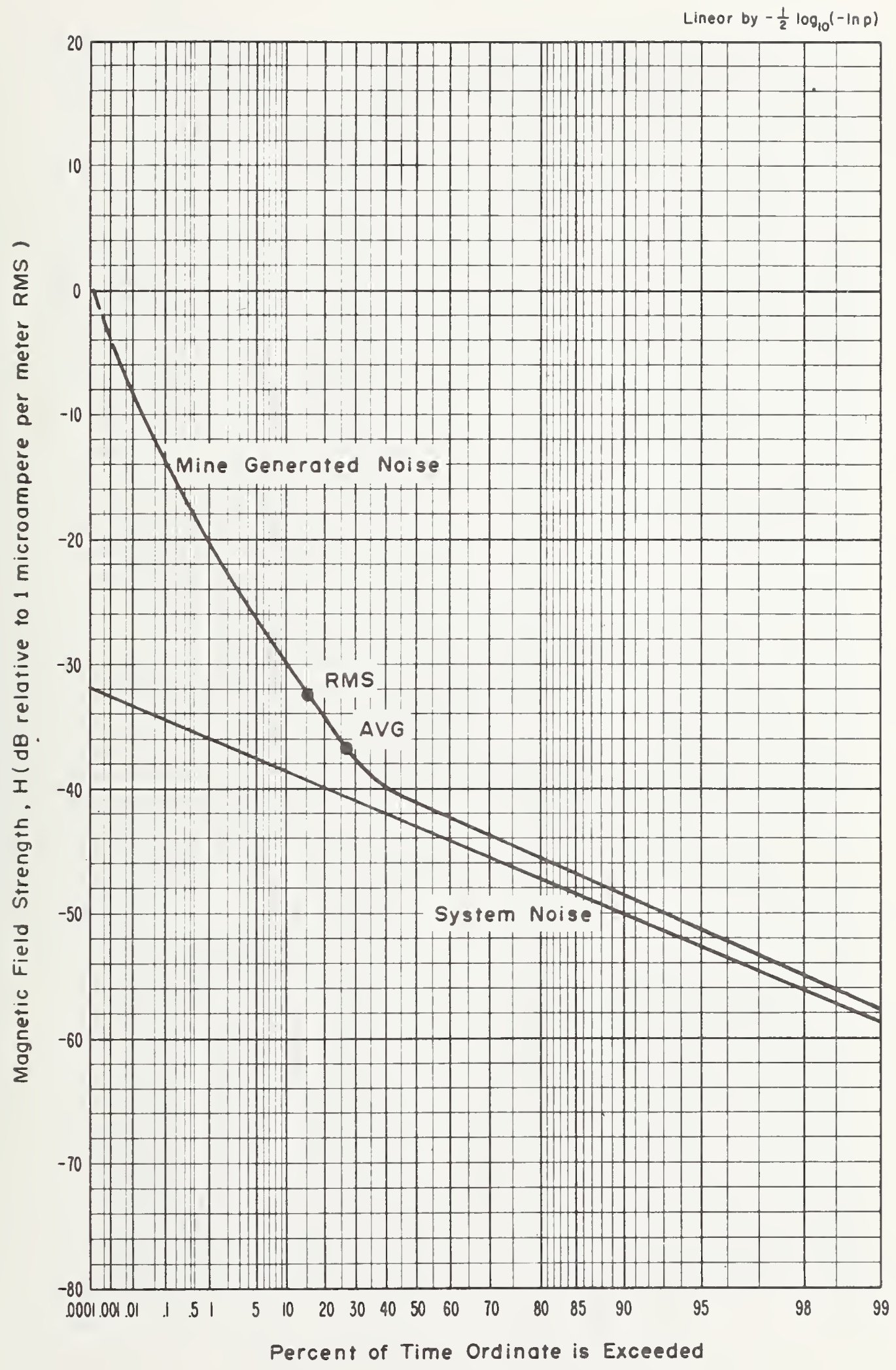

Figure 4-39 APD, $14 \mathrm{MHz}$, vertical component, $1.2 \mathrm{kHz}$ predetection bandwidth, April 19, 1973, 12:30 p.m., Farley Headpiece, I tmann 非3. 


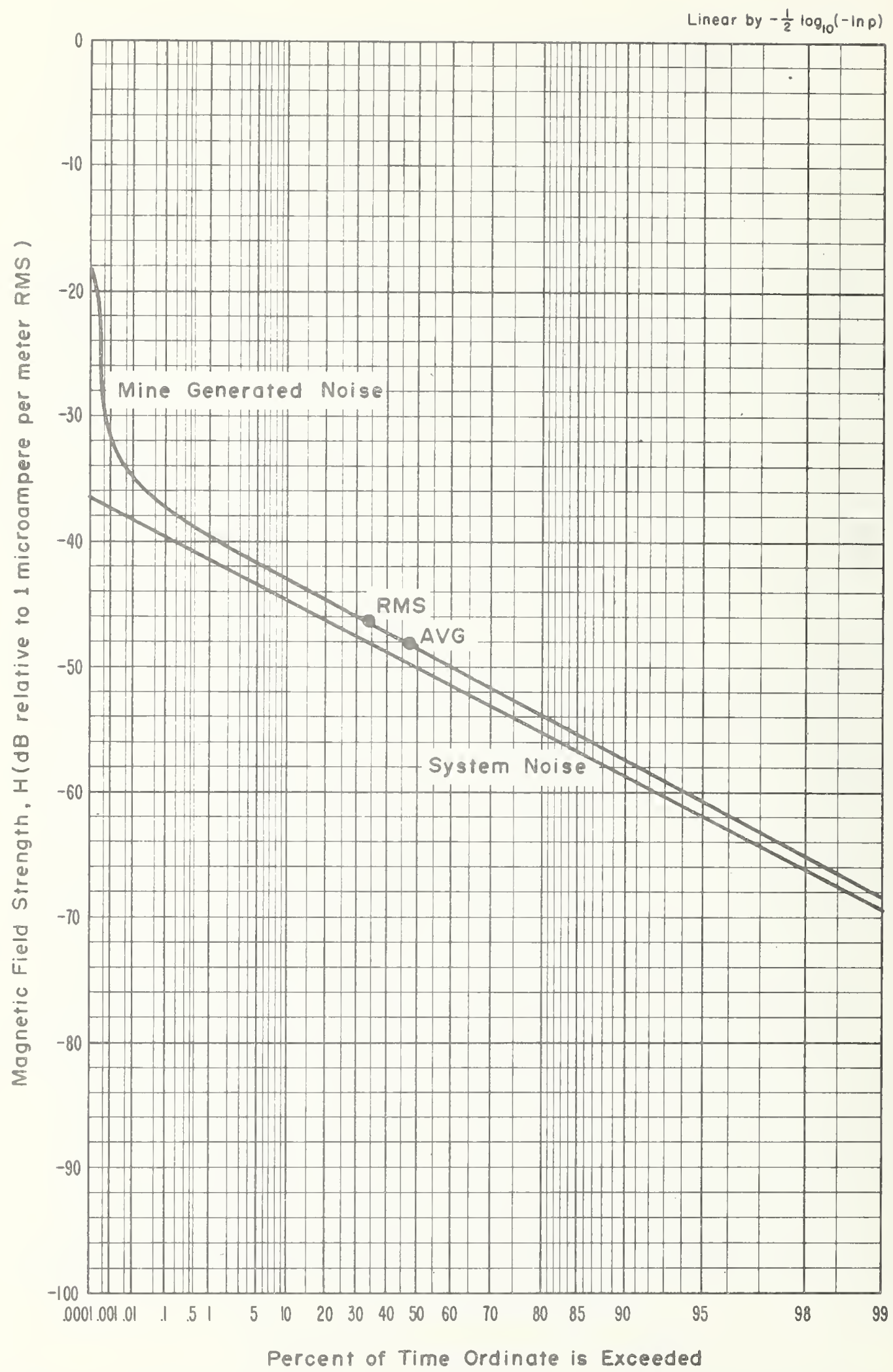

Figure 4-40 APD, $32 \mathrm{MHz}$, vertical component, $1.2 \mathrm{kHz}$ predetection bandwidth, Apr11 19, 1973, 1:00 p.m., Farley Headplece, Itmann 非3. 


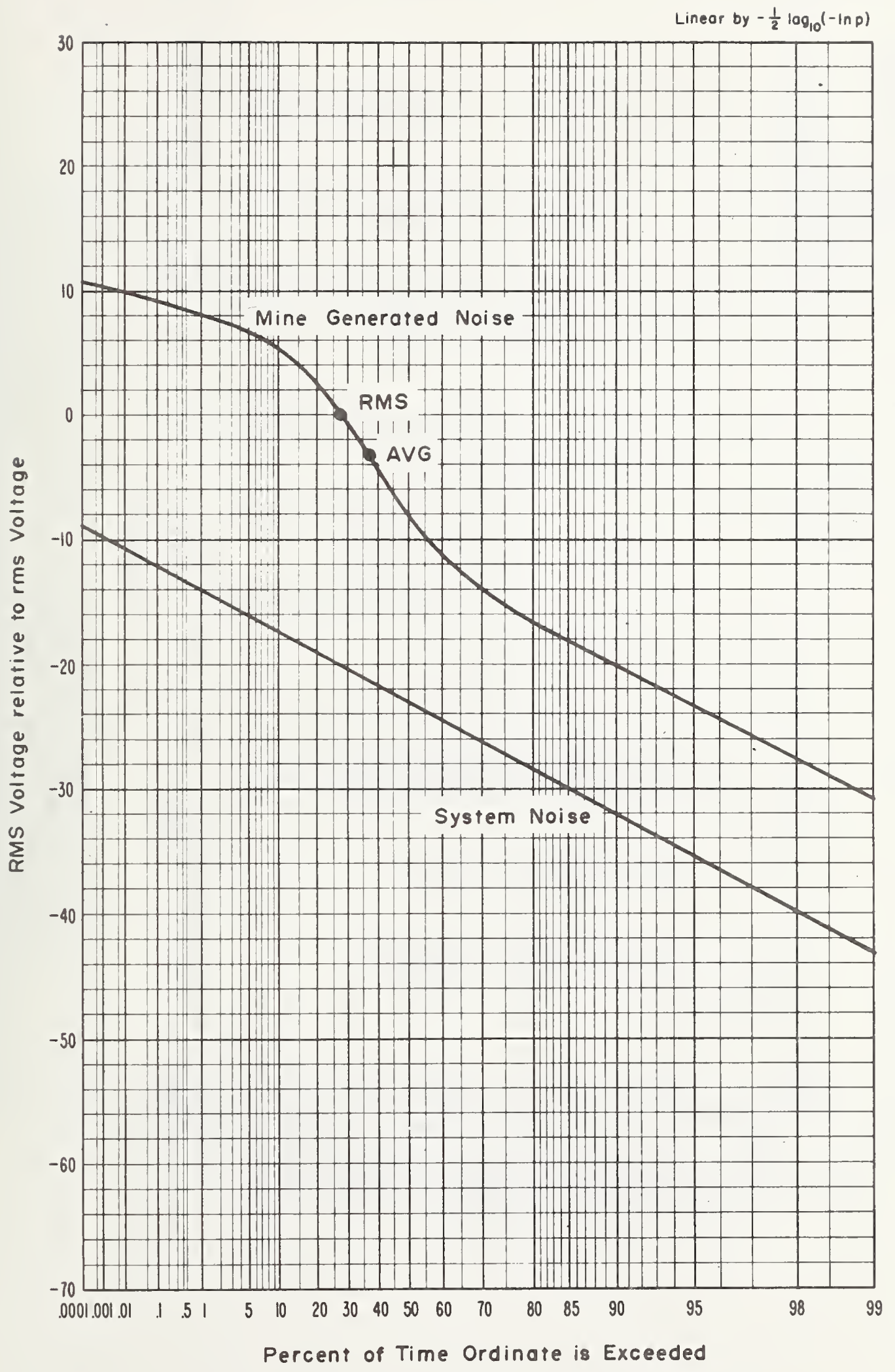

Figure 4-41 APD, I0 kHz, roof bolt measurement, $1.0 \mathrm{kHz}$ predetection bandwidth, Apr11 19, 1973, 1:30 p.m., Farley Headplece, Itmann 非3. 93 


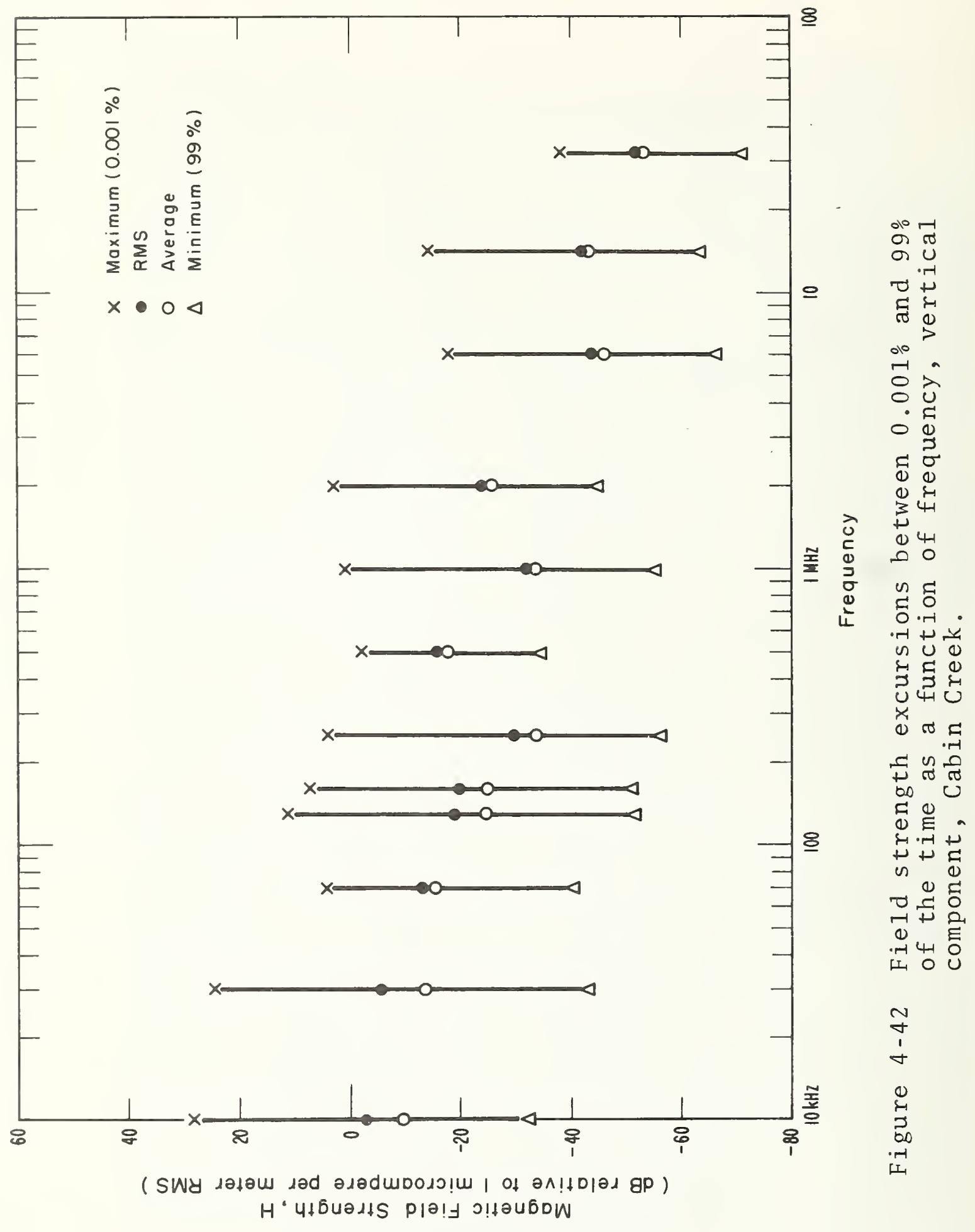




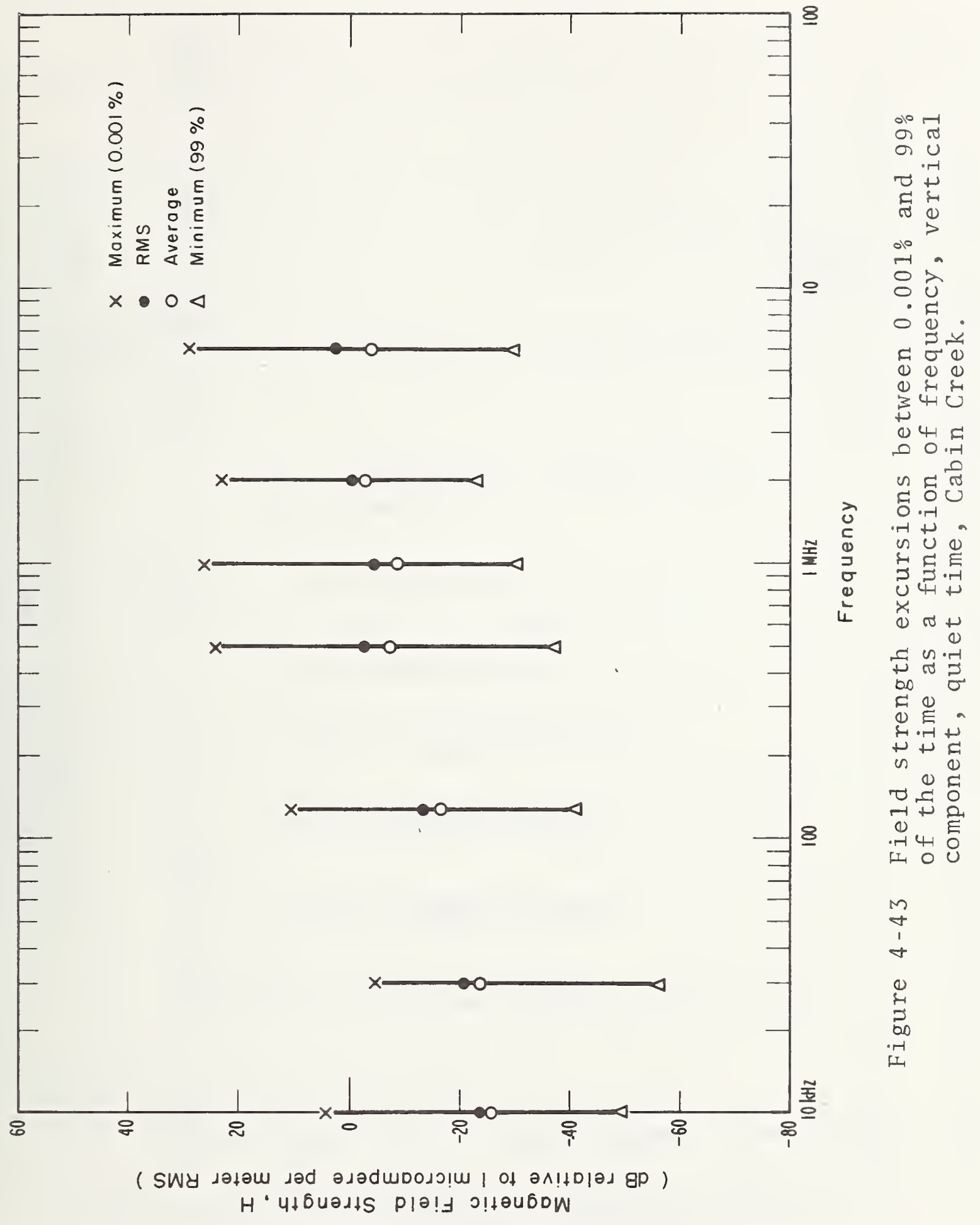




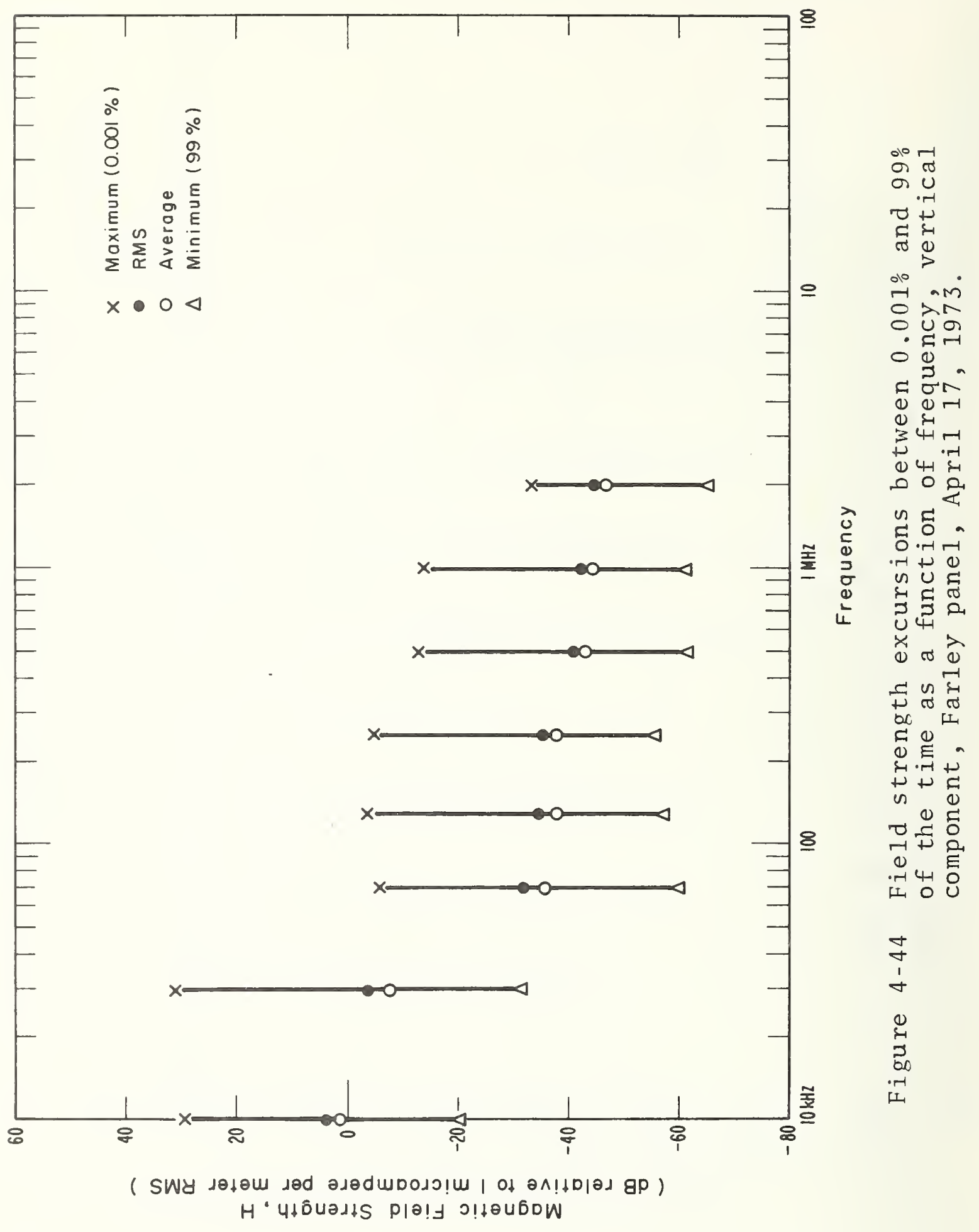




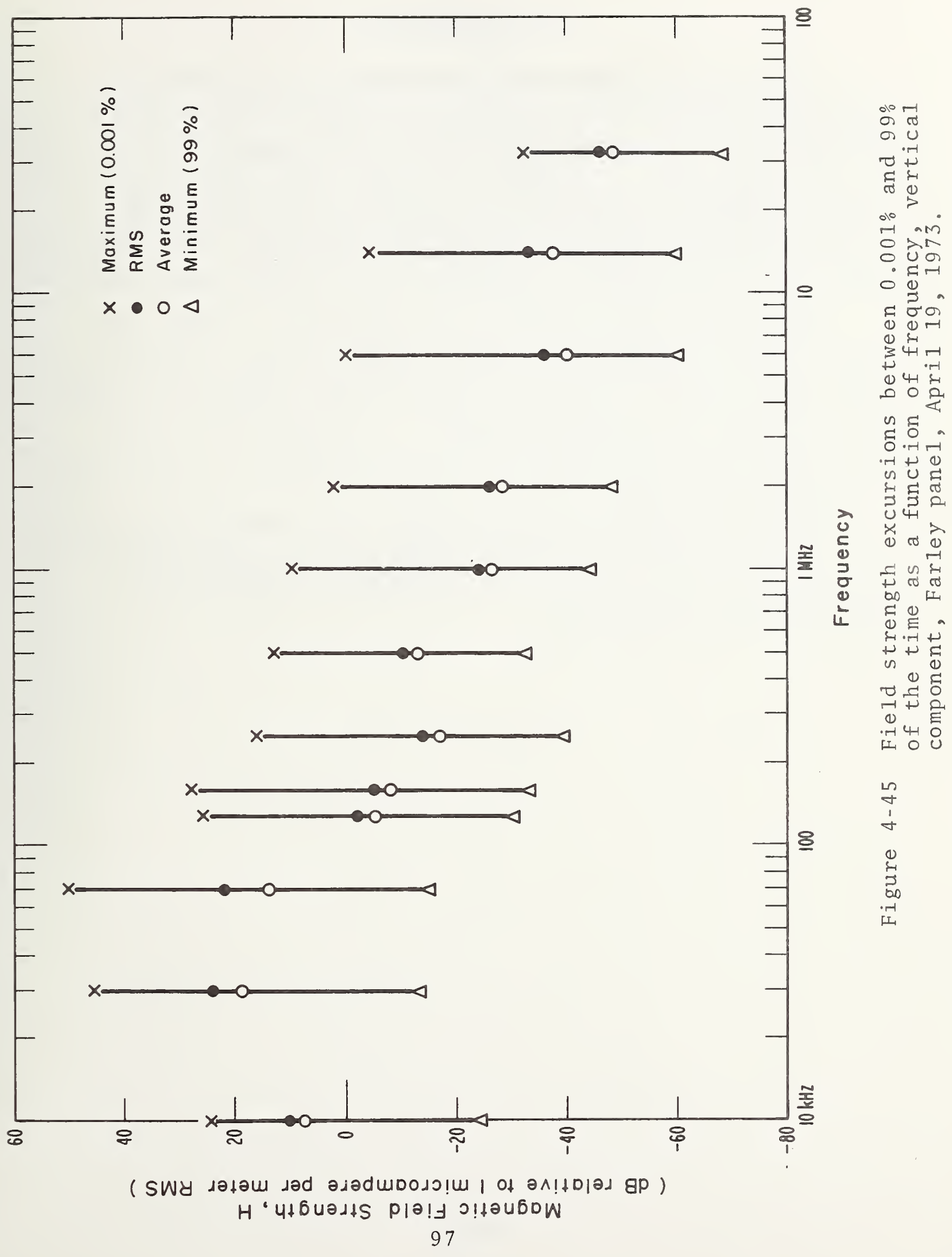




\section{CONCLUS IONS}

In Itmann, we found that the haulageways usually had higher EM noise levels than exist near the face area. This was different from other mines; usually the face equipment is the prime source of noise. At higher frequencies, above $100 \mathrm{kHz}$, Itmann was noisier than other mines. So called "quiet" periods have low noise levels only at low frequencies, and only at considerable distances from rail haulageways.

The $88 \mathrm{kHz}$ trolley phones in Itmann No. 3 may not have worse harmonic output than exists in other mines, but relatively high levels of harmonic signals were observed to $8 \mathrm{MHz}$ in this mine on a spectrum analyzer. This was not true in one other mine, Grace Mine, but this measurement was not made in most mines visited.

There were also carriers present on an intermittent bas is at frequencies other than the $88 \mathrm{kHz}$ of the trolley phone. A strong one was at $202 \mathrm{kHz}$. In general dc machinery is noisier than ac machinery. 


\section{RECOMMENDAT IONS}

In Itmann, in addition to the lower than usual powerline-harmonic noise and the average impulsive noise, there are more intermittent $\mathrm{cw}$ carriers and harmonics of these carriers than in any other mine visited. Therefore, longer intervals of interference may be present at more discrete frequencies, and design of communication equipment should take this into account . 


\section{ACKNOWLEDGMENTS}

Those making significant contributions to this program are as follows: laboratory development and field use of measurement equipment, Ed Neisen, Doug Schulze, and Tom Bremer; data processing, Anne Rumfelt, Nancy Tomoeda, Winston Scott, Frank Cowley, and David Stearns. Those making valuable but less time-consuming contributions were Gerry Reeve, Bob Matheson, Don Spaulding, John Chukoski, Lorne Matheson, Dave Lewis, and Sharon Foote.

Winston Scott provided much assistance in proofreading, while Sharon Foote and Janet Becker typed tirelessly through many versions. Jocelyn Spencer and Barbara Bolton provided drafting assistance.

Finally, none of this would have been possible without the excellent cooperation of John Burr of Lee Engineering Company and of Bill Starling, Wes McDonald, John Henry Johnson, Hamp Clark, Thurman Tilley, and Jack Holt of Consolidation Coal Company. 


\section{REFERENCES}

[1] Bensema, W.D., Kanda, M., Adams, J.W., Electromagnetic Noise in Robena No. 4 Coal Mine, NBS Tech. Note 654, Apri1 1974.

[2] Adams, J.W., Bensema, W.D., Kanda, M., Electromagnetic Noise in Grace Hardrock Mine, NBSIR 74-388, June 1974.

[3] The Institute of Electrical and Electronic Engineers, Inc., IEEE Dictionary of Electrical and Electronic Terms, Std. 100,1972 .

[4] Taggart, H.E. and Workman, J.L., Calibration Principles and Procedures for Field Strength Meters (30 $\mathrm{Hz}$ to $1 \mathrm{GHz}$ ), NBS Tech. Note 370, March 1969.

[5] Crichlow, W.O., et al., Amplitude-probability distributions for atmospheric radio noise, NBS Monograph 23 (1960b).

[6] Thompson, W.I., III, Bibliography of ground vehicle communications and control. AKWIC index, Report No. DOTTSC-UMTA-71-3, JuIy 1971.

[7] Kanda, Motohisa, Adams, J.W., Bensema, W.D., Electromagnetic Noise in McElroy Coal Mine, NBSIR 74-389.

[8] Spaulding, A.D., and Disney, R.T., Man-Made Radio Noise, Part I: Estimates for Business, Residential, and Rural Areas, OT Report 74-38, June 1974. 
Spectrum captions are generally organized into the following format:

First 1ine: MP NDT NZS NDA NPO RC DF date, time, frame, serial, where

MP = Two's power of length of Fourier transform, example, $2^{\text {MP }}$ where MP $=12$

NDT = Detrending option, example, 0 (dc removed $)^{\circ}$

NZS = Restart spectral average after output, example, 0 (restarted)

$\mathrm{NDA}=$ Data segment advance increment, example, 2048

NPO = Number of spectra averaged between output calls, example, 20

$\mathrm{RC}=$ Integration time in seconds per spectra, example, 0.168

DF = Resolution bandwidth, spectral estimate spacing in hertz, example, 62.5

Date $=$ Date of computer processing, example, 03/21/73

Time $=$ Time of computer processing, example, 15:06:34

Frame $=$ Frame set number, example, 10

Serial = Film frame serial number, example, 42.

Second line: DTA DA(1) DA(2) DA(3) NSA NRP NPP, where

DTA = Detrending filter parameter $\alpha$, example, 0.00195

$\mathrm{DA}(1)=$ Detrending filter average, $\mathrm{K}=1$, example, 59.4

$\mathrm{DA}(2)=$ Detrending filter average, $\mathrm{K}=2$, example, 0

$\mathrm{DA}(3)=$ Detrending filter average, $\mathrm{K}=3$, example, 0

NSA = Number of periodograms averaged, example, 20

NRP = Number of data points processed since spectrum initialization, example, 43008

NPP = Number of data points processed since data initialization, example, 43008 . 
Third line: RUN, SESSION, DAY, MONTH, YEAR Gain corr., rec. = tot. constr. =, where

Run and Session = the title of the portrayed frame identifying the digitizing session and run number, example, $21-83$

Month, Day, Year = date data were recorded in the mine, example, 82573

Gain corr. rec. = receiver gain correction, example, 0

tot. const. = constant gain correction of entire system, example, 46.4

Fourth line: $\mathrm{C}=, \mathrm{RG}=, \dot{\mathrm{DG}}=, \mathrm{FG}=, \mathrm{AG}=$, where

$\mathrm{C}=$ correction curve used with data, example, 25

$\mathrm{RG}=$ receiver gain and accompanying correction in $\mathrm{dB}$ added to the data, example, $200(-6 \mathrm{~dB})$

DG = digitizer gain, example, 0

$F G=$ filter gain in $d B$, often rounded to nearest single digit, example, 0

$A G=$ absolute gain correction added to data, example, 52

Fifth line: Top of Scale, Standard Error, Spectral Peak, where Top of Scale = largest scale marking for computer drawn graph, example, $1.000+004\left(1.0 \times 10^{4}\right)$

Standard Error = standard error of curve, example, 0.3162 Spectral Peak = largest spectral peak observed, example, $4.108+003\left(4.108 \times 10^{3}\right)$ 


\begin{tabular}{|c|c|c|c|}
\hline $\begin{array}{l}\text { U.S. DEPT. OF COMM. } \\
\text { BIBLIOGRAPHIC DATA } \\
\text { SHEET }\end{array}$ & $\begin{array}{l}\text { 1. PUBLICATION OR REPORT NO. } \\
\text { NBSIR } 74-390\end{array}$ & $\begin{array}{l}\text { 2. Gov't Accession } \\
\text { No. }\end{array}$ & 3. Recipient's Accession No. \\
\hline \multicolumn{3}{|l|}{ 4. TITLE AND SUBTITLE } & $\begin{array}{c}\text { 5. Publication Date } \\
\text { June } 1974 \\
\end{array}$ \\
\hline \multicolumn{3}{|c|}{ Electromagnetic Noise in Itmann Mine } & 6. Performing Organization Code \\
\hline $\begin{array}{l}\text { 7. AUTHOR(S) } \\
\text { William D. Bensema, }\end{array}$ & tohisa Kanda, and John W & Adams & 8. Performing Organ. Report No. \\
\hline \multicolumn{3}{|c|}{$\begin{array}{l}\text { 9. PERFORMING ORGANIZATION NAME AND ADDRESS } \\
\text { NATIONAL BUREAU OF STANDARDS, Boulder Labs } \\
\text { DEPARTMENT OF COMMERCE } \\
\text { Washington, D.C. } 20234\end{array}$} & $\begin{array}{l}\text { 10. Project/Task/Work Unit No. } \\
2768412 \\
\text { 11. Contract/Grant No. }\end{array}$ \\
\hline \multicolumn{3}{|c|}{$\begin{array}{l}\text { 12. Sponsoring Organization Name and Complete Address (Street, City, State, ZIP) } \\
\text { U. S. Bureau of Mines } \\
\text { Pittsburgh Mining \& Safety Research Center } \\
4800 \text { Forbes Avenue } \\
\text { Pittsburgh, Pennsylvania } 15213\end{array}$} & $\begin{array}{l}\text { 13. Type of Report \& Period } \\
\text { Covered } \\
\text { Report to Sponsor } \\
\text { 14. Sponsoring Agency Code }\end{array}$ \\
\hline
\end{tabular}

15. SUPPLEMENTARY NOTES

16. ABSTRACT (A 200-word or less factual summary of most significant in formation. If document includes a significant bibliography or literature survey, mention it here.)

Two different techniques were used to make measurements of the absolute value of electromagnetic noise in an operating coal mine, Itmann No. 3 Mine, located near Mullens, West Virginia. The electromagnetic environment created by 250 -volt-dc and 550- and 950-volt-ac machinery in two longwall panels was measured and is reported. One technique measures noise over the entire electromagnetic spectrum of interest for brief time periods. It is recorded using broadband analog magnetic tape, and the noise data is later transformed to give spectral plots. The other technique records noise amplitudes at several discrete frequencies for a sufficient amount of time to provide amplitude probability distributions.

The specific, measured results are given in a number of spectral plots and amplitude probability distribution plots.

17. KEY WORDS (six to twelve entries; alphabetical order; capitalize only the first letter of the first key word unless a proper name; separated by semicolons) Amplitude probability distribution; coal mine noise, digital electromagnetic communications; electromagnetic interference; electromagnetic noise; Fast Fourier Transform; Gaussian distribution; impulsive noise; magnetic field strength; measurement instrumentation; spectral density; time-dependent spectral density.

18. AVAILABILITY

For Official Distribution. Do Not Release to NTIS

Order From Sup. of Doc., U.S. Government Printing Office Washington, D.C. 20402, SD Cat. No.C13

Order From National Technical Information Service (NTIS) Springfield, Virginia 22151
19. SECURITY CLASS (THIS REPURT)

UNCL ASSIF IE D

20. SECURITY CLASS ( THIS PAGE)

UNCLASSIFIED
21. NO. OF PAGES 